Copyright

by

Han-Joo Lee

2009 
The Dissertation Committee for Han-Joo Lee

Certifies that this is the approved version of the following dissertation:

\section{Attentional Biases in Social Anxiety:}

\section{An Investigation Using the Inattentional Blindness Paradigm}

Committee:

Michael J. Telch, Supervisor

Caryn L. Carlson

Christopher G. Beevers

Bradley C. Love

S. Natasha Beretvas 


\author{
Attentional Biases in Social Anxiety: \\ An Investigation Using the Inattentional Blindness Paradigm \\ by \\ Han-Joo Lee, M.A. \\ Dissertation \\ Presented to the Faculty of Graduate School of \\ The University of Texas at Austin \\ in Partial Fulfillment \\ of the Requirements \\ for the Degree of \\ Doctor of Philosophy
}

The University of Texas at Austin

August, 2009 


\title{
Attentional Biases in Social Anxiety: An Investigation Using the Inattentional Blindness Paradigm
}

\author{
Han-Joo Lee, Ph.D. \\ The University of Texas at Austin, 2009 \\ Supervisor: Michael J. Telch
}

\begin{abstract}
Social anxiety disorder is the third most common mental disorder with the lifetime prevalence rate of $13.3 \%$ in the US population. Typically, it causes significant impairment in a wide range of functioning and follows a chronic, unremitting course if untreated. Over the past two decades, there has been a dramatic increase in clinical research aimed at examining underlying mechanisms maintaining social anxiety. One line of research has investigated attentional biases in social anxiety, using various cognitive experiment paradigms, including the emotional Stroop and the modified dotprobe tasks. However, overall findings are equivocal about the nature of attentional biases in social anxiety and several methodological problems limit the interpretability of the data. The present study examined attentional biases associated with social anxiety using a new research paradigm in the field of anxiety disorders: the inattentional blindness paradigm. This paradigm presents a social cue in the absence of the subjects' expectation while they are engaged in a cognitively demanding task, thereby enabling the
\end{abstract}


more purely attentional aspect of information processing to be examined reducing the influence of potential response biases or effortful strategies. Two independent experiments were conducted using nonclinical student samples consisting of individuals high in social anxiety (HSAs) versus individuals low in social anxiety (LSAs) based on the static and sustained inattentional blindness tasks. Overall, results revealed that HSAs were more likely to detect or identify a socially-threatening cue, relative to LSAs; whereas LSAs were more likely to detect or identify a non-threatening social cue, relative to HSAs. These findings were observed only in the presence of a bogus-speech manipulation. These data suggest the promising utility of the inattentional blindness paradigm in investigating attentional biases in social anxiety and perhaps other psychopathological conditions. Theoretical and clinical implications are discussed. 


\section{Table of Contents}

Chapter 1: Introduction

1.1. Overview of Social Anxiety Disorder (SAD) $\ldots \ldots \ldots \ldots \ldots \ldots \ldots \ldots \ldots \ldots \ldots \ldots \ldots$

1.1.1. DSM.IV Definition and Clinical Features.......................... 2

1.1.2. Costs of the Problem............................................ 4

1.2. Current Models of SAD ............................................. 6

1.2.1. Cognitive-Behavioral Approaches........................... 6

1.2.2. Biological/Pharmacological Approaches........................... 10

1.2.2.1. Twin and Family Studies............................. 10

1.2.2.2. Neurotransmitter System............................ 11

1.2.2.3. Neuroimaging Studies............................... 11

1.2.2.4. Summary ....................................... 12

Chapter 2: Attentional Biases in Social anxiety.................................. 13

2.1. Overview of Attentional Biases in SAD .............................. 13

2.2. Existing Experiment Paradigms..................................... 14

2.2.1. Emotional Stroop Test........................................ 14

2.2.2. Modified Dot-probe Test................................. 17

2.2.2.1. Modified Dot-probe Test based on Word Stimuli........... 17

2.2.2.2. Modified Dot-probe Test based on Facial Stimuli.......... 20

2.2.3. Other Paradigms......................................... 21

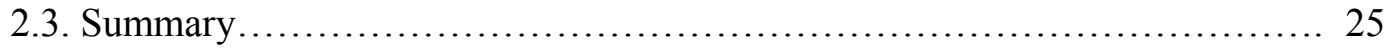

Chapter 3: The Inattentional Blindness Paradigm................................. 26

3.1. The Static Inattentional Blindness Paradigm........................... 26

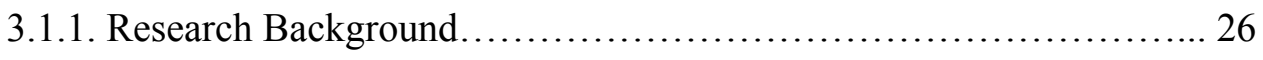

3.1.2. Inattentional Blindness Task............................... 26

3.1.3. Stimuli Seen Under the Inattentional Condition..................... 29

3.1.3.1. One's Own Name.................................... 29

3.1.3.2. Happy Face..................................... 31

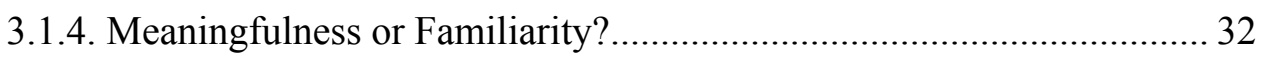


3.1.5. Some Additional Evidence for the Meaningfulness Hypothesis....... 34

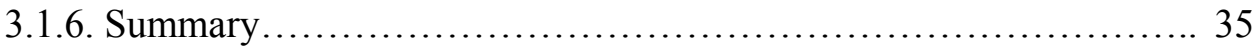

3.2. The Sustained Inattentional Blindness Paradigm.......................... 36

3.2.1. Selective Looking Studies.................................... 36

3.2.2. The Sustained Inattentional Blindness Studies....................... 36

3.2.3. The Effects of Attentional Set on Detecting Unexpected Stimuli..... 37

3.2.4. Roles of Stimuli Properties in the Sustained IB Experiments ......... 39

3.3. Advantages of the IB Paradigm ........................................ 40

3.4. The Present Studies................................................ 43

Chapter 4: Experiment 1 - An Investigation Using the Static IB Paradigm................ 44

4.1. Participants.................................................... 45

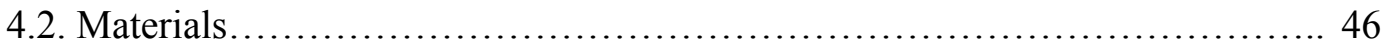

4.3. Experiment Design.............................................. 48

4.4. Measures........................................................... 48

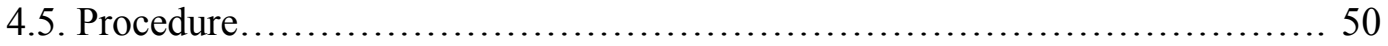

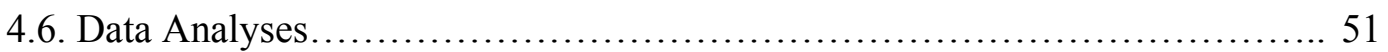

4.7. Statistical Power to Detect Differences in Detection/Identification Rates...... 51

4.8. Results ............................................................ 52

4.8.1. Group Characteristics.....................................52

4.8.2. Social Anxiety Induction Manipulation Check................... 52

4.8.3. Differences in Detection Rates for the Inattentional Trial............ 53

4.8.4. Differences in Identification Rates for the Inattentional Trial......... 54

4.8.5. Controlling for Gender and General Emotional Distress............ 56

4.8.6. Differences in Detection and Identification Rates for the Divided and Full-Attention Trials........................... 57

4.8.7. Gender Differences in Detection and Identification Rates........... 58

4.8.7.1. Prediction of detection rates.......................... 58

4.8.7.2. Prediction of identification rates......................... 59

4.8.8. Additional Evidence of Vigilant Attention towards the Critical Item.. 59

4.9. Discussion ......................................................... 65 
Chapter 5: Experiment 2 - An Investigation Using the Sustained IB Paradigm.............. 73

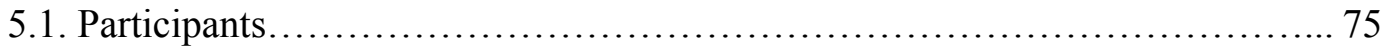

5.2. Materials.................................................................... 75

5.3. Experiment Design................................................ 77

5.4. Measures........................................................... 78

5.5. Procedure ............................................................. 78

5.6. Data Analyses...................................................... 79

5.7. Statistical Power to Detect Differences in Detection/Identification Rates...... 80

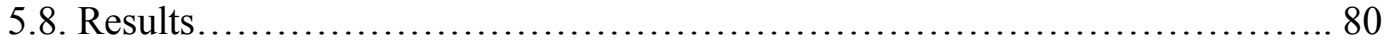

5.8.1. Group Characteristics..................................... 80

5.8.2. Social Anxiety Induction Manipulation Check......................81

5.8.3. Differences in Detection Rates for the Inattentional Trial............81

5.8.4. Differences in Identification Rates for the Inattentional Trial........ 83

5.8.5. Controlling for Gender and General Emotional Distress............ 85

5.8.6. Differences in Detection and Identification Rates for the Divided and Full-Attention Trials.............................. 86

5.8.7. Gender Differences in Detection and Identification Rates............ 87

5.8.8. Additional Evidence of Vigilant Attention towards the Critical Item.. 87

5.9. Discussion ....................................................... 93

Chapter 6: General Discussion.............................................. 100

6.1. Inattentional Blindness in Clinical Reality.............................. 100

6.2. A Model of Attentional Processing for the IB Paradigm.................... 102

6.3. Static vs. Dynamic Critical Items.................................... 108

6.4. The Role of Bogus-Speech Manipulation in Attentional Bias Investigation... 110

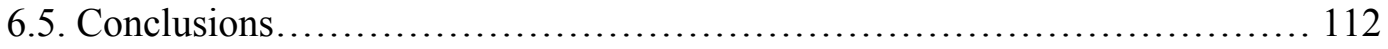

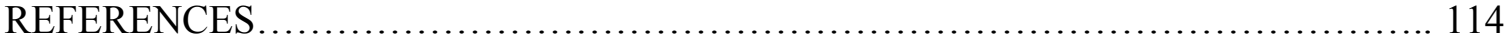

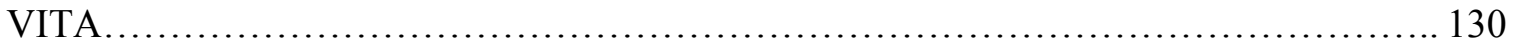




\section{CHAPTER 1: INTRODUCTION}

\subsection{Overview of Social Anxiety Disorder}

Until as recent as 20 years ago, social phobia, also known as social anxiety disorder (SAD), had not been the focus of clinical research. In 1985, Liebowitz, Gorman, Fyer, and Klein titled their article "Social Phobia: Review of a Neglected Anxiety Disorder". It was only two decades ago that this condition gained a formal diagnosable title in the Diagnostic and Statistical Manual of Mental Disorder system (DSM-III; American Psychiatric Association, 1980). However, various descriptions related to fears and anxieties in social situations have existed throughout history. For instance, "Ereutophobia", invented by a German psychiatrist, J. Casper (as cited by Himmelhoch, Levine, \& Gershon, 2001), was widely used in the $19^{\text {th }}$ century to describe patients displaying social inhibition due to their fear of criticism or humiliation (1902). The modern definition of social phobia as a condition encompassing an excessive performance fear in response to the possible scrutiny of others first appeared in the 1960s (Marks \& Gelder, 1966).

With a lifetime prevalence of approximately $15 \%$, SAD currently ranks as the third most common mental disorder in the United States (Kessler et al., 1994). SAD is no longer the neglected child of anxiety disorders. During the past two decades, we have observed an explosive increase in clinical research on this condition. 


\subsubsection{DSM-IV Definition and Clinical Features}

The central feature of SAD is a marked and persistent fear of social/performance situations in which embarrassment or humiliation may occur (DSM-IV; APA, 1994). Individuals with SAD are excessively concerned about being negatively evaluated as anxious, weak, incompetent, “crazy”, or stupid. Typically, feared social situations cause a wide array of anxiety symptoms (e.g., palpitations, tremors, sweating, gastrointestinal discomfort, diarrhea, muscle tension, blushing, confusion, etc.). Individuals with SAD may dread one or two relatively specific social/performance situations such as speaking, writing, or playing a musical instrument in public (i.e., social phobia, non-generalized). However, most victims of SAD fear multiple social/performance situations (Holt, Heimberg, Hope, \& Liebowitz, 1992; Turner, Beidel, Dancu, \& Keys, 1986). DSM-IV classifies SAD with multiple social fears as the "generalized" subtype.

Data from the U.S. National Comorbidity Survey (NCS; Kessler et al., 1994) revealed that the lifetime prevalence rate of SAD is $13.3 \%$ based on DSM-III-R, which was exceeded only by depression and alcoholism among mental disorders. SAD has also been found to be more prevalent in young people. One study using a young adult sample $($ mean $=18 \mathrm{yrs})$ revealed that $23 \%$ of them met the criteria for both SAD and simple phobia, with approximately half meeting the criteria for SAD only (Reinherz, Giaconia, Lefkowitz, Pakiz, \& Frost, 1993). Furthermore, it may be that the prevalence of SAD has been underestimated because its sufferers are likely to withdraw from social interaction and thus unwilling to consult their family doctor (den Boer, 2000). Relatedly, one French study found that $5 \%$ of primary care patients had SAD, but physicians overlooked their 
psychological problems unless it was accompanied by depression (Weiller, Bisserbe, Boyer, Lepine, \& Lecrubier, 1996). The Epidemiologic Catchment Area (ECA) study also found that only 3 of 98 individuals with SAD openly sought help for this problem (Davidson, Hughes, George, \& Blazer, 1993).

Moreover, the prevalence of SAD seems to be on the rise. A follow-up examination of the NCS data demonstrated a robust cohort effect based on synthetic estimates of retrospectively reported onset ages of SAD (Magee, Eaton, Wittchen, McGonagle, \& Kessler, 1996). Lifetime prevalence rates of SAD were higher among younger individuals (ages 15-24 $=14.9 \%$; ages $25-34=13.8 \%$ ), relative to older individuals (ages $35-44=12.1 \%$; ages $45-54=12.2 \%$ ). A more recent follow-up analysis revealed that the cohort effect observed from the NCS data was largely due to the increasing lifetime prevalence of SAD characterized by one or more non-speaking fears (Heimberg, Stein, Hiripi, \& Kessler, 2000), which resembles the DSM-IV generalized subtype. This is consistent with the findings that generalized SAD is a more severe form of the condition characterized by being more impairing, persistent, highly comorbid with other disorders, compared to SAD exclusively with public speaking fears (Kessler, Stein, \& Berglund, 1998). No cohort effect has been found in the subtype exclusively with speaking fears. Overall, these data suggest that $\mathrm{SAD}$ is becoming a greater challenge to clinicians and society.

SAD is also likely to co-occurs with numerous mental disorders, including depression, other anxiety disorders, and substance use disorders, and it typically precedes the onset of these comorbid conditions (Davidson, Hughes et al., 1993; Hunt \& Andrews, 
1995; Magee et al., 1996; Sanderson, Dinardo, Rapee, \& Barlow, 1990; Schneier, Johnson, Hornig, Liebowitz, \& Weissman, 1992). The ECA study revealed that $69 \%$ of individuals with SAD exhibited comorbid DSM-III disorders (Schneier, Johnson et al., 1992): simple phobia (59\%), agoraphobia (45\%), alcohol abuse (19\%), and major depression (17\%). Similarly, in the NCS, $81 \%$ of individuals with SAD displayed additional DSM-III-R(APA, 1987) disorders: simple phobia (37.6\%), major depression (37.2\%), alcohol dependence (23.9\%), and agoraphobia (23.3\%). A more recent study based on DSM-IV also demonstrated that 51\% of 141 patients with SAD were given additional diagnoses (Erwin, Heimberg, Juster, \& Mindlin, 2002): generalized anxiety disorder (GAD; 23.4\%), specific phobia (12.8\%), and major depressive disorder (12.8\%). Moreover, the data showed that the presence of comorbid mental disorders placed individuals with SAD at greater risk of experiencing several negative outcomes such as increased suicidal attempts and greater utilization of mental health service (Schneier, Johnson et al., 1992).

\subsubsection{Costs of the Problem}

Many other aspects of SAD also illuminate the gravity of the illness. SAD is typically associated with significant impairment in functioning (Schneier, Johnson et al., 1992). One study revealed that $50 \%$ of individuals in their early 30 s with SAD had never married, compared to $36 \%$ of individuals with panic disorder and agoraphobia and $18 \%$ of individuals with GAD (Sanderson et al., 1990). The vast majority of individuals with SAD tend to perceive their careers, academic lives, and social functions to be severely impaired due to their social anxiety (Liebowitz, Gorman, Fyer, \& Klein, 1985; Schneier 
et al., 1994; Turner et al., 1986). Not surprisingly, SAD is associated with marked reduction in quality of life (Stein \& Kean, 2000). Increased rates of suicidal ideation was also observed in connection with this condition (Katzelnick et al., 2001; Schneier, Johnson et al., 1992). SAD was also associated with diminished educational and occupational attainment (Davidson, Hughes, George, \& Blazer, 1994; Katzelnick et al., 2001), and poor socio-economic status, employment rates, and household income (Patel, Knapp, Henderson, \& Baldwin, 2002). Relatedly, SAD is also characterized by an early age of onset and its victims typically undergo a chronic and unremitting course (Reich, Goldenberg, Goisman, Vasile, \& Keller, 1994; Reich, Goldenberg, Vasile, Goisman, \& Keller, 1994; Schneier, Johnson et al., 1992).

Some studies estimated more direct costs of SAD. In general, anxiety disorders result in staggering financial costs. Based on the NCS data, the total costs of anxiety disorders in 1998 were estimated to be 63.1 billion dollars, which included medical and psychiatric treatment costs, indirect workplace cost, and mortality costs (Greenberg et al., 1999). Of them, workplace cost was most strongly linked to SAD. Other studies also revealed that $\mathrm{SAD}$ is associated with increased health care seeking. Compared to individuals with no diagnoses, those with generalized SAD displayed a greater number of annual outpatient visits and a greater total medical expenditures (Katzelnick et al., 2001). Individuals with SAD also displayed higher levels of drug dependency and use of health services than those with no psychiatric morbidity (Patel et al., 2002).

In summary, with the vigorous research on the nature, epidemiology, and treatment of SAD during the past 20 years, our perception of this illness has significantly 
changed. SAD is considered a highly prevalent, debilitating illness with an early age of onset, a chronic course, and huge costs to both the affected individuals and the society.

\subsection{Current Models of SAD}

\subsubsection{Cognitive-Behavioral Approaches}

On the basis of the foundational formulation that misperceived threat leads to pathological anxiety (Beck, Emery, \& Greenberg, 1985), several authors have formulated cognitive-behavioral accounts of SAD (Clark \& Wells, 1995; Rapee \& Heimberg, 1997). Given the similarities of the Clark and Wells' and Rapee and Heimberg's models, this next section summarizes the major theoretical components shared by both models along with some differences between them.

First, both models postulate the presence of dysfunctional assumptions (about oneself and social situation) originating from early experience, and their role in fostering negative social misinterpretations. For instance, Clark (2001) presented three major categories of dysfunctional assumptions: (a) excessively high standards for social performance, (b) conditional beliefs regarding the consequences of performing in a certain way, and (c) unconditional negative beliefs about the self. Rapee and Heimberg's model also states that excessive threat appraisals of social situations may be fostered by early experiences, including upbringing by overprotective/overintrusive parents (Rapee, 1997), dysfunctional modeling of over-emphasizing the importance of other people's opinions (Bruch \& Heimberg, 1994), or the parents' promoting social avoidance (Barrett, Rapee, Dadds, \& Ryan, 1996; Bruch \& Heimberg, 1994; Dadds, Barrett, Rapee, \& Ryan, 1996). Some research data exist in support of their position. Amir, Foa and Coles (1999) 
found that patients with SAD were likely to more negatively interpret an ambiguous social event relevant to the self, relative to patients with obsessive-compulsive disorder (OCD) or healthy controls. Stopa and Clark (2000) also found that patients with generalized SAD interpreted social events (but not non-social events) more negatively compared to patients with other anxiety disorders or non-patient controls.

Second, biased attentional processing is considered to make a central contribution to maintaining social anxiety. Both models propose that individuals with SAD are likely to attend to internal (=mental) processes when entering social-evaluative situations. In such situations, they shift the focus of attention to internal information (e.g., thoughts, images, memories, physiological reactions, etc.) and utilize this self-generated negative information to infer how they appear to others or how they will be evaluated (Clark \& Wells, 1995). Clark (2001) suggested that the inwardly-oriented attention generate selfconfirmatory evidence of misinterpreted social interaction and blocks the access to external disconfirming social information. Rapee and Heimberg (1998) also proposed that social phobics pay attention to mental representation of the self, on which they base their judgment as to how others would evaluate them. Some supporting evidence exists. Patients with SAD were found to display higher levels of self-focused attention than patients with other anxiety disorders and non-patients (Mellings \& Alden, 2000). Woody (1996) also found that an experimental manipulation of increasing self-focused attention during a speech task led to an increase of anxiety in patients with generalized SAD.

Third, both models also propose that social phobics display biased attentional processing toward external social threats. Rapee and Heimberg (1998) suggested that 
social phobics display "rapid and extensive allocation of attentional resources" to the detection of negative evaluative threat, which is in line with the general pattern of attentional processing in anxiety disorders. In contrast, Clark and Wells (1995) propose that social phobic's attentional processing of external environments is reduced due to self-focused attention. However, both models concur that (hypervigilant or reduced) processing of external social cues is negatively biased. Some studies have provided support for negatively biased processing of external social cues. Veljaca and Rapee (1998) demonstrated that relative to those low in social anxiety, those high in social anxiety were better at detecting negative audience reactions (e.g., yawing, looking at watch, coughing) than positive audience behaviors (e.g., leaning forward, smiling, nodding). Other authors have shown that social phobics were faster in detecting angry faces than happy faces in a crowd of neutral faces using a face-in-the-crowd paradigm (Gilboa-Schechtman, Foa, \& Amir, 1999). Furthermore, a number of studies using cognitive experimental paradigms (e.g., emotional Stroop tests, dot-probe tasks) have revealed that social anxiety is associated with hypervigilant/selective attention to social threat cues (See Chapter 2).

Fourth, both models suggest that social phobics process the self as a social object, thereby forming images or mental representation in which they see themselves as if viewed from an observer's perspective. One study found that spontaneous imagery reported by the majority (77\%) of patients with SAD was characterized by negative, observer-perspective images, whereas only $10 \%$ of nonclinical controls reported such images (Heckmann, Surawy, \& Clark, 1998). 
Fifth, both models also emphasize safety behaviors as a crucial maintenance factor of SAD. Safety behaviors aimed at avoiding potential source of negative evaluation/humiliation could range from very subtle internal mental processes (e.g., cognitive rehearsal prior to a public speech) to active avoidance of social situations (Clark \& Wells, 1995; Rapee \& Heimberg, 1997; Wells et al., 1995). Typically, social phobics engage in numerous safety behaviors when they enter or anticipate social situations. The deleterious effects of safety behaviors have been well documented (Clark, 2001; Clark \& Wells, 1995; Rapee \& Heimberg, 1997): (a) they may paradoxically generate the feared symptoms (e.g., keeping one's arm to the side makes one sweat more), (b) they increase self-focused attention thereby intensifying the salience of one's negative self-image, (c) some safety behaviors even more actively draw other people's attention to the patient (e.g., covering one's blushed face makes others look into one's face), and (d) they influence other people such that the patient's fears are partly confirmed (e.g., unnatural safety behaviors make them appear aloof and cold in social interactions and reduce their attention to other people, leading to unfavorable social feedback). The two models also propose that the chronic use of safety behaviors may result in social skills deficits. Some studies provide support for the role of safety behavior in SAD. Socially anxious individuals were found to use more safety behaviors and elicit more negative reactions from others when anticipating negative social feedback (Alden \& Bieling, 1998). Moreover, some authors reported that eliminating safety behaviors enhanced the efficacy of exposure treatment for SAD (Morgan \& Raffle, 1999; Wells et al., 1995). 
In summary, the two cognitive-behavioral models provide detailed accounts of how individuals maintain/intensify excessive social fears in a vicious feedback loop. In particular, information processing biases, including excessive self-focused attention and biased attentional processing of external social cues, are thought to play a central role in the maintenance of SAD.

\subsubsection{Biological/Pharmacological Approaches}

Various methodologies have been adopted to investigate the genetic and neurobiological features of SAD.

\subsubsection{Twin and Family Studies}

Data from family and twin studies have shown a modest but significant genetic contribution in the development of SAD. Early family studies reported an approximately three times higher risk of SAD in relatives of probands with SAD compared to relatives of healthy controls (e.g., Fyer, 1993). A follow-up study also revealed an escalated risk of developing SAD in close family members of probands with SAD (Fyer, Mannuzza, Chapman, Martin, \& Klein, 1995). One study found that $23 \%$ of the children of adults with SAD also met criteria for SAD (Mancini, VanAmeringen, Szatmari, Fugere, \& Boyle, 1996).

Heritability estimates based on twin studies tend to fall in the moderate range. Heritability for SAD was estimated as .31 on the basis of 2163 personally interviewed female twins (Kendler, Neale, Kessler, Heath, \& Eaves, 1992). More recently, Kendler and colleagues provided a higher heritability estimate of $\operatorname{SAD}(=.51)$, correcting for unreliability by means of conducting repeated assessments 8 years apart (Kendler, 
Karkowski, \& Prescott, 1999). A recent meta-analysis of twin studies reported a heritability estimate of .65 (Beatty, Heisel, Hall, Levine, \& La France, 2002). Overall, these data indicate a mild to moderate genetic contribution to the development of social anxiety. However, Hofmann and Barlow (2002) pointed out that the genetic disposition leading to social anxiety may be nonspecific and shared with other anxiety disorders. Relatedly, it is yet to be clarified how the genotype determines the behavioral phenotype (Rapee \& Spence, 2004).

\subsubsection{Neurotransmitter system}

Another line of research has investigated the role of anomalous neurotransmitter functions in social anxiety, particularly serotonin (5-hydroxytryptamine, or 5-HT). The role of serotonergic function in social anxiety was suggested by the effectiveness of serotonin-selective reuptake inhibitors (SSRIs) in treating this condition. Presently, Paroxetine (brand name: Paxil) and Sertraline (Zoloft) are FDA-approved drugs for the treatment of SAD. Various studies have demonstrated the efficacy of SSRIs in treating social anxiety (Katzelnick et al., 1995; Schneier, Chin, Hollander, \& Liebowitz, 1992;

Stein et al., 1998). There also exists some limited evidence suggesting that a disturbance in noradrenergic and dopaminergic functions is associated with social anxiety (for a review, see den Boer, 2000).

\subsubsection{Neuroimaging Studies}

Neuroimaging approaches have also helped understand the neurobiological features of social anxiety. Recently, based on a single photon emission computed tomography (SPECT), one study provided data that suggest a possible dysfunction of the 
striatal dopaminergic system in social phobics (Tiihonen et al., 1997). Specifically, striatal dopamine reuptake site densities were markedly lower in social phobics than in controls. These data suggest that dopamine reuptake inhibitors may be beneficial to social phobics (den Boer, 2000). Using positron emission tomography (PET), Tillfors and colleagues (2001) demonstrated that when challenged with a speech task, social phobics showed enhanced regional cerebral blood flow $(\mathrm{rCBF})$ in the amygdaloid complex, whereas non-phobic subjects exhibited an increase in cortical perfusion during the speech challenge. These data were interpreted as suggesting a linkage between social anxiety and phylogenetically older subcortical danger-recognition system (Tillfors et al., 2001). Tillfors and colleagues' follow-up study sought to further examine the neural correlates of social anxiety evoked by anticipating a public speech (Tillfors, Furmark, Marteinsdottir, \& Fredrikson, 2002). They found that the induced speech anxiety was accompanied by enhanced cerebral blood flow in the right dorsolateral prefrontal cortex, left inferior temporal cortex, and in the left amygdaloid-hippocampal region. These findings led to a speculation that social anxiety is linked to a neural network encompassing the amygdaloid-hippocampal region, prefrontal, and temporal areas (Tillfors et al., 2002).

\subsubsection{Summary}

In summary, various research methodologies have been adopted to illuminate the genetic and biological features of SAD. Overall, these data have demonstrated the genetic contribution and neurobiological dysfunctions linked to social anxiety. However, the specificity and causal status of these neurobiological factors have yet to be demonstrated. 


\section{CHAPTER 2: ATTENTIONAL BIASES IN SOCIAL ANXIETY}

\subsection{Overview of Attentional Biases in SAD}

Information processing biases associated with social anxiety have been addressed in several domains, including attention, memory, interpretation and judgment (Heinrichs \& Hofmann, 2001). Particularly, a number of researchers have examined attentional biases as a potential maintenance factor of social anxiety. As reviewed in the previous chapter, attentional biases (e.g., hypervigilance, self-focused attention) constitute the central feature of cognitive-behavioral models of SAD (Clark \& Wells, 1995; Rapee \& Heimberg, 1997). Several experimental paradigms have been employed to illuminate the nature of attentional biases involved in social anxiety.

Investigations of biased attention in social anxiety have varied along several dimensions including: (a) the paradigm used for assessing attentional bias (e.g., emotional Stroop task vs. dot-probe paradigm); (b) the nature of socially threatening cues (e.g., threatening words vs. threatening faces); (c) clinical status of the subjects studied (i.e., individuals meeting threshold diagnoses for SAD vs. non-clinical samples scoring high or low in social anxiety); and (d) whether a social anxiety induction manipulation was included prior to the assessment of attentional biases.

Overall, they have yielded a mixed pattern of findings (Heinrichs \& Hofmann, 2001): (a) hypervigilance (i.e., an attentional bias towards threatening information), (b) avoidance (i.e., cognitive avoidance of deep processing of threatening stimuli), (c) hypervigilance-avoidance (i.e., hypervigilance in the early stage of processing followed 
by avoidance in the later stages), and (d) specificity (the bias occurs only if the threat corresponds to the core of anxiety disorder). The present chapter is devoted to reviewing relevant findings according to each experiment paradigm.

\subsection{Existing Experiment Paradigms}

\subsubsection{Emotional Stroop Test}

The original Stroop color-naming test (Stroop, 1935) presents a series of colored words to subjects and asks them to name the color of the words as rapidly as possible (while ignoring their meaning). Mismatch between the color and content of the word (e.g., the word "green" printed in red) typically results in a longer response latency, which has been typically regarded as evidence of cognitive interference. Modified versions of Stroop tests presenting emotional threat words have been used to examine attentional biases in numerous conditions, including depression (Klieger \& Cordner, 1990; Segal, Truchon, Gemar, \& Guirguis, 1995; Segal \& Vella, 1990), panic disorder (McNally et al., 1994; McNally, Riemann, \& Kim, 1990; McNally, Riemann, Louro, Lukach, \& Kim, 1992), obsessive-compulsive disorder (Foa, Ilai, McCarthy, Shoyer, \& Murdock, 1993;

Lavy, Vanoppen, \& Vandenhout, 1994), posttraumatic stress disorder (Foa, Feske, Murdock, Kozak, \& Mccarthy, 1991; Kaspi, McNally, \& Amir, 1995; McNally, English, \& Lipke, 1993), specific phobia (Lavy, Vandenhout, \& Arntz, 1993; Mathews \& Sebastian, 1993), and SAD (Becker, Rinck, Margraf, \& Roth, 2001; Hope, Rapee, Heimberg, \& Dombeck, 1990; Lundh \& Ost, 1996; Maidenberg, Chen, Craske, Bohn, \& Bystritsky, 1996; Mattia, Heimberg, \& Hope, 1993; McNeil et al., 1995; Spector, Pecknold, \& Libman, 2003). Generally, in the emotional Stroop paradigm, longer 
response latencies to threat words in contrast with non-threat words have been deemed to indicate selective attention towards the threat.

Given the central role of attentional bias in cognitive models of SAD, it is not surprising that the emotional Stroop paradigm has been extensively applied to investigate this condition. One of the earliest studies using social threat words (e.g., failure and pathetic), physical threat words (e.g., disease and cancer), and neutral words (e.g., secure and holiday) found that all anxious patients displayed longer latencies in naming the color of social threat words, but only physical worriers displayed longer latencies for physical threat words (Mathews \& Macleod, 1985).

Becker and colleagues (2001) compared 32 patients with GAD, 29 patients with SAD, and 31 non-anxious controls, presenting GAD-related words (e.g., illness, injury, debts, nervous, death, heartbeat, unemployed, failure, abandoned), social anxiety-related words (e.g., talk, stutter, embarrassment, blush, watched, audience, silence, criticize, dislike, clumsy, ridicule, shy), neutral words (e.g., chair, umbrella, solid, walk, potato), and positive words (e.g., baby, dreaming, flower, gift, marry, sunset, kiss, victory). They found that SAD patients displayed longer latencies specifically to social threat words, whereas GAD patients displayed longer latencies to all types of emotional words (Becker et al., 2001; Hope et al., 1990). McNeil and colleagues (1995) compared patients with circumscribed speech phobia, generalized SAD, and generalized SAD with avoidant personality disorder using an emotional Stroop test. They found that the two generalized SAD groups displayed longer latencies in response to threat words implying generalized social fears (e.g., party, conversation), which was not evident in the circumscribed speech 
phobia group. In contrast, speech-related words elicited delayed response across all groups (McNeil et al., 1995). A more recent study comparing patients with generalized SAD with nonanxious controls provided findings consistent with the specificity hypothesis (Spector et al., 2003). Patients with SAD displayed longer latencies to social threat words related to negative evaluation (e.g., criticize) or noticeable anxiety symptoms (e.g., blushing), but not to words denoting less observable symptoms by others (e.g., palpitations). The observed response latencies were also significantly associated with scores on self-report measures of social anxiety (Spector et al., 2003).

In contrast, in Amir and colleagues' study (1996), patients with DSM-III-R SAD displayed shorter latencies to social threat words relative to physical threat words when expecting to give a speech; whereas they exhibited longer latencies to social threat words under the no-anxiety induction condition. The authors suggested that the emotional Stroop effect was suppressed in the high anxiety context.

In summary, the emotional Stroop paradigm has been extensively used to examine attentional biases associated with SAD. Most studies using the Stroop paradigm have shown that individuals with heightened social anxiety or SAD display longer colornaming latencies in response to social threat words (e.g., Andersson, Westoo, \& Johansson, 2006; Spector, Pecknold, \& Libman, 2003; Amir, Freshman, \& Foa, 2002; Becker, Rinck, Margraf, \& Roth, 2001; McNeil et al., 1995; Hope, Rapee, Heimberg, \& Dombeck, 1990; Lundh \& Ost, 1996; Maidenberg, Chen, Craske, Bohn, \& Bystritsky, 1996; Mattia, Heimberg, \& Hope, 1993) with very few exceptions that have revealed no or shorter response latencies (e.g., Kindt, Bogels, \& Morren, 2003; Amir et al., 1996). 
However, as pointed out by Bogels and Mansell (2004), the specificity is questionable given some data indicating that other groups of patients also show delayed response to social threat words (e.g., Becker et al., 2001; Mathews \& Macleod, 1985).

\subsubsection{Modified Dot-probe Test}

\subsubsection{Modified Dot-probe Test based on Word Stimuli}

A typical modified dot-probe task proceeds as follows: (a) the subject is instructed to fixate a small central cue presented for about $500 \mathrm{~ms}$ to $1000 \mathrm{~ms}$ on a computer monitor, (b) the fixation cue is replaced by a pair of stimuli (either words or pictures) presented with one above and the other below the central point for about $500 \mathrm{~ms}$, (c) immediately after their offset, a small dot appears in either of the two stimuli positions, and (d) the subject's task is to hit either an upper or bottom response key as rapidly as possible to indicate the position of the probe (i.e., dot). For instance, the screen may display a threat word "ridiculed" paired with a neutral word "navigated", on one of which position the probe appears very shortly. Thus, a faster detection of the dot is considered to indicate that the subject's initial attention was oriented toward the location of the stimulus where the probe appeared afterwards.

Bogels and Mansell (2004) have outlined several methodological advantages of the dot-probe paradigm over the Stroop: (a) true selective attention can be examined via the simultaneous presentation of threat and distracter items, (b) the reliance on the meaningless detection cue (i.e., a dot) renders mental preoccupation unlikely to affect the reaction time, and (c) both hypervigilance and avoidance can be indexed in the same paradigm. Nonetheless, findings from this paradigm (using either words or pictures) are 
mixed, suggesting attentional hypervigilance (e.g., Mogg \& Bradley, 2002; Musa, Lepine, Clark, Mansell, \& Ehlers, 2003; Mogg, Philippot, \& Bradley, 2004; Sposari \& Rapee, 2007), attentional avoidance (e.g., Mansell, Clark, Ehlers, \& Chen, 1999; Chen, Ehlers, Clark, \& Mansell, 2002), difficulty in attentional disengagement (Amir, Elias, Klumpp, \& Przeworski, 2003) or no evidence of attentional bias linked to social anxiety (e.g., Horenstein \& Segui, 1997; Mansell, Ehlers, Clark, \& Chen, 2002).

Asmundson and Stein (1994) compared 24 patients with generalized SAD with 20 healthy controls using a modified dot-probe task. They found that patients with SAD responded faster to probes that appeared on the position of social threat words, relative to neutral or physical threat words (Asmundson \& Stein, 1994). However, this result occurred only when threat words were presented in the upper area of the screen, which was likely to receive initial attention. It suggests that an attentional shift did not occur towards threat words presented at the bottom. Similarly, Horenstein and Segui (1997) compared patients with SAD, patients with panic disorder, and healthy controls, and found that patients with panic disorder were faster in detecting dots preceded by physical threat words only in the upper area of the screen. This study also failed to provide evidence of attentional bias in patients with SAD (Horenstein \& Segui, 1997).

Amir and colleagues (2003) found that compared to healthy controls, patients with SAD displayed slower reactions when a social threat word preceded the probe in the opposite location. The authors suggested that individuals with SAD may have difficulty disengaging their attention from socially threatening material (Amir, Elias, Klumpp, \& Przeworski, 2003). Mansell and colleagues tested individuals high or low in social 
anxiety using a dot-probe task with or without leading them to anticipate giving a speech. Results revealed that individuals high in social anxiety displayed no attentional bias towards or away from social-evaluative words. In contrast, trait anxiety was associated with selective attention to negative relative to positive social threat words. The speech threat did not interact with social anxiety (Mansell, Ehlers, Clark, \& Chen, 2002).

Overall, data derived from modified dot-probe tasks using threat words are quite equivocal, only tentatively supporting the presence of attentional bias associated with social anxiety. Some methodological problems have been indicated. First, most studies did not address the issue of comorbidity (Bogels \& Mansell, 2004; Heinrichs \& Hofmann, 2001). A recent study demonstrated that social phobics with comorbid depression responded like non-patient controls, whereas patients with SAD only displayed an attentional bias towards social threat words. This suggests the possibility that comorbid depression may significantly attenuate SAD patients' hypervigilance toward social threat cues (Musa, Lepine, Clark, Mansell, \& Ehlers, 2003). It is not clear whether this may be true of all attentional bias investigations. Second, the specific words pools generally differ from study to study (Heinrichs \& Hofmann, 2001), which makes the findings incomparable. Relatedly, some threat words did not seem to tap the core concern of the targeted emotional disorder being investigated. Those with SAD may respond to "incompetent" or "criticized" and those with panic disorder may respond to "suffocating" or "collapse", whereas both groups may respond to "humiliation" or “embarrassed” (Heinrichs \& Hofmann, 2001). 


\subsubsection{Modified Dot-probe Test based on Facial Stimuli}

In contrast, modified dot-probe tests using emotional faces seem to have yielded more promising results. Mansell and colleagues (1999) compared individuals high vs. low in social anxiety using a modified dot-probe task, in which they were presented with pairs of pictures comprised of a face (positive, neutral, or negative) and a household object (e.g., a fan, a clock, a rope, etc) for $500 \mathrm{~ms}$ under the condition of social threat or no threat. Results revealed that relative to those low in social anxiety, those high in social anxiety exhibited an attentional avoidance from emotional faces (i.e., negative and positive) only in the presence of social threat (Mansell, Clark, Ehlers, \& Chen, 1999).

Another pattern of findings was provided by the same research group (Chen, Ehlers, Clark, \& Mansell, 2002). Twenty patients with SAD diverted their attention from any type of faces (i.e., positive, neutral, or negative) to household objects presented for 500ms. Non-anxious controls did not display attentional avoidance from faces. This study did not use a social threat induction procedure. Recently, Sposari and Rapee (2007) attempted to replicate Chen et al. (2002) study including a bogus-speech manipulation procedure. Interestingly, the addition of the bogus-speech manipulation led them to observe hypervigilant attentional processing towards (any) faces among patients with SAD compared to normal controls.

There are also some data suggesting that the pattern of dot-probe paradigm findings may vary as a function of the length of stimuli duration (Mogg, Philippot, \& Bradley, 2004; Cooper \& Langton, 2006). Mogg, Philippot, and Bradley (2004) compared individuals with SAD and normal controls using a modified dot-probe task, in 
which happy-neutral and angry-neutral face pairs are displayed for either 500ms or $1250 \mathrm{~ms}$. At $500 \mathrm{~ms}$, the SAD group showed hypervigilance to angry faces, relative to happy and neutral faces, in comparison with the control group. In contrast, at $1,250 \mathrm{ms,}$ this effect disappeared. Similarly, Cooper and Langton (2006) with a normal student sample found evidence for attentional hypervigilant towards threatening social cues for the stimulus duration of $100 \mathrm{~ms}$. However, this pattern was revered by $500 \mathrm{~ms}$.

Overall, the modified dot-probe paradigm has been more successful in detecting attentional bias in social anxiety when social threat was presented as emotional faces as opposed to threat words. Nevertheless, even with the picture stimuli consisting of emotional faces, findings are quite inconsistent. Cooper and Langton (2006) pointed out that dot-probe data could be interested in at least three ways: (a) vigilance towards one particular stimulus, (b) inhibition of the other pair, or (c) both. Further investigation is required to understand the precise nature of mechanisms involved in the modified dotprobe paradigm leading to differential speed of dot-detection. It seems also important to examine underlying differences in attentional processing of words and pictures in the context of the dot-probe paradigm. Clark and Wells (2005) hypothesized that faceprocessing studies measure attention to actual social cues, whereas word-processing studies reflect mental preoccupation.

\subsubsection{Other Paradigms}

Visual search paradigms provide a context in which selective attention can be indexed by faster detection of the target social threat or slower detection of a target surrounded by social threat stimuli. However, findings are mixed: only some of the 
studies demonstrated enhanced social threat detection in individuals with social anxiety (disorder). For instance, based on the face-in-the-crowd visual search paradigm, one study compared patients with generalized SAD with nonanxious controls with respect to the detection speed of an angry, happy, disgust, or neutral face in a crowd of 12 distracters photographs (Gilboa-Schechtman et al., 1999). Relative to normal controls, social phobics displayed faster detection of angry as opposed to happy faces out of a neutral crowd. However, another study using schematic faces found that all subjects detected an angry face among happy faces faster with fewer errors, relative to a happy face among angry faces, regardless of the levels of their social anxiety (Esteves, 1999). Thus, the observed bias was not specifically linked to social anxiety.

A more recent study compared 35 patients with generalized SAD, 27 patients with major depression, and 55 healthy controls to examine memory and attentional biases, using a visual search task based on word stimuli as part of the study tasks (Rinck \& Becker, 2005). In this task, subjects were shown a single probe word in the screen, which was replaced by a matrix of words immediately upon the keyboard input. Their task was to indicate the presence of the probe word in the matrix by pressing a key corresponding to "yes" or "no" as promptly as possible. Each word matrix consisted of three rows of three words from the same type (i.e., either depression-related, neutral, positive, or social anxiety-related), and the probe word also varied among the four types. Those with generalized SAD took longer to detect probe words embedded in the social anxiety words matrices, relative to the other three distracter matrices. In contrast, no enhancement effect was observed in the case of detecting social anxiety probe words. The same pattern of 
results emerged for those with depression in responding to depression-related words (Rinck \& Becker, 2005).

Taken together, data derived from the visual search paradigms have provided some evidence of hypervigilance toward social threat cues associated with social anxiety. However, overall findings are equivocal. Moreover, this paradigm may be unfit for examining attentional avoidance due to explicit instructions to search for the target (Bogels \& Mansell, 2004; Rinck \& Becker, 2005).

Recently, a few studies have used saccadic eye movement tracking devices to examine attentional bias in social anxiety (Garner, Rutherford, Baldwin, Bradley, \& Mogg, 2005; Horley, Williams, Gonsalvez, \& Gordon, 2003, 2004). Healthy individuals were found to focus mainly on the eyes, nose, and mouth, which form an inverted triangle in shape (Mertens, Siegmund, \& Grusser, 1993; Walkersmith, Gale, \& Findlay, 1977). Horley and colleagues (2004) argued that eye movement patterns provide more direct indices of selective attention to facial stimuli, whereas cognitive tasks provide only indirect measures. In their earlier study, 15 patients with generalized SAD and 15 healthy controls were compared with respect to visual scan paths in response to neutral, happy and frowning face stimuli, using a computerized infrared eye gaze monitoring system. Results revealed that social phobics displayed a distinctive hyperscanning of faces (suggestive of hypervigilance), characterized by a lack of fixations (both in number and duration) and a markedly increased raw scan path length. The hypervigilant pattern of facial scanning was more prominent for frowning and neutral faces, relative to happy faces. Social phobics also avoided fixating on the salient facial features (i.e., eyes, nose, 
mouth), and such avoidance from the eyes was more conspicuous in the case of sad faces (Horley et al., 2003). Their follow-up study compared 22 subjects with generalized SAD with 22 healthy controls using a specifically threat-related facial expression (i.e., anger), in comparison with sad, happy, and neutral expressions (Horley et al., 2004). Results revealed that social phobics showed hyperscanning (increased scanpath length) and avoidance (reduced foveal fixations) of the eye, particularly in the case of angry faces. They suggested that the observed disturbance is likely to be part of a defensive strategy aimed at avoiding negative evaluation (Horley et al., 2004). Another recent study compared individuals high vs. low in social anxiety with respect to their eye movements to pictures of faces and objects (Garner, Mogg, \& Bradley, 2006). Under social threat conditions, those high in social anxiety were faster to fixate on emotional faces than neutral faces, relative to those low in social anxiety. However, despite the initial prompt orienting towards emotional faces, those high in social anxiety maintained shorter gaze on them, relative to those low in social anxiety. Overall, this pattern of findings is consistent with a hypervigilance-avoidance account.

The research based on eye-movement patterns merits further investigations. It has demonstrated both attentional vigilance and avoidance related to social anxiety in the same paradigm. Particularly, Garner and colleagues (2006)' findings suggest that the two modes of attentional biases may be sequentially evident such that initial hypervigilance is followed by attentional avoidance. 


\subsection{Summary}

A variety of methods have been used to investigate the nature of attentional biases associated with social anxiety. Although overall findings are mixed, some tentative conclusions and considerations for future research may be drawn. First, attentional biases in social anxiety (disorder) take the form of hypervigilance and/or avoidance in response to social threat. Second, overall, facial stimuli seem more potent in eliciting attentional biases relative to word stimuli. As Clark and Wells (1995) hypothesized, threatening words may assess mental preoccupation, whereas threatening faces may measure attention to actual social cues. Third, the standard stimulus duration (i.e., 500ms) of the dot-probe paradigm may need to be shortened (e.g., 100ms; Cooper \& Langton, 2006) in order to keep earlier attentional processes (e.g., hypervigilance) from being masked by later attentional avoidance (see Garner, Mogg, \& Bradley, 2006; Mogg, Bradley, DeBono, \& Painter, 1997). Fourth, attentional biases in non-clinical samples in response to emotional faces are more likely to be observed under conditions in which social anxiety is induced prior to the attentional bias assessment.

Seeking convergent evidence from multiple experimental paradigms will help illuminate the nature of attentional bias in social anxiety because each paradigm may tap into different attentional mechanisms (Mogg et al., 2000). In Chapter 3, I will introduce the inattentional blindness experimental paradigm, which seems very relevant and applicable to the investigation of attentional biases in social anxiety with several methodological advantages over existing paradigms, particularly (the most widely used) emotional Stroop and dot-probe paradigms. 


\section{CHAPTER 3: THE INATTENTIONAL BLINDNESS PARADIGM}

\subsection{The Static Inattentional Blindness Paradigm}

\subsubsection{Research Background}

Inattentional Blindness (IB) is an intriguing phenomenon in which individuals fail to notice a supra-threshold stimulus presented in front of them when having no anticipation of its emergence. This paradigm was developed by Mack and Rock (1998) in an attempt to investigate the relationship between attention and perception. In this regard, prior research had typically sought to examine whether perception is "preattentive" (i.e., a search target is quickly detected regardless of the number of distracters) or "effortful" (i.e., target search is delayed as a function of the number of distracters). However, Mack and Rock (1998) argued that the prior methods failed to remove the contribution of attention from the task because a visual search necessarily leads the subjects to actively attend to the visual field due to the possible presence of the search target. To overcome this limitation, they invented a new method that effectively eliminates attention, in which the target object appears out of the blue while the individual is actively attending to a perceptual discrimination task. In this paradigm, the subject has no expectation of the real target object.

\subsubsection{Inattentional Blindness Task}

In a typical IB experiment, subjects are administered a computerized perceptual discrimination task. A small fixation cue appears at the center of the screen for $1500 \mathrm{~ms}$, which is replaced by a target cross placed at fixation for $200 \mathrm{~ms}$. This stimulus 
presentation is shorter than is required for a saccadic eye movement to occur (Mack \& Rock, 1998). The target cross is then covered by a circular pattern mask lasting for $500 \mathrm{~ms}$, which is aimed at eliminating any residual visual processing after the cross disappears. The subject's task is to determine the relative length of the vertical vs. horizontal line of the cross. This chain of events constitutes a regular discrimination trial, and approximately 10 trials are repeated with randomly varying crosses (See Figure 1).

On the third or fourth trial, an extra object (i.e., the critical item) unexpectedly appears in the parafovea (i.e., 2 degrees from fixation) along with the target cross for 200ms. This constitutes the inattentional trial. In this critical trial, subjects are asked whether they saw anything that had not been present on the screen in addition to the discrimination target cross. Another critical trial takes place on around the 7 th trial, but this is called a divided attentional trial because the subject may already have started allocating some attention to the possible emergence of an extra object. The last trial asks the subject to fully attend to the screen ignoring the cross, which is called a full attentional trial.

Testing a number of items as critical items under the inattentional trial, Mack and Rock (1998) have found that approximately $25 \%$ of the subjects did not even detect its presence, regardless of whether it was a moving bar, a black or colored small square or other geometric form. These individuals indeed failed to see the unexpected item, and accordingly their selection of the critical item from an array of alternatives remained at a chance level. Mack and Rock labeled this robust phenomenon as inattentional blindness (IB). Earlier, they sought to explore objects that may be perceived without attention. 
However, since these findings, their research has focused on stimulus properties that attract attention based on the working hypothesis that there is no perception without attention (Mack \& Rock, 1998; Mack, 2003).

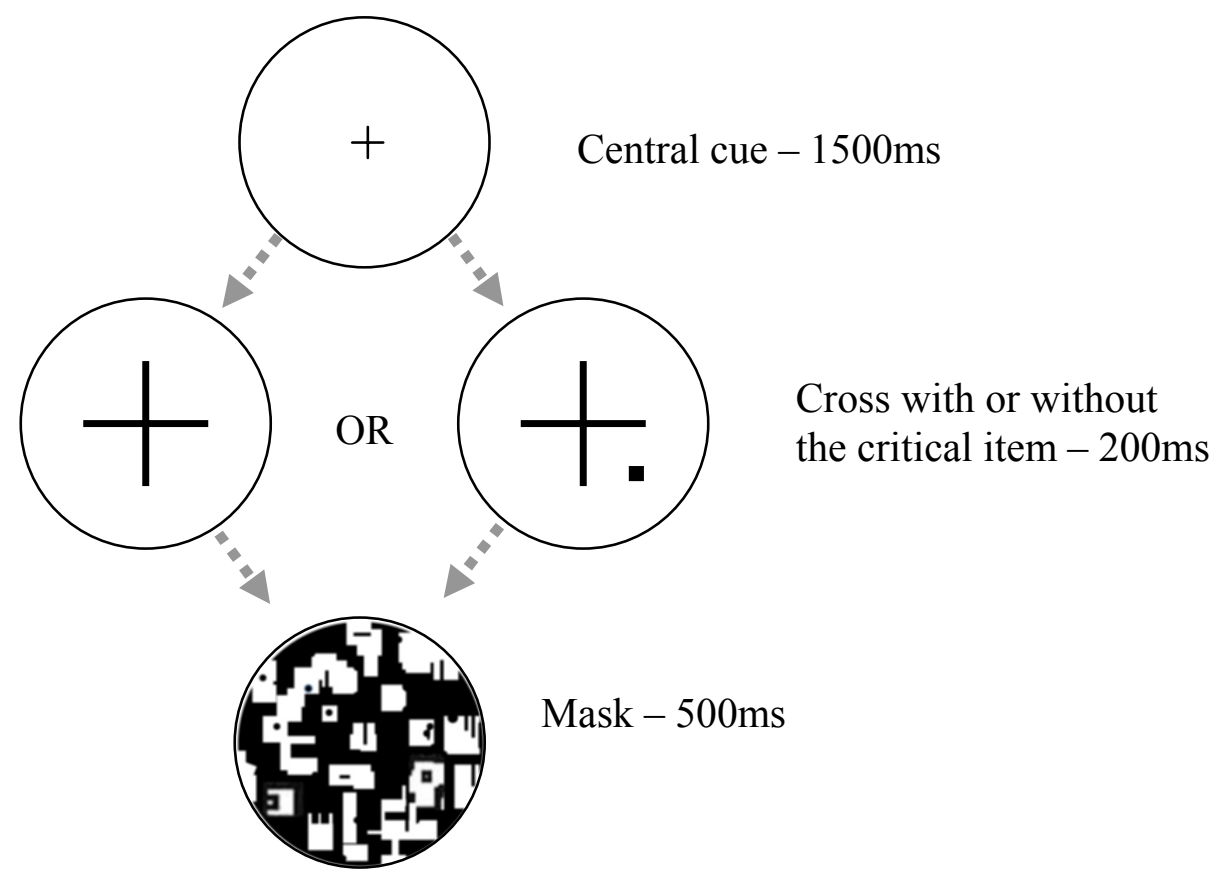

Figure 1. Regular and Critical Trials with the Critical Item in Parafovea.

Initially, Mack and Rock suspected that 25\% IB might have occurred because the critical item was placed in the parafovea. Thus, they expected the complete elimination of IB in the case of the critical item appearing at fixation. However, contrary to their prediction, three times higher rates of IB were observed when the target cross appeared parafoveally and the critical item appeared at fixation. Sixty to $80 \%$ of observers failed to detect critical stimuli such as a simple (solid black or outlined) geometric figure identical 
to those used in their earlier studies. This is counterintuitive considering the highest visual acuity and the maximum attention in the foveal region. Mack and Rock (1998) suggested that subjects actively inhibited their attention at fixation to handle the

peripherally-presented target. Indeed, a modified version of the IB task showed that subjects were able to tacitly learn to inhibit attention towards particular spatial locations, which led to an increase in IB (Mack \& Rock, 1998).

\subsubsection{Stimuli Seen Under the Inattentional Condition}

Particularly, Mack and Rock examined whether there exist some visual stimuli that would capture attention under the inattentional condition in which most stimuli went undetected. They found a few exceptional critical items that can be frequently seen, including the subject's own name and a schematic happy-face icon (:)).

\subsubsection{One's Own Name}

One's own name has been highlighted in the selective attention literature for its unique capability to capture attention. For example, one can hear one's own name being said elsewhere in a crowded noisy room (i.e., cocktail party effect; Cherry, 1953). The dichotic listening task also showed that about one-third of participants can hear their own name unexpectedly occurring from an unattended listening channel (Moray, 1959). Mack and Rock (1998) examined whether one's own name would be seen under the inattentional condition, although they expected that it was unlikely the case because even more primitive visual stimuli (e.g., color, motion, texture segregation, flicker) went undetected. 
They conducted an experiment presenting (a) one's own name ( 3 to 5 letter first name subtending .73 to 1.4 degrees of visual angles; $n=55$ ), (b) other common names (i.e., David; $n=20$ or Alex; $n=20$ ), or (c) very common English words (i.e., Time; $n=20$ or House; $\mathrm{n}=20$ ) as the critical item. For the three conditions, respectively, the IB rates were $12.7 \%, 35 \%$, and $50 \%$, and the correct identification rates of the detectors were $83 \%$, $45 \%$, and $35 \%$, respectively. One's own name was detected more often than the other two types, $\chi^{2}(1)=18.35, p<.001$. Findings did not differ as a function of the length of words.

Several follow-up studies were conducted with respect to the unique ability of one's own name to capture attention in the inattentional condition. In one experiment, they presented stimuli (i.e., both target crosses and the critical item) only for $100 \mathrm{~ms}$ with no mask. Of 15 participants, $74 \%(\mathrm{~N}=11)$ detected their own name, and $73 \%(\mathrm{~N}=8)$ of the detectors correctly identified it. Of another 15 subjects presented with "Time" for 100ms on the critical trial, only $20 \%(\mathrm{~N}=3)$ detected it and none of them correctly identified it. This is a more convincing demonstration of the unique ability of one's own name in capturing attention (Mack \& Rock, 1998).

In particular, they examined whether the perception of the unexpected presentation of one's own name was determined by its meaning or its global physical features. In one study, individuals' own names were modified in their first or second vowel (e.g., Ken to Kon, Jack to Jeck, Adam to Adem) with all other elements remaining constant. They predicted that a simple vowel modification should have little effect if the name perception was based on the coarse, global, or low-level stimulus information. Of those $(\mathrm{N}=20)$ who were presented with their own names without modification, $95 \%$ 
$(\mathrm{N}=19)$ detected their names; whereas of those $(\mathrm{N}=20)$ whose names were modified, only $40 \%(\mathrm{~N}=8)$ detected their names, $\chi^{2}(1)=13.8, p<.001$. In the modified name condition, none of the eight detectors correctly identified the critical item. In contrast, another experiment revealed that the modification of common words (i.e., time to teme, and house to hause) did not change the detection rates (about 50\%). From these findings, Mack and Rock (1988) concluded that it is the meaningfulness of the critical item that is critical in capturing attention under the inattentional condition.

These findings also bear an important implication with respect to the controversy between early and late selection theories in perception psychology. Early selection theories posited that an attentional filter operates at early stages on the basis of gross stimulus features of the input (Broadbent, 1958; Treisman, 1969), whereas late selection theories argued that selection occurs later after semantic processing has been completed (Deutsch \& Deutsch, 1963). Based on these findings, Mack and Rock (1998) suggest that attention enters at a later stage of processing. In other words, a stimulus will capture attention only after its meaning is analyzed (Mack, 2003).

\subsubsection{Happy Face}

Another object that can be seen under inattentional conditions was a schematic happy face. Mack and Rock (1998) chose to use schematic faces to keep the stimulus features as simple as other geometric figures used in their earlier studies. In a standard IB experiment, they presented a smiling face, a frowning face, a scrambled face, or a circle at fixation as critical items, which subtended a visual angle of 0.6 degree. IB rates were significantly lower in the happy face as opposed to frowning face condition, $\chi^{2}(1)=8.64$, 
$p<.01$ (See Table 1). They interpreted that the findings resulted from the meaningfulness of the happy face icon. With respect to the frowning face, they had initially suspected that its negative emotional valence might have repelled attention, leading to greater IB rates. However, they rejected this hypothesis based on another study that failed to demonstrate the difference between a frowning face and a neutral face in IB rates (Mack \& Rock, 1998). They also replicated these findings even after reducing the stimulus duration to $100 \mathrm{~ms}$. A shorter stimulus duration exerted little effect on the attentional capture of the happy face icon (IB rates of $27 \%$ and $53 \%$ for the happy and frowning face, respectively).

Table 1. Percentage of Those Who Detected or Correctly Identified the Critical Item (Mack \& Rock, 1998).

\begin{tabular}{lcccc}
\hline & $\begin{array}{c}\text { Happy face } \\
(\mathrm{n}=20)\end{array}$ & $\begin{array}{c}\text { Frowning face } \\
(\mathrm{n}=20)\end{array}$ & $\begin{array}{c}\text { Scrambled face } \\
(\mathrm{n}=35)\end{array}$ & $\begin{array}{c}\text { Circle } \\
(\mathrm{n}=20)\end{array}$ \\
\hline$\%$ of detectors & $85 \%$ & $40 \%$ & $63 \%$ & $15 \%$ \\
\hline $\begin{array}{l}\text { \% of correct } \\
\begin{array}{l}\text { identifiers among } \\
\text { detectors }\end{array}\end{array}$ & $88 \%$ & $63 \%$ & $27 \%$ & $15 \%$ \\
\hline
\end{tabular}

\subsubsection{Meaningfulness or Familiarity?}

Familiarity seems a reasonable alternative to meaningfulness in explaining the superior perception of one's own name and a happy face icon. Mack and Rock (1998) deemed a familiarity account untenable arguing that simple geometric figures, common words (e.g., Time or House), or a brightly colored/moving square must be at least as familiar as the happy face icon or even one's own name. Nonetheless, they further 
examined this issue due to its significance. In one study, they presented The as the critical item, which is the most frequently used English word with no independent meaning ( $\mathrm{n}=$ 25). Another critical item was Tie $(\mathrm{n}=25)$, which is graphically similar to The but less frequently used. If familiarity as opposed to meaningfulness is the primary determinant, The should be detected well in the critical trial. They found that The was detected by $63 \%$ $(\mathrm{n}=16)$ of the subjects, but only $37 \%(\mathrm{n}=6)$ of the detectors identified it. Tie was detected by $40 \%(n=10)$ of the subjects and only $40 \%(n=4)$ of the detectors correctly identified it. The two conditions did not significantly differ. Moreover, the IB rate of The (36\%) was significantly greater than that of one's own name $(5 \%), \chi^{2}(1)=15.8, p<.01$.

They also compared And and Ant as critical items in the same context. And is the fourth most frequent English word (Kucera \& Francis, 1967), whereas Ant is a meaningful but less frequent word. Both words share gross sensory features, but considerably differ with respect to their frequencies in English. Similar to the study comparing The and Tie, detection rates did not differ significantly between And and Ant, although the trend was in favor of familiarity (i.e., IB rates were $25 \%$ and $45 \%$ for And and Ant, respectively).

Another test of the familiarity hypothesis presented a solid 0.6 degree black circle as the critical item. Prior to the standard inattentional experiment, all subjects were exposed to 10 prefamiliarization trials, which asked them to determine whether or not two target stimuli sequentially presented at fixation each for $200 \mathrm{~ms}$ were identical. The black circle was one of the pair all throughout the ten trials. For 20 subjects, the black circle unexpectedly appeared on the third trial as usual. For another 10 subjects, it 
appeared on the first trial in order to examine whether prefamiliarization would result in a better detection of the black circle. Results revealed no difference in IB rates between the two conditions: $50 \%$ for the third trial condition and $60 \%$ for the first trial condition.

These findings are at odd with the familiarity hypothesis (Mack \& Rock, 1998).

Taken together, Mack and Rock (1998) reached a conclusion that meaningfulness is the primary determinant accounting for the perception of unexpected stimuli, whereas familiarity plays a much lesser role.

\subsubsection{Some Additional Evidence for the Meaningfulness Hypothesis}

From the perspective of the meaningfulness hypothesis, Mack and Rock (1998) explored other stimuli that may have significant signal values. In one study, they compared Rape with Pear, Stop with Post, and Help with Held, as critical items under the inattentional condition. The results are summarized in Table 2. Rape was detected significantly better than Pear, $\chi^{2}(1)=4.29, p<.05$, although Pear is a more common English word. In the same fashion, Stop was detected better than Post, $\chi^{2}(1)=8.89, p$ $<.01$. Help and Held did not significantly differ.

They also compared a swastika and two other novel figures made by transforming a swastika into an open or closed figure to eliminate its meaning. Of 15 subjects who were presented with the swastika as the critical item, $74 \%(n=11)$ detected it; whereas the other two transformed figures were detected merely by $40 \%$ and $47 \%$ of the subjects, respectively. Another experiment revealed that a stick human figure was detected by $80 \%$ of 20 participants, whereas a Christmas tree and house figures were detected by $45 \%$ and $33 \%$, respectively, $\chi^{2}(1)=7.74, p<.01$. As an additional test, all the three figures were 
examined again in the upside-down orientation. Rotating the tree and house did not affect the detection rates (30\% and $20 \%$, respectively). However, in the case of the inverted stick human figure, the detection rate dropped from $80 \%$ to $30 \%$. Mack and Rock (1998) suggested that the stick figure, which is even found in early prehistoric cave walls, is a basic schematic representation of a human, thereby being highly salient to human observers.

Table 2. Rates of IB and Correct Identification of Other Meaningful Stimuli (Mack \& Rock, 1998)

\begin{tabular}{lcc}
\hline & $\%$ of Detectors (IB) & $\begin{array}{c}\text { \% of Correct Identifiers } \\
\text { among Detectors }\end{array}$ \\
\hline Rape & $67 \%(33 \%)$ & $90 \%$ \\
Pear & $54 \%(46 \%)$ & $75 \%$ \\
\hline Stop & $87 \%(13 \%)$ & $69 \%$ \\
Post & $67 \%(33 \%)$ & $60 \%$ \\
\hline Help & $67 \%(33 \%)$ & $70 \%$ \\
Held & $54 \%(46 \%)$ & $63 \%$ \\
\hline
\end{tabular}

\subsubsection{Summary}

A series of the studies based on the static IB paradigm demonstrated that an object that has a salient meaning to the viewer is likely to capture attention even when the individual has no intention or expectation to see it. Some data revealed that familiarity may affect the rates of IB and identification, but its role seems to be minimal compared to that of meaningfulness. When meaningful critical items (e.g., one's own name, a stick 
human figure) were modified to dilute their salient meanings while maintaining the global stimulus features, the detection rates dropped noticeably. Taken together, overall data indicate the primary role of meaningfulness.

\subsection{The Sustained Inattentional Blindness Paradigm}

\subsubsection{Selective Looking Studies}

Other researchers have used dynamic stimuli to investigate IB or similar forms of cognitive blindness. Neisser (1979) reported that $79 \%$ of observers, who were asked to count the number of basketball passes made by a group of people wearing white or black shirts in a video clip, failed to notice a woman with an umbrella unexpectedly appearing

and walking across the screen. Recently, this selective-looking study was replicated by Simons and Chabris (1999). They found that $44 \%$ of participants failed to detect the unexpected emergence of a woman with an umbrella walking through a group of people passing basketballs one another. Interestingly, they found that the rates of detection failure arose to $73 \%$ in the case of an unexpected person appearing in a gorilla suit. Particularly, the failure was more frequent when the subjects were keeping track of the people in black than people in white. These findings suggest the importance of perceptual similarity between the unexpected stimulus and the ignored/attended stimuli (Simons \& Chabris, 1999).

\subsubsection{The Sustained Inattentional Blindness Studies}

A few concerns were raised regarding the static IB paradigm using the cross-line discrimination task: (a) the findings may not generalize to the real perceptual world and; (b) the short duration of stimulus presentation leaves open the possibility that the 
observed IB effects might be due to a memory failure (inattentional amnesia; Wolfe, 1999) rather than a perceptual failure resulting from inattention. To address these potential problems, Most and colleagues developed a sustained inattentional blindness paradigm (Most, Scholl, Clifford, \& Simons, 2005; Most et al., 2001; Simons \& Chabris, 1999). In this paradigm, for example, the subject views four white items and four black items on a dynamic computer display moving on haphazard paths for about $15 \mathrm{sec}$, occasionally bouncing off the edges of the display. The subject's task is to count the number of times either only black or white items bounce off the edges (i.e., half of them will be attended to and the other half will be ignored). This constitutes a regular judgment trial. However, on the third trial (inattentional trial), an unexpected item appears in the middle of the right side of the display and slowly moves and exits to the left side of the screen. The unexpected object is present for a total of $5 \mathrm{sec}$. The same critical trial is repeated on the fourth trial (divided attentional trial). On the fifth and last trial, subjects are asked to watch the display without keeping a tally of the previously attended items. A series of studies have shown that this task can effectively generate IB (Most et al., 2005; Most et al., 2001).

\subsubsection{The Effects of Attentional Set on Detecting Unexpected Stimuli}

Through a series of experiments based on the sustained IB paradigm, Most and colleagues have reached the conclusion that attentional set primarily determines what people see under the inattentional condition (For a review, see Most et al., 2005). In one experiment, the display consisted of two black circles, two black squares, two white circles, and two white squares moving on haphazard paths, using an additional black 
circle as the critical item. Subjects were asked to count the number of bounces made by either (a) black shapes, (b) white shapes, (c) circles, or (d) squares. Results clearly demonstrated that the induced attentional set directly affected the detection of the critical item. Of subjects told to attend to the black shapes or the circles, the majority ( $88 \%$ and $81 \%$, respectively) detected the black circle. In contrast, among those instructed to attend to the white shapes or the squares, almost none detected the critical item ( $0 \%$ and $6 \%$, respectively). These findings suggest that the critical item is likely to be detected when it matches the characteristics of the induced attentional set (Most et al., 2005).

To address the possibility that subjects might not have reported the presence of the critical item simply because they had regarded it as one of the distracter items, Most et al (2005) conducted a follow-up experiment using a critical item that was more clearly distinguished from the distracter items (i.e., a gray circle). Regardless of the increased salience, a strong effect of attentional set emerged with respect to shape. Of those attending to the circles, only $14 \%$ missed the gray circle; whereas of those keeping track of the squares, $93 \%$ missed it (Most et al., 2005). Another study also demonstrated the effect of attentional set using more complex stimuli. The display consisted of four Caucasian male faces and four African American male faces, and the critical item was either of the two faces. Results revealed that the African American face was more likely to be detected by those attending to African American faces (81\%) than those attending to Caucasian faces (40\%). In contrast, the Caucasian face was more likely to be detected by those attending to Caucasian faces (68\%) than those attending to African American faces $(56 \%)$. 
Taken together, the sustained IB paradigm seems to provide a test setting more analogous to the real perceptual world that is filled with dynamic, complex and sustained visual images. Overall data indicate the strong role of the perceiver's mindset to attend to certain properties of stimuli.

\subsubsection{Roles of Stimuli Properties in the Sustained IB Experiments}

Most and colleagues particularly emphasized the role of attentional set in detecting the unexpected objects under the sustained inattentional condition. However, they also examined the role of stimuli salience (Most et al., 2005) as an alternative account. In one experiment, distracters were four black circles and four black squares, with either a white or black triangle as the critical item. Subjects were told to count the number of bounces made by the circles. They hypothesized that the white and the black triangles should be detected equivalently if stimulus salience (i.e., white color) has no effect, given that the shape is the critical dimension of the induced attentional set. Results showed that detection rates for the white triangle and the black triangle was $68 \%$ and $38 \%$, respectively. This finding suggests that sustained IB is indeed affected by the salience of the critical item. However, the magnitude of its impact did not seem to match that of perceiver's attentional set (Most et al., 2005).

To increase the salience of the critical item, Most and colleagues used a critical item abruptly appearing in the display. The implicit attention capture literature has reliably demonstrated that a sudden onset attracts attention (Jonides \& Yantis, 1988). A series of experiments were conducted where critical items appeared abruptly about 1.5 $\mathrm{cm}$ away from the right edge of the display and moved and exited to the left side (Most et 
al., 2005). However, results failed to clearly demonstrate the benefits of sudden onsets. Overall, the detection rates did not differ between the gradual onset and sudden onset conditions ( $42 \%$ vs. $45 \%)$.

Taken together, these findings suggest that the top-down influence of the perceiver's attentional set is greater than the bottom-up contribution of the stimuli salience in the detection of the critical stimuli under the sustained inattentional condition. Contrary to the implicit attention capture literature, even sudden onsets of the critical item did not increase its capability to capture the viewer's attention. Relative to the physical features of the stimuli themselves, their match (or mismatch) with the viewer's attentional set is more important in the sustained IB paradigm (Most et al., 2005).

\subsection{Advantages of the IB Paradigm}

This dissertation study was primarily motivated by the expectation that modified versions of static and sustained IB tasks presenting socially relevant stimuli such as emotional faces would be a promising method to investigate attentional biases in social anxiety. Particularly, this approach is expected to circumvent some methodological problems underlying the existing cognitive experiment paradigms in the field of social anxiety.

Despite the overall success of the emotional Stroop paradigm in demonstrating longer color-naming latencies linked to social anxiety, some methodological and interpretational problems render its status as an attentional bias measure for social anxiety questionable. First, the specificity of these findings is uncertain because other groups of patients have also exhibited delayed response to social threat words (Becker et al., 2001; 
Mathews \& Macleod, 1985). Second, several authors have indicated that the Stroop effect is likely confounded with various non-attentional mental processes such as mental preoccupation, cognitive avoidance, or emotional reaction to threat words (Bogels \& Mansell, 2004; Heinrichs \& Hofmann, 2001; Williams, Mathews, \& MacLeod, 1996; Asmundson \& Stein, 1994). Third, it has been found that the Stroop interference may be overridden by effortful control strategies (Amir et al., 1996; Amir et al., 2002). Williams and colleagues (1996) suggested that participants may increase their effort to compensate for the Stroop interference when becoming anxious. Taken together, the Stroop paradigm does not seem to necessarily tap into biased attentional processing in social anxiety.

The dot-probe paradigm also has some methodological limitations. First, some studies using threat word stimuli demonstrated attentional biases only when threat cues appeared in the upper area of the screen, to which initial visual attention may be oriented (Asmundson \& Stein, 1994; Horenstein and Segui, 1997). These findings suggest that the dot-probe paradigm still leaves room for non-attentional response factors. Relatedly, Mogg and colleagues (2000) suggested that high trait anxious individuals may easily use strategies to counteract their vigilance towards threat words and that the dot-probe paradigm presents a relatively fragile index of attentional biases in normal samples. Second, this paradigm has to place social cues in competition with non-social or less threatening social cues in order to index attentional bias. This comparative context does not allow the attentional processing of a social cue to be independently examined. The competition within the pair of stimuli also poses some interpretative ambiguity. For instance, the faster detection of a dot following a more threatening cue, relative to a less 
threatening or neutral cue, may arise from the inhibition of the less threatening cue, the facilitation of the more threatening cue, or both (see Cooper \& Langton, 2006; Koster, Crombez, Verschuere, \& De Houwer, 2004). Unlike previous studies, Cooper and Langton (2006) revealed that it was not the vigilance to the threat, but the inhibition of less threatening cues that accounted for the faster detection of the probe following threatening faces.

In contrast, the IB paradigm offers several potential advantages over the existing Stroop and Dot-Probe paradigms in the assessment of information processing biases associated with psychopathology in general and social anxiety in particular. First, due to the unexpected emergence of the real search target, potential non-attentional response factors on the part of the subject are reduced. In any simple, repetitive cognitive task with an apparent task goal, subjects may be apt to employ some response strategies particularly when asked to perform under the pressure of time and accuracy. In this regard, the IB paradigm has a unique methodological strength due to its secretive and unexpected nature of the real search target, which would help investigate more purely attentional aspects of cognitive processing. Second, the IB paradigm may provide a more direct measure of attentional hypervigilance to the social threat cue itself, relative to the emotional Stroop or dot-probe paradigms in which attentional biases are inferred indirectly through either slower (Stroop) or faster (dot-probe) processing of non-social stimuli (i.e., color of words or location of dots). Moreover, the IB paradigm allows us to examine how the social cue itself was processed in a very attentionally-limited condition, whereas the dot-probe paradigm allows one to infer only where attention was oriented 
while leaving it uncertain how the individual processed the social cue. Taken together, compared to the emotional Stroop or dot-probe paradigms, the IB paradigm seems to present a testing situation that better emulates the clinical reality of SAD where attentional bias leads the socially anxious individual to engage in the processing of potentially negative social cues that could unexpectedly occur even in essentially nonevaluative situations.

\subsection{The Present Studies}

In Chapter 4 and 5, I will report data from two independent experiments conducted on the basis of the static IB (Experiment 1) and sustained IB (Experiment 2) paradigms, respectively. The present studies employed an analogue approach based on non-clinical samples, which makes it possible to use a complex experimental design requiring a large number of subjects and to pilot a new task in an efficient fashion (Stopa \& Clark, 2001). The FNES has been extensively used in analogue studies of SAD, and its validity in this context has been well demonstrated (For a review, see Stopa \& Clark, 2001). The FNES distinguishes social phobics from normal controls and patients with other anxiety disorders. It is also significantly associated with other social anxiety measures; and the differences observed between high and low scorers on this instrument mirror those observed between social phobics and non-anxious controls. A pilot study including approximately 1500 University of Texas students revealed that total scores of "22 or higher" and "10 or lower" on the FNES determined the top and bottom $25 \%$, respectively. Stopa and Clark (2001) suggested that $75^{\text {th }}$ and $25^{\text {th }}$ percentile scores be used as the cutoff lines of high and low FNE groups for analogue studies of SAD. 


\section{CHAPTER 4: EXPERIMENT 1 - AN INVESTIGATION USING THE STATIC IB PARADIGM}

The principal goal of the present study was to examine the utility of the IB paradigm for investigating attentional bias in social anxiety. Given that this is the first study to use the IB paradigm in a psychopathology context, I sought to replicate the experimental setting of the original Mack \& Rock (1998) study using the schematic facial icons. In the present study, college students who displayed high (HSAs) or low (LSAs) levels of social anxiety on the Fear of Negative Evaluation Scale (FNES; Watson \& Friend, 1969) were randomly assigned to one of three critical item conditions (i.e., happy face, frowning face, or circle) in the presence or absence of a bogus-speech social anxiety induction manipulation.

In the context of social anxiety, negative facial expressions are likely to carry a more meaningful signal portending negative social evaluation to HSAs than to LSAs. Thus, we hypothesized that HSAs would show a significantly higher detection/identification rate of the frowning face relative to LSAs; LSAs would show a significantly higher detection/identification rate of the happy face relative to HSAs; and that these hypothesized differences in detection/identification rates would be present only for participants assigned to the social anxiety induction condition. The instructional manipulation based on a bogus speech task would activate individuals' social schema related to social anxiety-provoking situations, thereby maximizing the differences between HSAs and LSAs in cognitive responses to social threat cues. Thus, Experiment 1 
hypotheses put forth a three-way interaction between social anxiety status (high vs. low), social anxiety induction manipulation (present or absent), and critical item condition (i.e., happy face, frowning face, or circle). No significant interaction effects were expected with respect to detection/identification rates from the divided and full attention trials because it should be far less difficult to detect or identify the supra-threshold stimuli presented in the fovea once one is expecting its emergence. In addition, no significant effects were expected with respect to detection/identification of the non-social critical item (i.e., circle).

Taken together, attentional hypervigilance to social threat was indexed by the significant increases of the detection/identification rates in response to the frowning face as opposed to the happy face. Although the "IB rates" and the "detection rates" provide the identical information, we chose to frame our hypotheses and findings in terms of detection rather than IB because detection denotes attentional vigilance more directly.

\subsection{Participants}

Undergraduate students $(\mathrm{N}=1684)$ enrolled in introductory psychology courses at the University of Texas at Austin were screened using the FNES. Those who scored less than or equal to 10 (LSAs; $\mathrm{N}=410$ ) or greater than or equal to 22 (HSAs; $\mathrm{N}=421$ ) were invited to participate in the experiment in partial fulfillment of their experimental credit. Of those, 298 students replied to the invitation. Upon retesting, 22 participants no longer met the FNES criteria. The final sample consisted of 276 students (110 males, 166 females, mean age $=18.95$ years, $\mathrm{SD}=1.51)$. They were ethnically diverse: Caucasian 
(54.2\%), Hispanic (21.5\%), Asian/Pacific Islander (15.3\%), African American (5.8\%) and other $(3.2 \%)$.

\subsection{Materials}

An IB task was generated following the description of the original study (Mack \& Rock, 1998). All trials took place on a white background of a 14.1 inch color monitor screen, from which the subject was seated at a $76 \mathrm{~cm}$. distance. Each regular discrimination trial proceeded as follows: (a) a small black fixation point was presented at the center of the white screen for $1500 \mathrm{msec}$; (b) a target cross appeared in the parafovea within 2.3 degrees of fixation on one of the four quadrants for $200 \mathrm{msec}$; (c) the cross was replaced by a circle $10.6 \mathrm{~cm}$ in diameter with a complex black and white pattern lasting for $500 \mathrm{msec}$; and (d) subjects were then asked to indicate their judgment as to the relative length of the cross lines by pressing the "V" key in the case of the vertical line being longer, or the "H" key in the case of the horizontal line being longer. The experiment consisted of 10 discrimination trials in total (See Figure 2). The size of the target cross varied from trial to trial, with the length of a cross line ranging from 3.0 to 4.5 degrees. The difference between the vertical and horizontal lines was approximately 0.3 to 0.5 degrees.

Of the 10 trials, the fourth, eighth, and tenth trials presented an additional unexpected item for $200 \mathrm{msec}$ at fixation. The fourth trial constituted the inattentional trial. During this trial, participants were presented with a happy face, frowning face, or circle. The happy and frowning faces differed only with respect to the orientation of the mouth: a U-shaped versus an inverted U-shaped mouth. The circle was of the same size 
with the two facial icons. These critical items subtended a visual angle of 0.6 degree (i.e., approximately 1 centimeter). In this trial, after the regular cross judgment procedure, the subjects were asked whether they saw anything that had not been present on the screen. Affirmative responses were further probed (e.g., what kind of object did you notice? How big was the object? Where did you see that?) to determine what was noticed and to ensure that the participant was referring to the intended target. Then, a recognition test followed asking them to select what they saw in the inattentional trial from an array of five items consisting of a square, a diamond, and the three critical items (See Figure 3). If they reported seeing nothing but the cross, they were first asked to guess what they failed to detect. Following this open-ended probe, they were then presented the object array and instructed to select the stimulus that they failed to detect.

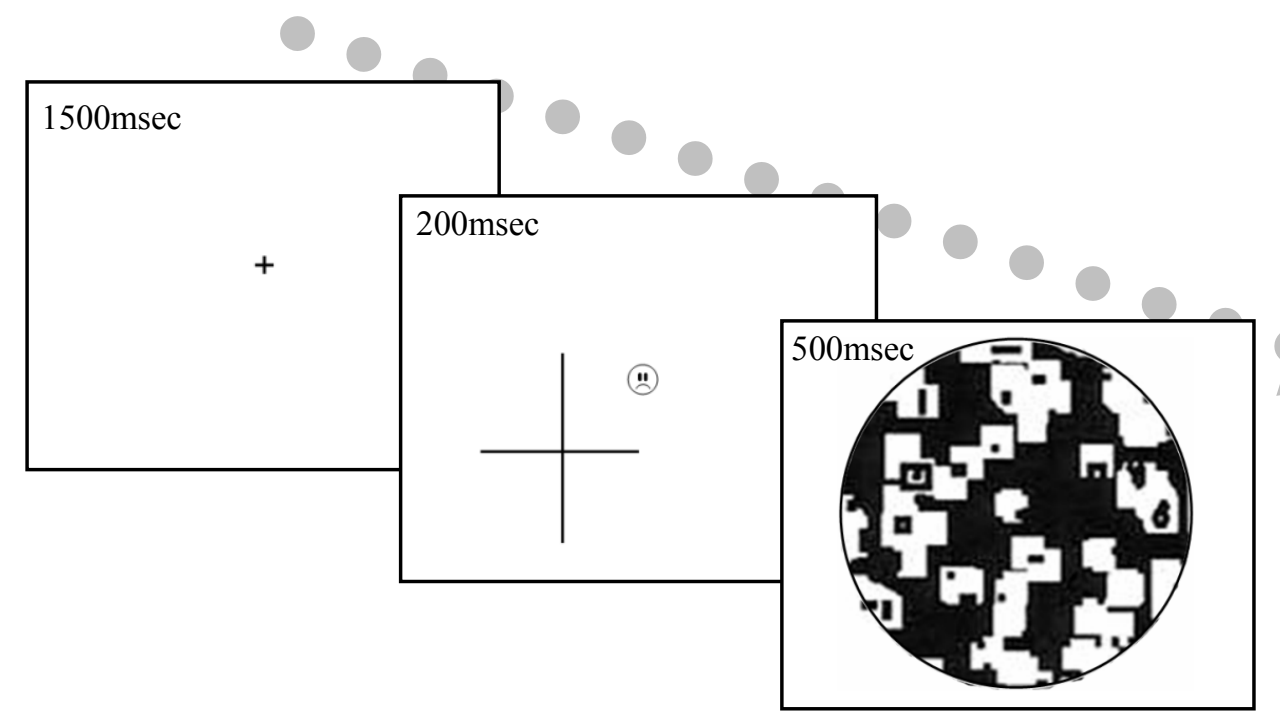

Figure 2. The sequence of the inattentional trial from the static IB task 
The eighth trial was identical to the fourth trial, but constituted a divided attentional trial because the subject was likely to be privy to the possible emergence of an additional object. The tenth trial presented the same critical item used in the fourth and eighth trials, but subjects were instructed to ignore the cross and just to report what they may see in the display, thereby constituting the full attentional trial.

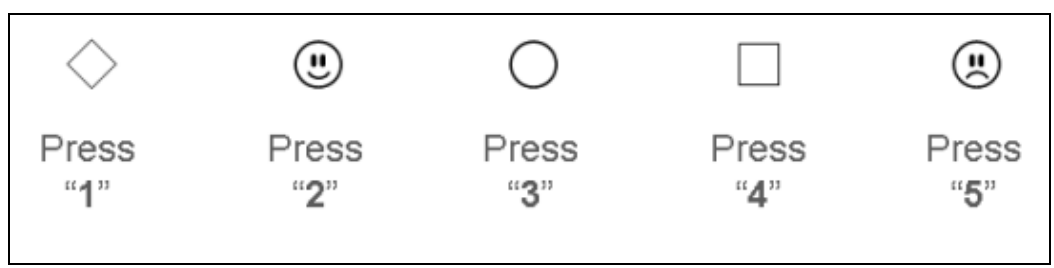

Figure 3. The Object Array for the Recognition Test in the static IB task

\subsection{Experimental Design}

A $2 \times 3 \times 2$ completely crossed factorial design was used to investigate the effects of participants' social anxiety status (high vs. low), critical item condition (happy face, frowning face, and circle), and the presence or absence of a bogus speech anxiety induction task on detection/identification rates using the IB paradigm. HSAs and LSAs were each randomized to one of six experimental conditions: (a) Frowning face - Social Anxiety Induction, (b) Frowning face - No Social Anxiety Induction; (c) Happy face Social Anxiety Induction, (d) Happy face - No Social Anxiety Induction; (e) Circle Social Anxiety Induction, (f) Circle - No Social Anxiety Induction. Participants' detection/identification of the critical item was assessed under three separate critical 
trials: Trial 4 (Inattention trial), Trial 8 (Divided Attention Trial), and Trial 10 (Full Attention Trial).

\subsection{Measures}

The Fear of Negative Evaluation Scale (FNES; Watson \& Friend, 1969), which is a 30-item questionnaire measuring social-evaluative concern, was used as a pre-screening instrument. A pilot study based on 1520 students at the University of Texas at Austin revealed that total scores of " 22 or higher" and " 10 or lower" on the FNES determined the top and bottom $25 \%$, respectively.

A battery of social anxiety measures was administered prior to the IB task, which included: (a) the FNES; (b) Social Interaction Anxiety Scale (SIAS: Mattick \& Clarke, 1998) - a 20 item questionnaire assessing social anxiety experienced in dyadic and group interactions; and (c) Social Phobia Scale (SPS: Mattick \& Clarke, 1998) - a 20 item questionnaire assessing fear of performance and observation situations.

General emotional distress was measured by the State Trait Anxiety QuestionnaireTrait Version (STAI-T; Spielberger, Grosuch, Luchere, Vagg, \& Jacobs, 1983) and the Beck Depression Inventory (BDI; Beck, Ward, Mendelsohn, Mock, \& Erlbaugh, 1961). An author-constructed mood checklist was administered to obtain participants’ ratings on 8 emotional adjectives (i.e., angry, anxious, happy, despondent, tense, rested, nervous, and jittery) in reference to their current mood on a 0 (Not at all) to 100 (Extremely) scale. Of these, 5 anxiety-related adjectives (i.e., anxious, tense, rested, nervous, and jittery) were used to generate the manipulation check for the bogus speech manipulation. 


\subsection{Procedure}

The experimenter met with each participant in the laboratory and provided an explanation about the study. Subjects were briefly told that the study was designed to examine the nature of social discomfort and that the procedure would involve a packet of questionnaires, a short computer task, (and a videotaped speech task in the case of subjects who were assigned to the social anxiety induction condition). After obtaining informed written consent, the questionnaire battery was administered. Upon its completion, those assigned to the social anxiety induction condition received an additional instruction, "As written in the consent form, you will be asked to prepare and give a 3-minute videotaped speech in front of a panel of three speech evaluators. They will evaluate your speech in terms of appearance, speech content, vocalization, interaction with the audience, demonstrated confidence and so forth. I will provide you with a list of speech topics from which you can choose to speak about, and you will be left alone for 3 minutes to prepare the speech". The subject was then given a list of 12 controversial speech topics (e.g., abortion, seatbelt regulation laws, gay marriage, war in Iraq, etc.) and spent three minutes preparing for the speech on the selected topic. After the three minutes, the experimenter came back with a video camera and said "The preparation time is over. This video camera will be used to record your speech. Now before starting the speech task, you need to carry out a computer task as part of the preassessment". The mood checklist was administered again before the IB computer task began. Participants who did not undergo the social anxiety induction manipulation were given instead a three-minute break after completing the questionnaire battery. 
After the experimenter explained about the cross-line discrimination task, the subject began the IB computer task by pressing the space bar of the keyboard. According to the assigned condition, one of three IB tasks was executed presenting a happy face, a frowning face, or a circle as the critical item. Throughout the IB task, the experimenter stayed at a distance of 1.5 meters from the subject and remained silent except in the three critical trials, in which they guided the subject through each additional probing step (i.e., asking the subject to elaborate the detected item and recognize/guess the item from the object array).

\subsection{Data Analyses}

Two primary indices were used in the data analyses. They consisted of: (a) the proportion of participants who detected the critical item in the inattentional trial and (b) the proportion of participants who identified the critical item in the inattentional trial. The identification rates included those who detected and correctly identified the critical item. Hierarchical logistic regression analyses were performed to examine the singular and interactive effects of each of the three independent variables (i.e., social anxiety status, critical item condition, and social anxiety-induction manipulation) on the binary outcomes of detection and identification in the inattentional trial. The same analytic procedure was applied to detection and correct identification rates of the divided and full attentional trials.

\subsection{Statistical Power to Detect Differences in Detection/Identification Rates}

The program $\mathrm{G}^{*}$ Power 3 (SPSS, Release 2.0) was used to calculate power for the analyses examining differences in detection/identification rates. Power analyses were 
conducted for the most stringent analytic test — the social anxiety status ${ }^{\mathrm{L}}$ critical item ${ }^{\mathrm{b}}$ bogus speech manipulation three-way interaction-following the logic that the sufficient power for these stringent analyses will yield more than adequate power for the less stringent analyses. Statistical power to detect a medium effect size (difference in detection/identification rate of .25 ) in the hypothesized direction with the sample size in Experiment 1 and setting alpha at .05 (one-tailed) was .79.

\subsection{Results}

\subsubsection{Group Characteristics}

Table 3 presents means and standard deviations of the demographic and clinical measures across the 12 experimental conditions. Compared with LSAs, HSAs consisted of more females $(67 \%$ vs. $54 \%), \chi^{2}(1)=4.70, p=.030$. HSAs also scored significantly higher than LSAs on the FNES (mean $=25.22$ vs. 5.54), $t(274)=59.93, p<.001$; SPS $($ mean $=28.55$ vs. 7.09$), t(274)=17.44, p<.001 ;$ SIAS $($ mean $=36.21$ vs. 12.97$), t(274)$ $=20.02 ; p<.001 ; \mathrm{BDI}($ mean $=11.73$ vs. 3.60$), t(274)=11.51, p<.001$; and STAI-trait $($ mean $=50.24$ vs. 32.86$), t(274)=15.94, p<.001$. There were no significant differences in the demographic and clinical measures between the two social anxiety induction conditions or the three critical item conditions. Overall, the randomization was successful in creating group equivalence on the study measures.

\subsubsection{Social Anxiety Induction Manipulation Check}

The effectiveness of the social anxiety induction manipulation was assessed by comparing the pre- and post manipulation anxiety index computed from the Mood Checklist for participants in the two social anxiety induction conditions. The two groups 
did not differ significantly in their pre-manipulation state anxiety scores (social anxiety induction condition - mean $=27.15, \mathrm{SD}=18.84$; no social anxiety induction condition mean $=23.59, \mathrm{SD}=14.32 ; t(274)=1.77, p=.079)$. Whereas, after the anxiety-induction manipulation, those who received the social anxiety induction manipulation reported significantly higher anxiety scores $($ mean $=48.49, \mathrm{SD}=27.65)$ compared to those who did not receive the social anxiety induction manipulation $($ mean $=23.39, \mathrm{SD}=15.16)$, $t(274)=9.35, p<.001$. The differences between pre- and post manipulation anxiety scores were also significant only for those who received the social anxiety induction manipulation, $t(137)=12.84, p<.001$. Table 4 presents the means and standard deviations of pre- and post manipulation anxiety scores across the 12 experimental groups. Overall, relative to LSAs, HSAs displayed a greater increase in the anxiety scores in response to the social anxiety induction manipulation.

\subsubsection{Differences in Detection Rates for the Inattentional Trial}

The three dichotomous independent variables were entered into a hierarchical logistic regression model to predict the binary outcome of detection performance in the inattentional trial. Entered in Step 1 were the three main effects (i.e., social anxiety status, critical item condition, and social anxiety-induction manipulation). In Step 2, the three two-way interaction terms formed by the cross-product of the three predictors were entered, and in Step 3, the three-way interaction term was entered.

Table 5 presents the detection rates across the 12 experimental. In Step 1, there was a main effect only for the critical item condition: (a) the happy face was detected better than the circle $(60.6 \%$ vs. $24.4 \%), \mathrm{B}=1.56$, Wald $=23.15, p<.001$, odds ratio $=$ 
4.77, $95 \%$ Confidence Interval (CI) $[2.52,9.01]$; and (b) the frowning was also detected better than the circle $(64.8 \%$ vs. $24.4 \%), \mathrm{B}=1.75$, Wald $=27.35, p<.001$, odds ratio $=$ 5.73, 95\% CI [2.98, 11.02]. In Step 2, a significant two-way interaction was observed between the critical item condition and the social anxiety-induction condition, $(\mathrm{B}=1.25$, Wald $=4.09, p=.043$, odds ratio $=3.48,95 \% \mathrm{CI}[1.04,11.63])$. Follow-up analyses showed that participants undergoing the social anxiety induction manipulation were significantly more likely to detect the frowning face better than the happy face $(72.7 \%$ vs. 54.0\%), Fisher's Exact Test, $p=.048$. In contrast, there was a non-significant reverse trend among those not undergoing the social anxiety induction manipulation to detect the happy face better than the frowning face (67.3\% vs. 57.4\%), Fisher's Exact Test, $p=$ .215. Figure 4 depicts this significant critical item by social anxiety induction interaction. In Step 3, the three-way interaction was not significant.

\subsubsection{Differences in Identification Rates for the Inattentional Trial}

An identical analytic approach used for the analyses of detection rates was applied to the binary outcome of identification in the inattentional trial. Step 1 revealed a significant main effect for the critical item condition indicating: (a) the happy face was identified better than the circle (55.6\% vs. $17.4 \%), \mathrm{B}=1.78$, Wald $=26.02, p<.001$, odds ratio $=5.95,95 \% \mathrm{CI}[3.00,11.81]$, and $(\mathrm{b})$ the frowning face was also identified better than the circle $(41.8 \%$ vs. $17.4 \%), \mathrm{B}=1.23$, Wald $=11.92, p=.001$, odds ratio $=$ $3.42,95 \%$ CI $[1.70,6.86]$. In Step 2, none of the two-way interaction terms were significant. In Step 3, the three-way interaction term involving the contrast between the happy and frowning faces was statistically significant above and beyond the main effects 
of the three individual predictors and their two-way interactions, $\mathrm{B}=2.54$, Wald $=4.41$, $p=.036$, odds ratio $=12.70,95 \%$ CI $[1.18,136.17]$. To further probe this three-way interaction, the two-way critical item by social anxiety status interaction was further examined for each level of the social anxiety induction condition. Results revealed a significant critical item (happy vs. frowning face) by social anxiety status interaction only for those who underwent the social anxiety-induction manipulation, $\mathrm{B}=2.34$, Wald $=$ $7.19, p=.007$, odds ratio $=10.36,95 \%$ CI $[1.88,57.25]$. Further analyses revealed that under the social anxiety-induction manipulation, HSAs outperformed LSAs in identifying the frowning face $(61.9 \%$ vs. $26.1 \%)$, Fisher's exact test, $p=.018$. In contrast, there was a non-significant reverse trend for LSAs to outperform HSAs in identifying the happy face $(60.0 \%$ vs. $40.0 \%)$, Fisher's exact test, $p=.129$. In the absence of the social anxietyinduction manipulation, HSAs and LSAs did not differ in identifying the facial icons.

The nature of the observed three-way interaction was also examined by comparing the happy vs. frowning face conditions separately for LSAs and HSAs. LSAs who underwent the social anxiety-induction manipulation identified the happy face significantly better than the frowning face $(60.0 \%$ vs. $26.1 \%)$, Fisher's exact test, $p=$ .018. There was a non-significant trend for HSAs to identify the frowning face better than the happy face $(61.9 \%$ vs. $40.0 \%)$, Fisher's exact test, $p=.118$. In contrast, both LSAs and HSAs assigned to the no social anxiety-induction condition, showed a non-significant trend for better identification of the happy face over the frowning face (LSAs $-56.0 \% \mathrm{vs}$. $37.5 \%$, Fisher's exact test, $p=.156$; HSAs $-66.7 \%$ vs. $43.5 \%$, Fisher's exact test, $p=$ 
.096). Figure 5 presents the identification rates in the inattentional trial across the 12 experiment groups.

\subsubsection{Controlling for Gender and General Emotional Distress}

HSA and LSA participants differed significantly with respect to gender. Thus, we repeated the logistic hierarchical regression analyses using gender as a covariate in Step 1 for the detection and identification rates from the inattentional trial. We also entered the BDI and STAI-trait in Step 1 to examine the possibility that the observed interaction effects were accounted for by general emotional distress. For the detection rates, depression and trait anxiety did not significantly contribute to the model, whereas there was a significant gender effect indicating that males displayed a higher detection rate than females $(59.1 \%$ vs. $45.2 \%), \mathrm{B}=.62$, Wald $=5.23, p=.022$, odds ratio $=1.86,95 \%$ CI $[1.09,3.18]$; Fisher's Exact Test, $p=.016$. However, after controlling for the three covariates, the observed critical item condition by social anxiety induction condition interaction still remained significant, $\mathrm{B}=1.28$, Wald $=4.17, p=.041$, odds ratio $=3.59$, $95 \%$ CI $[1.05,12.20]$.

In Step 1, none of the three covariates significantly predicted identification rates from the inattentional trial. However, there was a non-significant trend for males to outperform females in overall identification rates $(44.5 \%$ vs. $35.5 \%), \mathrm{B}=.49, \mathrm{Wald}=$ $3.21, p=.073$, odds ratio $=1.63,95 \%$ CI $[.96,2.77]$; Fisher's Exact Test, $p=.085$. The three-way interaction remained significant even after controlling for the effects of depression, trait anxiety, and gender, $\mathrm{B}=2.75$, Wald $=4.98, p=.026$, odds ratio $=15.61$, $95 \%$ CI $[1.40,174.22]$. 
We also examined the possibility that the observed group differences may be due to differential perceptual accuracy by comparing participants' cross-line discrimination accuracy across the 12 experiment groups. The overall accuracy for the entire sample was $73.4 \%(\mathrm{SD}=18.28)$ and there were no significant differences across the 12 experimental groups.

\subsubsection{Differences in Detection and Identification Rates for the Divided and Full-}

\section{Attention Trials}

Table 5 presents the detection and identification rates from the divided and full attentional trials. Although our primary interest was in examining the detection and identification rates in the inattentional trial, we repeated the analyses reported above for the data derived from the divided and full attentional trials. Consistent with prediction, once participants expected the emergence of the critical item (divided attentional trial) the significant interactions observed in the inattentional trial were no longer present. However, the critical item main effect for the detection rates was still significant indicating that the happy face was detected better than the circle $(96.0 \%$ vs. $77.6 \%), \mathrm{B}=$ 1.92, Wald $=11.25, p=.001$, odds ratio $=6.87,95 \% \mathrm{CI}[2.23,21.18]$, and the frowning face was detected better than the circle $(91.2 \%$ vs. $77.6 \%), \mathrm{B}=1.09$, Wald $=5.72, p=$ .017 , odds ratio $=2.97,95 \%$ CI $[1.22,7.23]$. The critical item main effect for the identification rates was also significant indicating that the happy face was identified better than the frowning face $(86.9 \%$ vs. $73.6 \%), \mathrm{B}=.86$, Wald $=5.12, p=.024$, odds ratio $=2.37,95 \% \mathrm{CI}[1.12,5.01]$, or the circle $(86.9 \%$ vs. $74.4 \%), \mathrm{B}=.82, \mathrm{Wald}=4.50$ $p=.034$, odds ratio $=2.27,95 \%$ CI $[1.07,4.86]$. As expected, once participants were 
instructed to attend fully to the emergence of the critical item (full attentional trial), detection and identification rates were uniformly high with no significant main or interaction effects of participants' social anxiety status, critical item, or social anxiety induction (See Table 5).

\subsubsection{Gender Differences in Detection and Identification Rates}

Although the observed interaction effects remained unaffected after controlling for the gender effect, we conducted another set of hierarchical logistic regression analyses to further examine the role of gender and its possible interaction with the three IVs (i.e., critical item, social anxiety status, and social anxiety-induction) in predicting the detection and identification rates from the three critical trials. Gender and the three IVs were entered into Step 1, and the two-way interaction terms of gender by each of the three IVs were entered into Step 2.

\subsubsection{Prediction of detection rates}

Results revealed significant effects of gender only in the case of the detection and identification rates from the inattentional trial. In Step 1, the main effect of gender was significant, indicating that males outperformed females in overall detection $(59.1 \% \mathrm{vs}$.

$45.2 \%), \mathrm{B}=.62, \mathrm{Wald}=5.16, p=.023$, odds ratio $=1.85,95 \%$ CI $[1.09,3.15]$. In Step 2, there was a significant gender by critical item interaction involving the contrast between the happy and frowning faces, $\mathrm{B}=1.52$, Wald $=5.27, p=.022$, odds ratio $=4.59,95 \% \mathrm{CI}$ $[1.25,16.83]$. Follow-up analyses revealed that males significantly outperformed females in detecting the happy face ( $81.1 \%$ vs. $48.4 \%)$, Fisher's Exact Test, $p=.001$. In contrast, there was no gender difference in the detection rates of the frowning face (males $-65.0 \%$ 
vs. females $-64.7 \%$; Fisher's Exact Test, $p=.577$ ) or the circle (males $-27.3 \%$ vs. females $-22.6 \%$; Fisher's Exact Test, $p=.406$ ).

\subsubsection{Prediction of identification rates}

With respect to the identification rates from the inattentional trial, Step 1 revealed a non-significant trend for males to outperform females in overall identification of the critical item (35.5\% vs. $44.5 \%), \mathrm{B}=.47$, Wald $=3.04, p=.081$, odds ratio $=1.60,95 \%$ CI $[.94,2.72]$. A similar gender by critical item interaction was observed, $B=2.36$, Wald $=13.04, p<.001$, odds ratio $=10.58,95 \%$ CI $[2.94,38.04]$. Further analyses revealed that males significantly outperformed females in identifying the happy face (males $78.4 \%$ vs. females $-41.9 \%$; Fisher's Exact Test, $p<.001$ ), whereas females showed a non-significant trend of better identification of the frowning face (males $-32.5 \% \mathrm{vs}$. females $-49.0 \%$; Fisher's Exact Test, $p=.085$ ). There was no gender difference for the circle (males $-21.2 \%$ vs. females $-15.1 \%$; Fisher's Exact Test, $p=.328$ ).

These gender by critical item condition interaction effects remained significant even after controlling for social anxiety, trait anxiety, and depression. Gender did not interact with either participants' social anxiety status or their social anxiety induction manipulation.

\subsubsection{Additional Evidence of Vigilant Attention towards the Critical Item}

Finally, we conducted additional analyses to further examine the evidence of attentional vigilance towards the critical items. If the critical item attracted the viewer's attention, one would expect a reduction in the attentional resources available for the 
cross-line discrimination task, thereby leading to poorer performance on the cross-line discrimination task among those who detected or identified the critical item. The accuracy of the cross-line discrimination was compared between detectors and nondetectors (also between identifiers and non-identifiers) determined from the inattentional trial. Consistent with expectation, the discrimination accuracy did not differ between detectors (identifiers) and non-detectors (non-identifiers) on regular cross trials (\#1, 2, 3, $5,6,7$, and 9). In contrast, relative to non-detectors, detectors showed a significantly poorer performance on the inattentional trial (\#4; Fisher's Exact Test, $p=.040$ ), and on the divided attention trial (\#8, Fisher's Exact Tests, $p=.009$ ). Likewise, relative to nonidentifiers, identifiers showed a nonsignificant trend toward poorer performance on the inattentional trial, Fisher's Exact Test, $p=.075$, and a significantly poorer performance on the divided attention trial, Fisher's Exact Test, $p=.015$. Table 6 presents correct response rates between detectors (identifiers) and non-detectors (non-identifiers) across the cross-line discrimination trials. 
Table 3. Experimental Group Characteristics in Experiment 1

\begin{tabular}{|c|c|c|c|c|c|c|c|c|c|c|c|c|}
\hline & \multicolumn{6}{|c|}{ No Speech } & \multicolumn{6}{|c|}{ Bogus Speech } \\
\hline & \multicolumn{2}{|c|}{ Happy } & \multicolumn{2}{|c|}{ Frowning } & \multicolumn{2}{|c|}{ Circle } & \multicolumn{2}{|c|}{ Happy } & \multicolumn{2}{|c|}{ Frowning } & \multicolumn{2}{|c|}{ Circle } \\
\hline & $\begin{array}{c}\text { LSAs } \\
(\mathrm{N}=25)\end{array}$ & $\begin{array}{c}\text { HSAs } \\
(\mathrm{N}=24)\end{array}$ & $\begin{array}{c}\text { LSAs } \\
(\mathrm{N}=24)\end{array}$ & $\begin{array}{l}\text { HSAs } \\
(\mathrm{N}=23)\end{array}$ & $\begin{array}{c}\text { LSAs } \\
(\mathrm{N}=22)\end{array}$ & $\begin{array}{c}\text { HSAs } \\
(\mathrm{N}=20)\end{array}$ & $\begin{array}{l}\text { LSAs } \\
(\mathrm{N}=25)\end{array}$ & $\begin{array}{l}\text { HSAs } \\
(\mathrm{N}=25)\end{array}$ & $\begin{array}{l}\text { LSAs } \\
(\mathrm{N}=23)\end{array}$ & $\begin{array}{l}\text { HSAs } \\
(\mathrm{N}=21)\end{array}$ & $\begin{array}{c}\text { LSAs } \\
(\mathrm{N}=22)\end{array}$ & $\begin{array}{c}\text { HSAs } \\
(\mathrm{N}=22)\end{array}$ \\
\hline & $\begin{array}{c}M \\
(S D)\end{array}$ & $\begin{array}{c}M \\
(S D)\end{array}$ & $\begin{array}{c}M \\
(S D)\end{array}$ & $\begin{array}{c}M \\
(S D)\end{array}$ & $\begin{array}{c}M \\
(S D)\end{array}$ & $\begin{array}{c}M \\
(S D)\end{array}$ & $\begin{array}{c}M \\
(S D)\end{array}$ & $\begin{array}{c}M \\
(S D)\end{array}$ & $\begin{array}{c}M \\
(S D)\end{array}$ & $\begin{array}{c}M \\
(S D)\end{array}$ & $\begin{array}{c}M \\
(S D)\end{array}$ & $\begin{array}{c}M \\
(S D)\end{array}$ \\
\hline Age & $\begin{array}{c}19.48 \\
(2.60)\end{array}$ & $\begin{array}{l}18.96 \\
(0.75)\end{array}$ & $\begin{array}{c}18.75 \\
(0.44)\end{array}$ & $\begin{array}{c}18.83 \\
(1.07)\end{array}$ & $\begin{array}{r}19.50 \\
(1.82)\end{array}$ & $\begin{array}{c}18.50 \\
(0.61)\end{array}$ & $\begin{array}{l}18.80 \\
(1.12)\end{array}$ & $\begin{array}{l}18.76 \\
(1.64)\end{array}$ & $\begin{array}{l}18.87 \\
(1.06)\end{array}$ & $\begin{array}{l}18.62 \\
(0.92)\end{array}$ & $\begin{array}{l}19.05 \\
(1.76)\end{array}$ & $\begin{array}{l}19.18 \\
(2.40)\end{array}$ \\
\hline $\begin{array}{l}\text { Gender } \\
(\% \text { Male) }\end{array}$ & $40 \%$ & $29 \%$ & $42 \%$ & $43 \%$ & $36 \%$ & $35 \%$ & $48 \%$ & $32 \%$ & $56 \%$ & $33 \%$ & $55 \%$ & $27 \%$ \\
\hline FNES & $\begin{array}{c}4.92 \\
(3.34)\end{array}$ & $\begin{array}{l}25.21 \\
(2.36)\end{array}$ & $\begin{array}{c}5.88 \\
(2.63)\end{array}$ & $\begin{array}{l}24.96 \\
(2.67)\end{array}$ & $\begin{array}{c}6.09 \\
(3.39)\end{array}$ & $\begin{array}{l}24.30 \\
(3.01)\end{array}$ & $\begin{array}{c}5.48 \\
(3.07)\end{array}$ & $\begin{array}{l}25.20 \\
(2.00)\end{array}$ & $\begin{array}{c}4.57 \\
(2.79)\end{array}$ & $\begin{array}{l}25.81 \\
(2.16)\end{array}$ & $\begin{array}{c}6.41 \\
(2.75)\end{array}$ & $\begin{array}{l}25.82 \\
(2.13)\end{array}$ \\
\hline SPS & $\begin{array}{c}6.16 \\
(3.54)\end{array}$ & $\begin{array}{c}28.79 \\
(14.90)\end{array}$ & $\begin{array}{c}7.63 \\
(4.50)\end{array}$ & $\begin{array}{c}27.30 \\
(11.57)\end{array}$ & $\begin{array}{c}8.36 \\
(7.42)\end{array}$ & $\begin{array}{c}23.70 \\
(11.59)\end{array}$ & $\begin{array}{c}6.88 \\
(4.19)\end{array}$ & $\begin{array}{c}30.28 \\
(14.65)\end{array}$ & $\begin{array}{c}6.65 \\
(8.24)\end{array}$ & $\begin{array}{c}31.57 \\
(11.44)\end{array}$ & $\begin{array}{c}6.95 \\
(4.23)\end{array}$ & $\begin{array}{c}29.14 \\
(15.69)\end{array}$ \\
\hline SIAS & $\begin{array}{r}11.24 \\
(4.00)\end{array}$ & $\begin{array}{c}32.08 \\
(12.40)\end{array}$ & $\begin{array}{c}14.50 \\
(4.77)\end{array}$ & $\begin{array}{c}36.26 \\
(12.21)\end{array}$ & $\begin{array}{r}13.82 \\
(6.73)\end{array}$ & $\begin{array}{l}31.20 \\
(9.87)\end{array}$ & $\begin{array}{l}12.24 \\
(5.90)\end{array}$ & $\begin{array}{c}40.04 \\
(11.92)\end{array}$ & $\begin{array}{l}12.04 \\
(5.83)\end{array}$ & $\begin{array}{c}37.19 \\
(12.27)\end{array}$ & $\begin{array}{l}14.23 \\
(6.24)\end{array}$ & $\begin{array}{c}39.91 \\
(13.04)\end{array}$ \\
\hline BDI & $\begin{array}{c}2.16 \\
(2.59)\end{array}$ & $\begin{array}{l}12.17 \\
(8.30)\end{array}$ & $\begin{array}{c}3.33 \\
(2.81)\end{array}$ & $\begin{array}{l}13.57 \\
(9.41)\end{array}$ & $\begin{array}{c}4.91 \\
(3.89)\end{array}$ & $\begin{array}{c}7.80 \\
(5.52)\end{array}$ & $\begin{array}{c}3.28 \\
(3.06)\end{array}$ & $\begin{array}{l}11.92 \\
(6.48)\end{array}$ & $\begin{array}{c}4.26 \\
(3.62)\end{array}$ & $\begin{array}{l}11.29 \\
(6.92)\end{array}$ & $\begin{array}{c}3.91 \\
(4.37)\end{array}$ & $\begin{array}{l}13.09 \\
(6.75)\end{array}$ \\
\hline STAI & $\begin{array}{l}31.68 \\
(4.77)\end{array}$ & $\begin{array}{l}49.42 \\
(9.38)\end{array}$ & $\begin{array}{l}31.83 \\
(7.60)\end{array}$ & $\begin{array}{l}50.13 \\
(7.36)\end{array}$ & $\begin{array}{l}34.32 \\
(7.44)\end{array}$ & $\begin{array}{l}45.65 \\
(8.12)\end{array}$ & $\begin{array}{l}31.16 \\
(9.37)\end{array}$ & $\begin{array}{l}53.80 \\
(8.80)\end{array}$ & $\begin{array}{l}31.43 \\
(8.31)\end{array}$ & $\begin{array}{c}49.86 \\
(10.46)\end{array}$ & $\begin{array}{c}37.27 \\
(12.92)\end{array}$ & $\begin{array}{c}51.77 \\
(10.56)\end{array}$ \\
\hline
\end{tabular}


Table 4. Pre- and Post Manipulation Anxiety Scores across the 12 Experiment Groups in Experiment 1

\begin{tabular}{|c|c|c|c|c|c|c|c|c|c|c|c|c|}
\hline & \multicolumn{6}{|c|}{ No Speech } & \multicolumn{6}{|c|}{ Bogus Speech } \\
\hline & \multicolumn{2}{|c|}{ Happy } & \multicolumn{2}{|c|}{ Frowning } & \multicolumn{2}{|c|}{ Circle } & \multicolumn{2}{|c|}{ Happy } & \multicolumn{2}{|c|}{ Frowning } & \multicolumn{2}{|c|}{ Circle } \\
\hline & $\begin{array}{c}\text { LSAs } \\
(\mathrm{N}=25)\end{array}$ & $\begin{array}{c}\text { HSAs } \\
(\mathrm{N}=24)\end{array}$ & $\begin{array}{c}\text { LSAs } \\
(\mathrm{N}=24)\end{array}$ & $\begin{array}{l}\text { HSAs } \\
(\mathrm{N}=23)\end{array}$ & $\begin{array}{c}\text { LSAs } \\
(\mathrm{N}=22)\end{array}$ & $\begin{array}{c}\text { HSAs } \\
(\mathrm{N}=20)\end{array}$ & $\begin{array}{l}\text { LSAs } \\
(\mathrm{N}=25)\end{array}$ & $\begin{array}{l}\text { HSAs } \\
(\mathrm{N}=25)\end{array}$ & $\begin{array}{c}\text { LSAs } \\
(\mathrm{N}=23)\end{array}$ & $\begin{array}{l}\text { HSAs } \\
(\mathrm{N}=21)\end{array}$ & $\begin{array}{c}\text { LSAs } \\
(\mathrm{N}=22)\end{array}$ & $\begin{array}{c}\text { HSAs } \\
(\mathrm{N}=22)\end{array}$ \\
\hline & $\begin{array}{c}M \\
(S D) \\
\end{array}$ & $\begin{array}{c}M \\
(S D) \\
\end{array}$ & $\begin{array}{c}M \\
(S D) \\
\end{array}$ & $\begin{array}{c}M \\
(S D) \\
\end{array}$ & $\begin{array}{c}M \\
(S D) \\
\end{array}$ & $\begin{array}{c}M \\
(S D) \\
\end{array}$ & $\begin{array}{c}M \\
(S D) \\
\end{array}$ & $\begin{array}{c}M \\
(S D) \\
\end{array}$ & $\begin{array}{c}M \\
(S D) \\
\end{array}$ & $\begin{array}{c}M \\
(S D) \\
\end{array}$ & $\begin{array}{c}M \\
(S D) \\
\end{array}$ & $\begin{array}{c}M \\
(S D) \\
\end{array}$ \\
\hline Pre & $\begin{array}{l}15.28 \\
(5.97)\end{array}$ & $\begin{array}{c}30.92 \\
(16.12)\end{array}$ & $\begin{array}{l}17.67 \\
(8.72)\end{array}$ & $\begin{array}{c}32.09 \\
(16.52)\end{array}$ & $\begin{array}{c}17.36 \\
(10.94)\end{array}$ & $\begin{array}{c}29.40 \\
(14.39)\end{array}$ & $\begin{array}{c}18.64 \\
(12.37)\end{array}$ & $\begin{array}{c}38.64 \\
(16.08)\end{array}$ & $\begin{array}{c}17.04 \\
(16.66)\end{array}$ & $\begin{array}{c}39.86 \\
(18.44)\end{array}$ & $\begin{array}{l}13.64 \\
(8.96)\end{array}$ & $\begin{array}{c}35.73 \\
(19.13)\end{array}$ \\
\hline Post & $\begin{array}{l}14.16 \\
(6.61)\end{array}$ & $\begin{array}{c}30.42 \\
(17.39)\end{array}$ & $\begin{array}{l}17.83 \\
(8.52)\end{array}$ & $\begin{array}{c}33.39 \\
(16.03)\end{array}$ & $\begin{array}{c}16.36 \\
(14.46)\end{array}$ & $\begin{array}{c}29.40 \\
(13.75)\end{array}$ & $\begin{array}{c}29.88 \\
(17.56)\end{array}$ & $\begin{array}{c}73.52 \\
(14.37)\end{array}$ & $\begin{array}{c}28.87 \\
(19.00)\end{array}$ & $\begin{array}{c}71.14 \\
(17.68)\end{array}$ & $\begin{array}{c}27.00 \\
(19.54)\end{array}$ & $\begin{array}{c}61.55 \\
(24.18)\end{array}$ \\
\hline
\end{tabular}


Table 5. Detection and Identification Rates of the Three Critical Trials across the 12 Experiment Groups in Experiment 1

\begin{tabular}{|c|c|c|c|c|c|c|c|c|c|c|c|c|}
\hline & \multicolumn{6}{|c|}{ No Speech } & \multicolumn{6}{|c|}{ Bogus Speech } \\
\hline & \multicolumn{2}{|c|}{ Happy } & \multicolumn{2}{|c|}{ Frowning } & \multicolumn{2}{|c|}{ Circle } & \multicolumn{2}{|c|}{ Happy } & \multicolumn{2}{|c|}{ Frowning } & \multicolumn{2}{|c|}{ Circle } \\
\hline & LSAs & HSAs & LSAs & HSAs & LSAs & HSAs & LSAs & HSAs & LSAs & HSAs & LSAs & HSAs \\
\hline \multicolumn{13}{|l|}{ Inattentional } \\
\hline Detection Rate (\%) & 68.0 & 66.7 & 50.0 & 65.2 & 22.7 & 20.0 & 60.0 & 48.0 & 69.6 & 76.2 & 27.3 & 27.3 \\
\hline Identification Rate (\%) & 56.0 & 66.7 & 37.5 & 43.5 & 9.1 & 15.0 & 60.0 & 40.0 & 26.1 & 61.9 & 22.7 & 22.7 \\
\hline $\begin{array}{l}\text { Divided Attention } \\
\text { Detection Rate (\%) }\end{array}$ & 92.0 & 100.0 & 83.3 & 100.0 & 90.9 & 78.9 & 96.0 & 96.0 & 91.3 & 90.5 & 72.7 & 68.2 \\
\hline Identification Rate (\%) & 88.0 & 83.3 & 58.3 & 87.0 & 81.8 & 75.0 & 84.0 & 92.0 & 73.9 & 76.2 & 72.7 & 68.2 \\
\hline \multicolumn{13}{|l|}{ Full Attention } \\
\hline Detection Rate (\%) & 100.0 & 95.8 & 100.0 & 100.0 & 95.5 & 100.0 & 100.0 & 100.0 & 95.7 & 100.0 & 100.0 & 95.5 \\
\hline Identification Rate (\%) & 92.0 & 87.5 & 87.5 & 95.7 & 90.9 & 100.0 & 96.0 & 96.0 & 87.0 & 100.0 & 95.5 & 95.5 \\
\hline $\begin{array}{l}\text { Overall Accuracy - Cross } \\
\text { Discrimination (\%) }\end{array}$ & 72.4 & 65.3 & 76.4 & 78.7 & 71.7 & 79.5 & 79.6 & 66.7 & 73.9 & 76.2 & 70.7 & 70.7 \\
\hline
\end{tabular}


Table 6. Proportions (\%) of Correct Responders across the Cross-Line Discrimination Trials in Experiment 1

\begin{tabular}{lcccc}
\hline & Detectors & Non-detectors & Identifiers & Non-identifiers \\
\hline Trial 1 & $62.9 \%$ & $63.2 \%$ & $61.1 \%$ & $64.3 \%$ \\
Trial 2 & $77.9 \%$ & $75.0 \%$ & $76.9 \%$ & $76.2 \%$ \\
Trial 3 & $80.7 \%$ & $78.7 \%$ & $79.6 \%$ & $79.8 \%$ \\
\hline Trial 4 & & & & \\
(Inattentional) & $77.1 \%$ & $86.0 \%$ & $76.9 \%$ & $84.5 \%$ \\
\hline Trial 5 & $69.3 \%$ & $67.6 \%$ & $72.2 \%$ & $66.1 \%$ \\
Trial 6 & $67.9 \%$ & $65.4 \%$ & $69.4 \%$ & $64.9 \%$ \\
Trial 7 & $85.7 \%$ & $80.9 \%$ & $85.2 \%$ & $82.1 \%$ \\
\hline Trial 8 & & & & \\
(Divided & $67.9 \%$ & $80.9 \%$ & $66.7 \%$ & $79.2 \%$ \\
Attention) & $69.3 \%$ & $64.7 \%$ & $67.6 \%$ & $66.7 \%$ \\
\hline Trial 9 & & & & \\
\hline
\end{tabular}

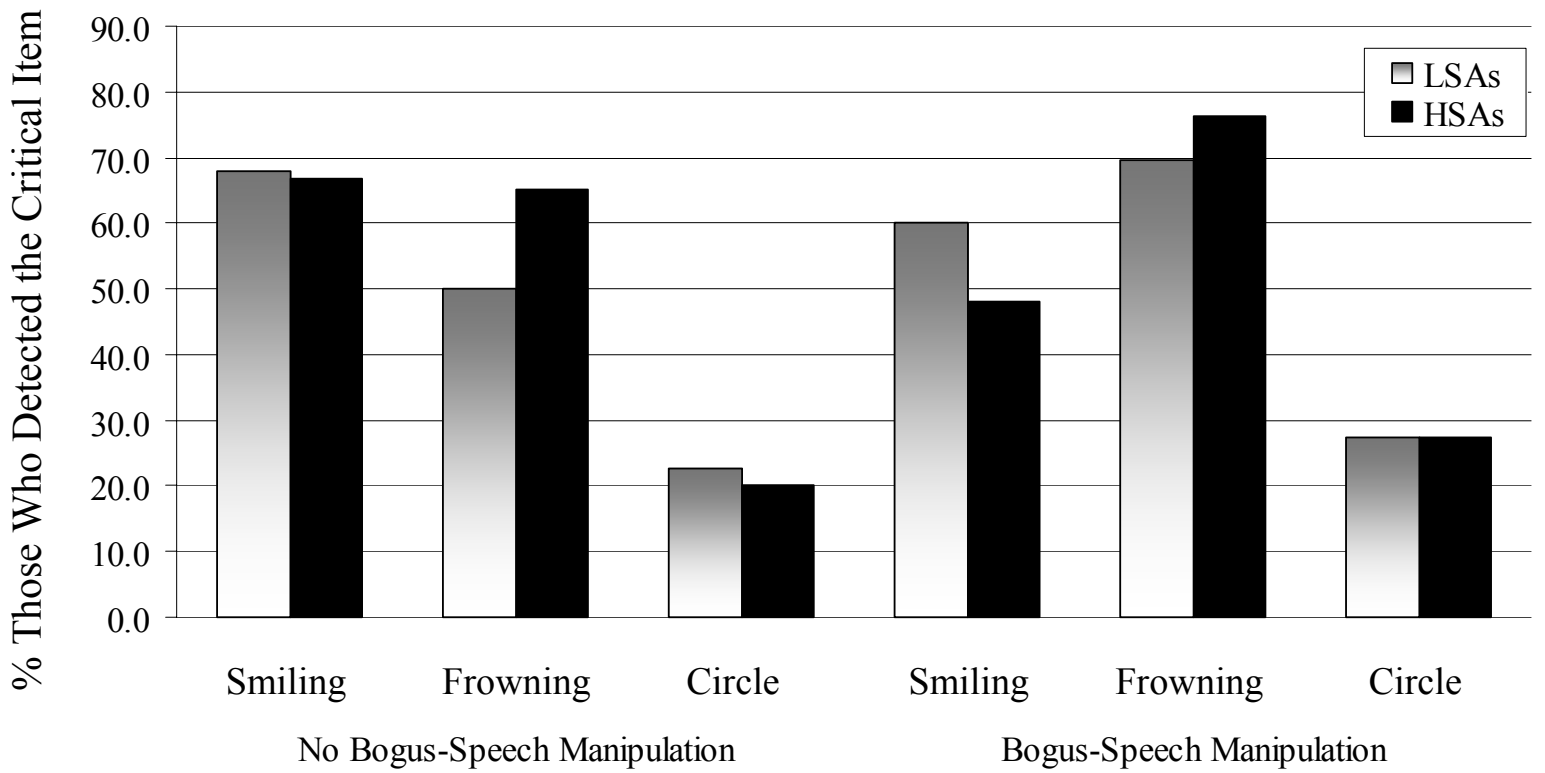

Figure 4. Detection Rates in the Inattentional Trial (Experiment 1) 


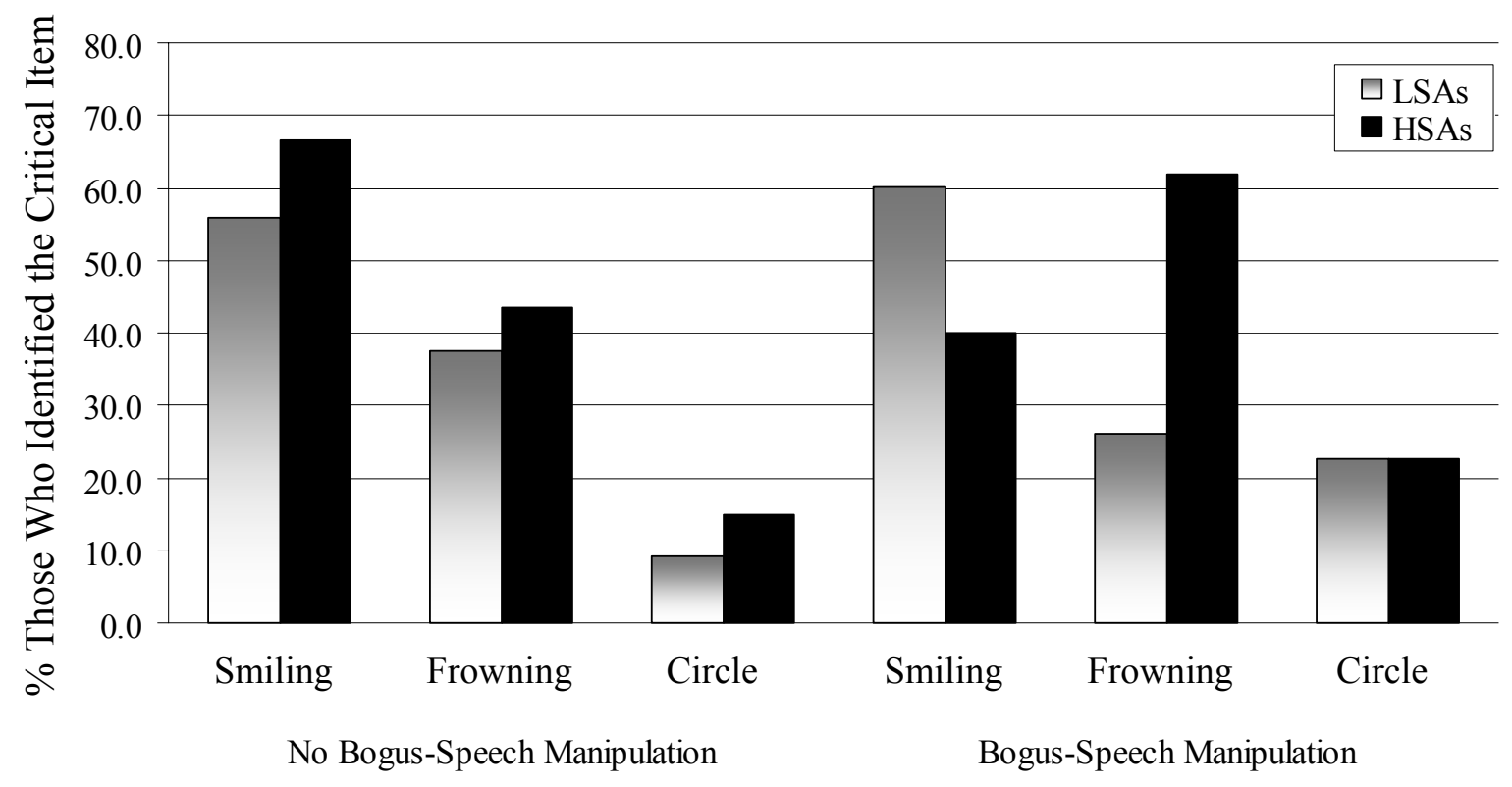

Figure 5. Identification Rates in the Inattentional Trial (Experiment 1)

\subsection{Discussion}

To my knowledge, this is the first study to apply the IB paradigm to the field of anxiety disorders specifically or psychopathology more generally. Mack and Rock (1998) argued that perception occurs only when attention is engaged in the target object. It follows that even an object being directly looked at can evade perception if it receives insufficient attention. The failure to perceive a stimulus despite its foveal presentation due to lack of attention is the essence of the IB phenomenon. Considering the convincing prior evidence indicating that detection and identification of the critical item in the IB paradigm are strongly influenced by its meaningfulness (Mack \& Rock, 1998, Mack, 2003), the IB paradigm provides a potentially useful vehicle for assessing attentional biases in social anxiety and psychopathology in general. This is particularly true for psychopathological conditions such as anxiety disorders in which attentional 
hypervigilance may play a central role. Since attentional hypervigilance can be operationalized as the perception of a critical item despite attention being directed elsewhere, the IB paradigm provides a more "pure" measure of attentional hypervigilance compared to indirect measures such as reaction times from the Stroop or Dot-Probe task.

The present study examined two primary performance indices derived from the IB paradigm (i.e., detection and identification rates). Identification rates provided support for the hypothesized three-way interaction. Specifically, under the bogus speech manipulation, HSAs were more than twice as likely to identify the frowning face relative to LSAs (61.9\% vs. $26.1 \%)$. In contrast, LSAs were more likely to identify the happy face relative to HSAs (60.0\% vs. $40.0 \%)$, The critical item by social anxiety status interaction was observed only from those who underwent the anxiety-induction manipulation. The influence of general emotional distress or gender did not affect these findings.

Contrary to the findings for identification rates, detection rates were not influenced by participants' social anxiety status, although the trend was consistent with the predicted direction in the presence of the bogus-speech manipulation. The discrepancy in findings surrounding detection vs. identification may be a function of the deeper level of attentional processing required for identification. One possibility is that the relatively shallow attentional processing may be enough for the low-level physical features to capture attention (i.e., detection of its presence), and accordingly the impact of the current contextual cue (i.e., the imminent social threat) on the face's signal value may have overridden any effects of dispositional social anxiety. In contrast, identifying faces 
is likely to require more extensive attentional processing, in which the impact of the contextual cue may be further influenced by participants' dispositional social anxiety. Relative to detection, identification may require greater attentional resources leading to more extensive perceptual and semantic processing. Future research on the underlying mechanisms governing the detection and identification of emotional faces is needed.

The present study presents a successful replication of the original study (Mack and Rock, 1998). Although the two studies differed in sample characteristics, LSAs in the no anxiety-induction condition in this study are likely most similar to the college student sample of the Mack and Rock (1998) study. For the inattentional trial, detection rates were $85 \%, 40 \%$, and $15 \%$, and identification rates were $75 \%, 25 \%$, and $15 \%$, for the happy face, frowning face, and circle, respectively. The pattern of differences across the three critical items was similar to those reported in the original Mack and Rock study. Experiment 1 also provides some possible explanation for what appeared to Mack and Rock as a puzzling finding in the context of their meaningfulness-signal hypothesis, namely the poorer detection and identification of frowning faces relative to happy faces. It is reasonable to assume that frowning faces are more likely to have greater signal value to those displaying heightened social anxiety either due to a dispositional tendency or through an experimental manipulation.

Overall, the present study contributes to the existing literature demonstrating that individuals with heightened social anxiety display attentional hypervigilance in response to socially threatening cues (e.g., Mogg \& Bradley, 2002). In addition, a careful inspection of the pattern of LSAs' responses to the facial icons suggests that social 
anxiety may be linked to the absence of positively oriented information processing as well as the presence of negative attentional bias. LSAs who received the social anxiety induction were more likely to identify the happy face compared to HSAs who also received the social anxiety induction. LSAs also exhibited a superior identification of the happy face over the frowning face. These findings suggest that relative to HSAs, LSAs are more likely to engage in preferential attentional processing for the happy face.

This study also suggests the possibility that LSAs may be characterized by a positively biased perceptual compensation in the event of forming an imperfect perceptual representation. When exposed to the social anxiety-induction, $76.2 \%$ of the HSAs (16 out of 21$)$ detected the frowning face. Of the 16 detectors, $81.3 \%(\mathrm{~N}=13)$ correctly identified it. In contrast, $69.6 \%$ (16 out of 23 ) of the LSAs detected the frowning face, but only $37.5 \%(\mathrm{~N}=6)$ of the 16 detectors correctly identified it. Interestingly, of the 10 LSAs who detected but failed to identify the frowning face, 9 (spontaneously) reported having seen a happy face and also selected a happy face out of the object array during the recognition test (one person reported having seen a circle). Perhaps LSAs compensate for their incomplete percept with some positively oriented top-down encoding process. It is believed that that the greater misidentification of the frowning face observed for LSAs reflects a perceptual failure caused by insufficient attentional engagement rather than an interpretation bias. Once attention was sufficiently engaged in the frowning face, it was correctly identified by most of the LSAs receiving the social anxiety-induction manipulation (i.e., identifiers among the detectors $-80.9 \%$ for the divided attention condition and $90.9 \%$ for the full attention condition). Taken 
together, LSAs are more likely to display preferential attentional processing towards a happy face, whereas HSAs are more likely to display hypervigilant attentional processing towards an angry face.

Interestingly, significant gender differences were observed from the inattentional trial, suggesting that males are likely to outperform females in detecting or identifying the happy face, but not the frowning face or the circle. In contrast, there was a nonsignificant trend for females to outperform males in identifying the frowning face. These gender differences cannot be explained by social anxiety, trait anxiety, or depression. It may be that relative to females, males are inherently predisposed to engage in a deeper attentional processing of positive rather than negative emotional cues. MacLeod (1991) concluded that there is no gender difference in emotional Stroop interference. Overall, evidence for gender differences in attentional biases linked to anxiety disorders is scarce. In fact, many studies investigating attentional biases in anxiety disorders seem to have paid little attention on gender differences, as indicated by Osorio and colleagues (2003). Future research needs to directly address potential gender differences in attentional processing.

Additional analyses on the accuracy of cross-line discrimination shed light on the utility of the IB task as a sensitive attentional measure. The pattern of cross-line discriminations across the 9 trials showed a consistent pattern of reduced accuracy corresponding to trials in which the critical item appeared. For those who failed to detect or identify the critical item, accuracy gradually improved across trials 1 through 4 , suggesting a practice effect. In contrast, detectors and identifiers showed a noticeable 
drop in accuracy on trial 4 (i.e., inattentional trial), suggesting a vigilant attentional deployment towards the critical item and a consequent loss of accuracy on cross-line discrimination. On trial 5 and 6, all participants showed lower levels of accuracy compared to those attained in earlier trials, suggesting that the critical trial probing procedure increased participants' attention to the potential emergence of an extra item on the display. On trial 7, they seemed to have discontinued the unsuccessful search for an extra object and instead reengaged their full attention to the cross, resulting in a sudden increase in accuracy. However, on trial 8 (i.e., divided attentional trial) the accuracy level noticeably dropped again only for detectors and identifiers with the presentation of the critical item. Again, on trial 9, all participants showed a noticeable drop in accuracy due to the presentation of the critical item in the preceding critical trial. Taken together, these data suggest that the covariation between cross-line discrimination accuracy and presentation of the critical stimulus might serve as an independent index of attentional vigilance. Unlike the Stroop and dot-probe tasks, the IB paradigm provides the opportunity to distinguish between the interference (i.e., attentional allocation) towards the primary task and attentional vigilance towards the threat stimuli. Future research should include a control group that undergoes only regular discrimination trials in order to directly test the effect of the presence vs. absence of the critical item.

One might argue that the self-report based on an object array presenting emotionally valenced items might have introduced a response bias during the identification stage. In this study, identification rates were computed excluding those who simply guessed but failed to detect the critical item from the object array. However, it is 
still possible that the selection of the critical item from the object array was differentially affected by the level of social anxiety. In other words, relative to LSAs, HSAs might have preferred to select the frowning face and vice versa for the happy face. To examine this issue, two additional analyses were performed. First, the guesswork on the object array of non-detectors (i.e., those who were unable to detect the critical item) was compared according to the level of social anxiety. Of the 70 LSA non-detectors, 22 selected the happy face and 4 selected the frowning face. Similarly, of the 66 HSA non-detectors, 21 selected the happy face and 4 selected the frowning face. Overall, these findings indicate that while participants displayed a pattern of guessing towards the more familiar object (i.e., happy face), their selection of emotional faces did not differ as a function of the level of participants' social anxiety. Secondly, the object-array selection of those who detected the neutral critical item (i.e., circle) was also examined. Of the 11 LSA detectors of the circle, 7 selected the circle, 3 selected the happy face, and 1 selected the frowning face. Of the 10 HSA detectors, 8 selected the circle, and 2 selected the happy face. Taken together, the pattern of these findings is not consistent with a response bias account. Some limitations of the present study should be noted. First, social cues were conveyed via schematic facial icons as opposed to real facial pictures. Moreover, the emotional valence of the "frowning" face was not specific, although it surely conveyed some negative emotional expression. Because this was the first attempt to apply the IB paradigm to the area of psychopathology, it was important to retain the original stimulus parameters used in the static IB experiments. Moreover, the use of the schematic versions makes the happy and frowning faces equivalent in terms of their deviation from an 
expressionless neutral face, thereby balancing their perceptual salience and removing a potential happy-face advantage (see Leppänen \& Hietanen, 2004). Nonetheless, future investigations of attentional biases using this paradigm might consider the use of real facial pictures (e.g., Ekman's emotional faces) to enhance the ecological validity of the findings. Another factor limiting the generalizability of the findings is the use of a college student sample. An analogue approach was taken because the completely crossed between-subject design of the IB paradigm required a large number of subjects. However, the FNES has been extensively used in analogue studies of SAD with its validity in this context well demonstrated (for a review, see Stopa \& Clark, 2001). Particularly, it was found that the differences observed between high and low scorers on the FNES mirror those observed between social phobics and non-anxious controls. Nonetheless, it is important to replicate the present study with a clinical sample of social phobics.

In summary, Experiment 1 suggests that the IB paradigm is a promising approach for investigating attentional biases in social anxiety. Its sensitivity in capturing attentional vigilance at an early processing stage while eliminating irrelevant response factors makes the IB task a useful addition to existing paradigms for assessing biased attention in social anxiety and perhaps other forms of psychopathology as well. 


\section{CHAPTER 5: EXPERIMENT 2 - AN INVESTIGATION USING THE SUSTAINED IB PARADIGM}

Despite its success in investigating the properties of stimuli that efficiently attract attention, the short stimulus presentation inherent in the static IB paradigm has raised concerns. For instance, Wolfe (1999) has put forward the possibility that IB may not reflect a perceptual failure caused by a lack of attention, but rather a memory failure resulting from instantaneous forgetting of the detected object. Studies using a rapid stimulus presentation method have shown that rapidly presented pictures may be identified within $125 \mathrm{~ms}$, but the consolidation into explicit memory may require approximately 300ms (Potter, 1975, 1976; Potter \& Levy, 1969). Thus, the possibility that instantaneous forgetting is operating in the static IB paradigm cannot be completely ruled out. Relatedly, Most and colleagues (2001) have suggested that the short stimulus duration of the static IB makes the testing situation far removed from the full range of dynamic and sustained images that we face in our day-to-day lives.

Experiment 2 was conducted using the sustained IB paradigm developed by Most and colleagues (2001). Compared to the static IB task used in Experiment 1, the sustained IB task designed for Experiment 2 presents several methodological advances. First, it effectively excludes the inattentional amnesia account because the subject is exposed to the critical item for $5 \mathrm{sec}$. Second, the dynamic and sustained visual stimuli better emulate visual reality. Third, in an additional effort to enhance the ecological validity of findings, Ekman's emotional faces were employed as critical items. Moreover, anger was 
conveyed by the social threat cue, which is a more social anxiety-relevant emotion compared to the rather ambiguous emotion delivered by the frowning facial icon.

Like Experiment 1, Experiment 2 was conducted using an analogue college student sample displaying high vs. low social anxiety as measured by the FNES. HSAs and LSAs were randomly assigned to one of three sustained IB conditions presenting a happy face, an angry face, or an oval in the presence or absence of the same bogusspeech social anxiety induction manipulation employed in Experiment 1.

As reviewed in Chapter 4, the primary determinant of attentional capture in the sustained IB paradigm is the perceptual match between the critical item and the perceiver's attentional set (Most et al., 2005). In the context of social anxiety, HSAs are more likely to maintain or readily activate a hypervigilant attentional set attuned to negative social cues, relative to LSAs (Rapee \& Heimberg, 1997). Accordingly, Experiment 2 was devoted to testing the hypothesis that HSAs would show a significantly higher detection/identification rate of the angry face relative to LSAs; LSAs would show a significantly higher detection/identification rate of the happy face relative to HSAs; and that these hypothesized differences in detection/identification rates would be present only for participants assigned to the social anxiety induction condition. Thus, identical to those of Experiment 1, Experiment 2 tested the same set of hypotheses, including a three-way interaction between social anxiety status (high vs. low), social anxiety induction manipulation (present or absent), and critical item condition (i.e., happy face, frowning face, or circle). No significant interaction effects were expected with respect to detection/identification rates from the divided and full attention trials. Nor 
were significant effects expected with respect to detection/identification of the non-social critical item (i.e., oval).

\subsection{Participants}

Undergraduate students $(\mathrm{N}=2350)$ enrolled in introductory psychology courses at the University of Texas at Austin were screened using the FNES. Those who scored 10 or below (LSAs; $\mathrm{N}=714$ ) or 22 or higher (HSAs; $\mathrm{N}=693$ ) were invited to participate in the experiment in partial fulfillment of their experimental credit. Of those, 305 students replied to the invitation. Upon retesting, 45 participants no longer met the FNES criteria. The final sample consisted of 261 students (97 males, 164 females, mean age $=18.82$ years, $\mathrm{SD}=1.66)$. They were ethnically diverse: Caucasian $(58.2 \%)$, Hispanic $(21.1 \%)$, Asian/Pacific Islander (11.5\%), African American (5.4\%) and other (3.4\%).

\subsection{Materials}

The present IB task was designed following the typical structure of sustained IB tasks (Most et al., 2001; Most et al., 2005). Subjects were seated at a comfortable distance from a 17 inch computer monitor (on average, about $35 \mathrm{~cm}$ ). The task was composed of five 15 -second judgment trials, which took place on a $13 \mathrm{~cm}$ by $18 \mathrm{~cm}$ gray display with a small fixation cross at the center. On each trial, four black squares and four light gray ovals moved on (predetermined) haphazard paths at a variable speed ranging from 2 to $5 \mathrm{~cm} / \mathrm{sec}$, occasionally occluding each other or bouncing off the edges of the display. Approximately, these objects had a height and width of $1 \mathrm{~cm}$. In a pilot study, this set of stimuli along with the critical item described below was found to present a moderate level of task difficulty. 
On each trial, subjects were asked to fixate on the central cue and keep track of the number of times the four black squares bounce off the edges. The first two trials were regular judgment trials. The third, fourth, and the fifth and last trial corresponded to the inattentional, divided attention, and full attention condition, respectively. Five seconds into each of the critical trials, the critical item entered the middle of the right side of the display and moved and exited to the left side of the screen during the next five second period (See Figure 6). Critical items included a happy face, an angry face, and a light gray oval. They were in the shape of an oval with the same size and overall luminance. In order to reduce any potential gender bias of the emotional critical items, one male and one female face from Ekman's facial stimuli (Ekman, 1976; Ekman \& Friesen, 1984) were averaged using image-morphing software (Morpheus Photo Morpher v3.00).

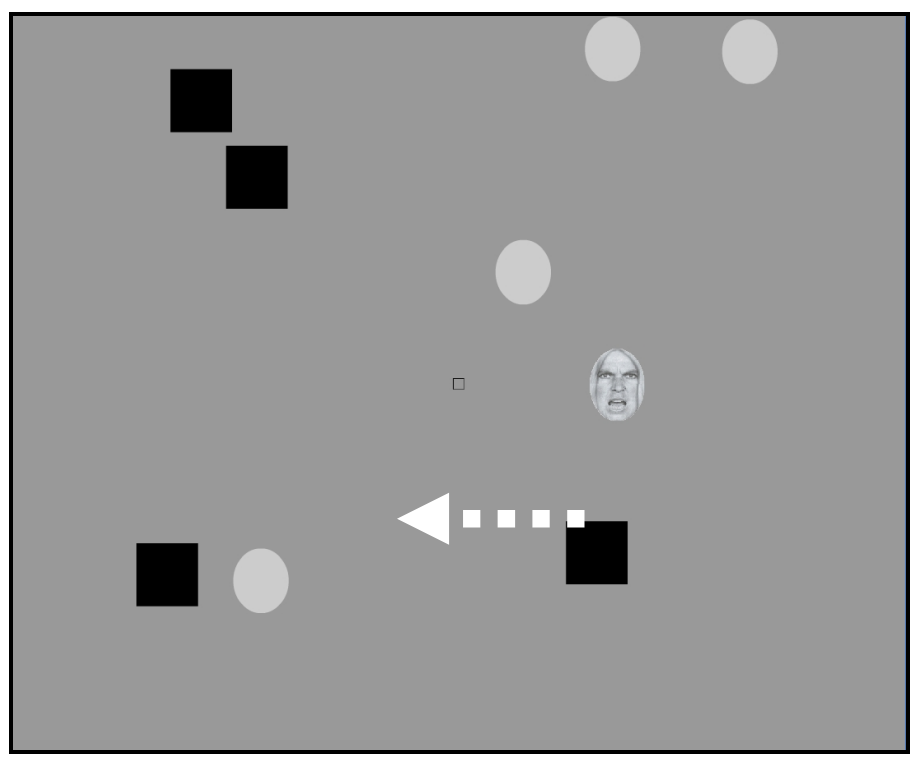

Figure 6. The Critical Trial in the Sustained IB Task 
In the inattentional and divided attention trials, the regular judgment of the number of bounces was followed by additional probing questions and a recognition (or guess) test based on an object array (See Figures 7) in the same fashion with Experiment 1. In the full attention condition, they were asked to simply watch the display without counting the bounces made by the squares.

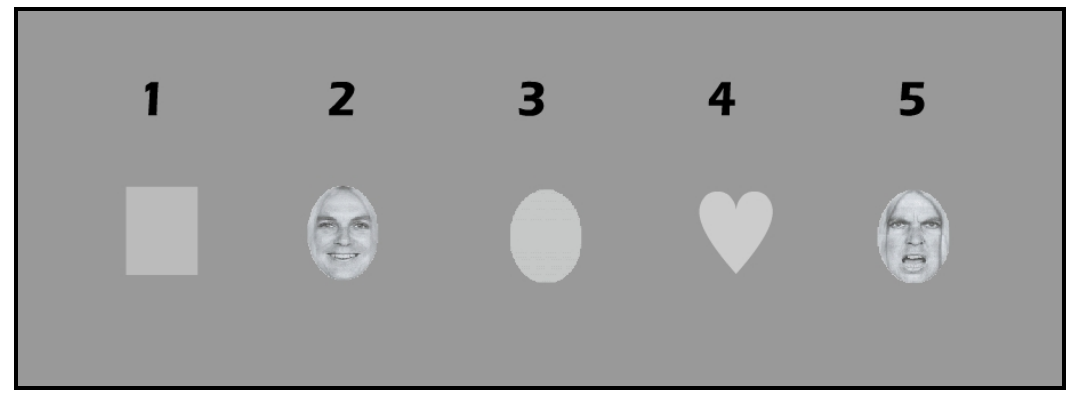

Figure 7. The object array for the recognition test in the sustained IB task

\subsection{Experiment Design}

A $2 \times 3 \times 2$ completely crossed factorial design was used to investigate the effects of participants' social anxiety status (high vs. low), critical item condition (happy face, angry face, and circle), and the presence or absence of a bogus speech anxiety induction task on detection/identification rates using the IB paradigm. HSAs and LSAs were each randomized to one of six experimental conditions: (a) Angry face - Social Anxiety Induction, (b) Angry face - No Social Anxiety Induction; (c) Happy face - Social Anxiety Induction, (d) Happy face - No Social Anxiety Induction; (e) Oval - Social Anxiety Induction, (f) Oval - No Social Anxiety Induction. Participants' detection/identification of the critical item was assessed under three separate critical 
trials: Trial 3 (Inattention trial), Trial 4 (Divided Attention Trial), and Trial 5 (Full Attention Trial).

\subsection{Measures}

The FNES was used as a pre-screening instrument with the cutoff scores of "22 or higher" and "10 or below" for recruiting HSAs and LSAs, respectively.

A battery of social anxiety measures was administered prior to the IB task, which included the FNES, SIAS, and the SPS. General emotional distress was measured by the STAI-T and the BDI. The author-constructed mood checklist consisting of 8 emotional adjectives was administered to generate the manipulation check for the bogus-speech manipulation.

\subsection{Procedure}

The experimenter met with each participant in the laboratory and provided an explanation about the study. Subjects were briefly told that the study was designed to examine the nature of social discomfort and that the procedure would involve a packet of questionnaires, a short computer task, (and a videotaped speech task in the case of subjects who were assigned to the social anxiety induction condition). After obtaining informed written consent, the questionnaire battery was administered. Upon its completion, those assigned to the social anxiety induction condition received an additional instruction, "As written in the consent form, you will be asked to prepare and give a 3-minute videotaped speech in front of a panel of three speech evaluators. They will evaluate your speech in terms of appearance, speech content, vocalization, interaction with the audience, demonstrated confidence and so forth. I will provide you 
with a list of speech topics from which you can choose to speak about, and you will be left alone for 3 minutes to prepare your speech". The subject was then given a list of 12 controversial speech topics (e.g., abortion, seatbelt regulation laws, gay marriage, war in Iraq, etc.) and spent three minutes preparing for the speech on the selected topic. After the three minutes, the experimenter came back with a video camera and said "The preparation time is over. This video camera will be used to record your speech. Now before starting the speech task, you need to carry out a computer task as part of the preassessment". The mood checklist was administered again before the IB computer task began. Participants who did not undergo the social anxiety induction manipulation were given instead a three-minute break after completing the questionnaire battery.

Following the three minute period, the sustained IB task was introduced to the subject. According to the assigned condition, one of three IB tasks was executed presenting a happy face, an angry face, or an oval as the critical item. Throughout the IB task, the experimenter stayed at a distance of 1.5 meters from the subject and remained silent except in the three critical trials, in which they guided the subject through each additional probing step (i.e., asking the subject to elaborate the detected item and recognize/guess the item from the object array).

\subsection{Data Analyses}

Experiment 2 used the same analytic techniques as those used in Experiment 1. Two primary indices were (a) the proportion of participants who detected the critical item in the inattentional trial and (b) the proportion of participants who identified the critical item in the inattentional trial. The identification rates included those who detected and 
correctly identified the critical item. Hierarchical logistic regression analyses were performed to examine the singular and interactive effects of each of the three independent variables (i.e., social anxiety status, critical item condition, and social anxiety-induction manipulation) on the binary outcomes of detection and identification in the inattentional trial. The same analytic procedure was applied to detection and correct identification rates of the divided and full attentional trials.

\subsection{Statistical Power to Detect Differences in Detection/Identification Rates}

Power analyses were conducted in the same fashion as Experiment 1. The statistical power to detect a medium effect size in the hypothesized direction with the current sample size and setting a at .05 (one-tailed) was . 73 .

\subsection{Results}

\subsubsection{Group Characteristics}

Table 7 presents means and standard deviations of the demographic and clinical measures across the 12 experimental conditions. Compared with LSAs, HSAs consisted of more females $(70 \%$ vs. $56 \%), \chi^{2}(1)=5.25, p=.022$. HSAs also scored significantly higher than LSAs on the FNES ( mean $=25.89$ vs. 5.15$), t(259)=63.34, p<.001$; SPS $($ mean $=27.16$ vs. 8.28$), t(259)=16.25, p<.001 ;$ SIAS $($ mean $=35.53$ vs. 13.86$), t(259)$ $=17.81 ; p<.001 ;$ BDI $($ mean $=10.90$ vs. 3.38$), t(259)=10.47, p<.001$; and STAI-trait $($ mean $=48.57$ vs. 34.00$), t(259)=17.18, p<.001$. There were no significant differences in the demographic and clinical measures between the two social anxiety induction conditions or the three critical item conditions. Overall, the randomization was successful in creating group equivalence on the study measures. 


\subsubsection{Social Anxiety Induction Manipulation Check}

The effectiveness of the social anxiety induction manipulation was assessed by comparing the pre- and post manipulation anxiety index computed from the Mood Checklist for participants in the two social anxiety induction conditions. The two groups did not differ significantly in their pre-manipulation state anxiety scores (social anxiety induction condition - mean $=30.39, \mathrm{SD}=18.70$; no social anxiety induction condition -

mean $=26.25, \mathrm{SD}=17.42 ; t(259)=1.85, p=.066)$. Whereas, after the anxiety-induction manipulation, those who received the social anxiety induction manipulation reported significantly higher anxiety scores $($ mean $=40.30, \mathrm{SD}=24.28)$ compared to those who did not receive the social anxiety induction manipulation $($ mean $=22.72, \mathrm{SD}=16.51)$, $t(259)=6.86, p<.001$. Moreover, there was a significant increase in pre- to post manipulation anxiety scores for those who received the social anxiety induction manipulation, $t(127)=7.64, p<.001$. In contrast, there was a significant decrease in preto post manipulation anxiety scores for those who did not receive the social anxiety induction manipulation, $t(132)=-4.35, p<.001$. Table 8 presents the means and standard deviations of pre- and post manipulation anxiety scores across the 12 experimental groups. Overall, relative to LSAs, HSAs displayed a greater increase in the manipulation anxiety scores in response to the social anxiety induction manipulation.

\subsubsection{Differences in Detection Rates for the Inattentional Trial}

The three dichotomous independent variables were entered into a hierarchical logistic regression model to predict the binary outcome of detection performance in the inattentional trial. Entered in Step 1 were the three main effects (i.e., social anxiety status, 
critical item condition, and social anxiety-induction manipulation). In Step 2, the three two-way interaction terms formed by the cross-product of the three predictors were entered, and in Step 3, the three-way interaction term was entered.

Table 9 presents the detection rates across the 12 experimental groups. In Step 1, there was a main effect only for the critical item condition: (a) the happy face was detected better than the oval $(58.0 \%$ vs. $3.4 \%), \mathrm{B}=3.68$, Wald $=24.21, p<.001$, odds ratio $=39.61,95 \%$ Confidence Interval $(\mathrm{CI})[9.15,171.50]$; and (b) the angry face was also detected better than the oval $(58.8 \%$ vs. $3.4 \%), \mathrm{B}=3.72$, Wald $=24.71, p<.001$, odds ratio $=41.08,95 \%$ CI $[9.49,177.79]$. In Step 2, none of the two-way interaction terms were significant. In Step 3, the three-way interaction term involving the contrast between the happy and angry faces was statistically significant above and beyond the main effects of the three individual predictors and their two-way interactions, $\mathrm{B}=2.53$, Wald $=4.71, p=.030$, odds ratio $=12.59,95 \%$ CI $[1.28,123.85]$. To further probe this three-way interaction, the two-way critical item by social anxiety status interaction was examined for each level of the social anxiety induction condition. Results revealed a significant critical item (happy vs. angry face) by social anxiety status interaction only for those who underwent the social anxiety-induction manipulation, $\mathrm{B}=1.71$, Wald $=4.09, p$ $=.043$, odds ratio $=5.54,95 \%$ CI $[1.06,29.09]$. Further analyses revealed a nonsignificant trend under the social anxiety-induction manipulation that HSAs outperformed LSAs in detecting the angry face (72.0\% vs. 54.2\%), Fisher's exact test, $p$ $=.159$, whereas LSAs outperformed HSAs in detecting the happy face $(66.7 \%$ vs. $44.0 \%$ ), Fisher's exact test, $p=.095$. In contrast, in the absence of the social anxiety- 
induction manipulation, there was a non-significant trend that compared to HSAs, LSAs detected the angry face better (63.0\% vs. $46.2 \%)$, Fisher's exact test, $p=.170$.

The nature of the observed three-way interaction was also examined by comparing the happy vs. frowning face conditions separately for LSAs and HSAs. In the presence of social-anxiety induction manipulation, HSAs detected the angry face significantly better than the happy face $(72.0 \%$ vs. $44.0 \%)$, Fisher's exact test, $p=.042$. In contrast, in the absence of social-anxiety induction manipulation, there was a non-significant reverse trend for HSAs to detect the happy face better than the angry face $(62.5 \%$ vs. $46.2 \%)$, Fisher's exact test, $p=.191$. Figure 8 presents the detection rates in the inattentional trial across the 12 experiment groups.

\subsubsection{Differences in Identification Rates for the Inattentional Trial}

An identical analytic approach used for the analyses of detection rates was applied to the binary outcome of identification in the inattentional trial. Step 1 revealed a significant main effect for the critical item condition indicating: (a) the happy face was identified better than the oval $(51.0 \%$ vs. $3.4 \%), \mathrm{B}=3.40$, Wald $=20.73, p<.001$, odds ratio $=30.06,95 \% \mathrm{CI}[6.95,130.10]$, and $(\mathrm{b})$ the angry face was also identified better than the oval $(45.5 \%$ vs. $3.4 \%), \mathrm{B}=3.16$, Wald $=17.92, p<.001$, odds ratio $=23.63$, 95\% CI [5.46, 102.19]. In Step 2, none of the two-way interaction terms were significant. In Step 3, the three-way interaction term involving the contrast between the happy and angry faces was marginally significant, $\mathrm{B}=2.06$, Wald $=3.19, p=.074$, odds ratio $=$ $7.85,95 \%$ CI $[.82,75.50]$. To further probe this non-significant trend of three-way interaction, the two-way critical item by social anxiety status interaction was further 
examined for each level of the social anxiety induction condition. Results revealed a significant critical item (happy vs. angry face) by social anxiety status interaction only for those who underwent the social anxiety-induction manipulation, $\mathrm{B}=2.04$, Wald $=5.87, p$ $=.015$, odds ratio $=7.69,95 \%$ CI $[1.48,40.07]$. Further analyses revealed that under the social anxiety-induction manipulation, HSAs outperformed LSAs in identifying the angry face $(64.0 \%$ vs. $29.2 \%)$, Fisher's exact test, $p=.015$. In contrast, there was a nonsignificant reverse trend for LSAs to outperform HSAs in identifying the happy face (58.3\% vs. $44.0 \%)$, Fisher's exact test, $p=.237$. In the absence of the social anxietyinduction manipulation, HSAs and LSAs did not differ in identifying the faces.

This marginally significant three-way interaction was also examined by comparing the happy vs. angry face conditions separately for LSAs and HSAs. LSAs who underwent the social anxiety-induction manipulation identified the happy face significantly better than the angry face ( $58.3 \%$ vs. $29.2 \%)$, Fisher's exact test, $p=.040$. In contrast, there was a non-significant trend for HSAs to identify the angry face better than the happy face ( $64.0 \%$ vs. $44.0 \%$ ), Fisher's exact test, $p=.128$. No significant difference in the identification rates between the happy face vs. angry face was observed for both LSAs and HSAs assigned to the no social anxiety-induction condition (LSAs $-48.1 \%$ vs. $40.7 \%$, Fisher's exact test, $p=.392$; HSAs $-54.2 \%$ vs. $46.2 \%$, Fisher's exact test, $p=$ .389). Figure 9 presents the identification rates in the inattentional trial across the 12 experiment groups. 


\subsubsection{Controlling for Gender and General Emotional Distress}

HSA and LSA participants differed significantly with respect to gender. Thus, we repeated the logistic hierarchical regression analyses using gender as a covariate in Step 1 for the detection and identification rates from the inattentional trial. We also entered the BDI and STAI-trait in Step 1 to examine the possibility that the observed interaction effects were accounted for by general emotional distress. Results revealed that neither gender nor general emotional distress was predictive of the detection rates. After controlling for the three covariates, the observed social anxiety by critical item by social anxiety induction three-way interaction remained significant, $\mathrm{B}=2.82$, Wald $=5.59, p=$ .018 , odds ratio $=16.77,95 \%$ CI $[1.62,173.57]$

In the case of the identification rates from the inattentional trial, none of the three covariates significantly contributed to the model; and after controlling for the three covariates, the social anxiety by critical item by social anxiety induction three-way interaction was significant, $\mathrm{B}=2.36$, Wald $=3.99, p=.046$, odds ratio $=10.57,95 \% \mathrm{CI}$ $[1.05,106.81]$

I also considered the possibility that the observed group differences may be due to differential perceptual accuracy or attentional investment by examining bounces-counting errors across the 12 experiment groups. The counting error for each trial was determined by taking the absolute number of difference between the reported number of bounces and the correct number of bounces made by the four black squares. The overall counting error for the entire sample was $2.01(\mathrm{SD}=1.16)$ and there were no significant differences across the 12 experimental groups. 


\subsubsection{Differences in Detection and Identification Rates for the Divided and Full- Attention Trials}

Table 9 presents the detection and identification rates from the divided and full attentional trials. Although our primary interest was in examining the detection and identification rates in the inattentional trial, we repeated the analyses reported above for the data derived from the divided and full attentional trials. Consistent with prediction, once participants expected the emergence of the critical item (i.e., divided attentional trial) the significant three-way interactions observed in the inattentional trial were no longer present. However, the critical item main effect for the detection rates was still significant indicating that the happy face was detected better than the oval $(89.0 \%$ vs.

$27.1 \%), \mathrm{B}=3.09$, Wald $=50.46, p<.001$, odds ratio $=22.04,95 \% \mathrm{CI}[9.39,51.74]$, and the angry face was detected better than the oval $(92.2 \%$ vs. $27.1 \%), \mathrm{B}=3.47$, Wald $=$ $53.82, p<.001$, odds ratio $=32.00,95 \%$ CI $[12.68,80.76]$. The critical item main effect for the identification rates was also significant indicating that the happy face was identified better than the angry face $(84.0 \%$ vs. $71.6 \%), \mathrm{B}=.73$, Wald $=4.43, p=.035$, odds ratio $=2.09,95 \% \mathrm{CI}[1.05,4.15]$, or the oval $(84.0 \%$ vs. $28.8 \%), \mathrm{B}=2.56$, Wald $=$ $41.78, p<.001$, odds ratio $=12.98,95 \%$ CI $[5.97,28.24]$.

As expected, once participants were instructed to attend fully to the emergence of the critical item (i.e., full attentional trial), detection and identification rates were uniformly high with no significant main or interaction effects of participants' social anxiety status, critical item, or social anxiety induction (See Table 9). 


\subsubsection{Gender Differences in Detection and Identification Rates}

Although the observed interaction effects remained unaffected after controlling for the influence of gender, we conducted another set of hierarchical logistic regression analyses to further examine the role of gender and its possible interaction with the three IVs (i.e., critical item, social anxiety status, and social anxiety-induction) in predicting the detection and identification rates from the three critical trials. However, results revealed no main or interactive effects for gender.

\subsubsection{Additional Evidence of Vigilant Attention towards the Critical Item}

Finally, we conducted additional analyses to further examine the evidence of attentional vigilance towards the critical items. If the critical item attracted the viewer's attention, one would expect a reduction in the attentional resources available for the black square-bounces counting task, thereby leading to greater counting errors among those who detected or identified the critical item. The counting error from each trial was compared between detectors and non-detectors (also between identifiers and nonidentifiers) determined based on the inattentional trial (i.e., \#3). Consistent with expectation, detectors and non-detectors did not differ in counting errors on the first two regular trials (trial $\# 1$ mean error $=3.08$ vs. $2.84, t(259)=.837, p=.403$; trial $\# 2$ mean error $=1.40$ vs. $1.31, t(259)=.565, p=.573)$. In contrast, relative to non-detectors, detectors showed significantly greater errors on the third (inattentional) trial (mean error $=2.38$ vs. $1.77 ; t(259)=2.84, p=.005)$. The same pattern of findings was observed for identifiers vs. non-identifiers from the inattentional trial. Table 10 presents correct 
response rates between detectors (identifiers) and non-detectors (non-identifiers) across the cross-line discrimination trials. 
Table 7. Experimental group characteristics in Experiment 2

\begin{tabular}{|c|c|c|c|c|c|c|c|c|c|c|c|c|}
\hline & \multicolumn{6}{|c|}{ No Bogus Speech Manipulation } & \multicolumn{6}{|c|}{ Bogus Speech Manipulation } \\
\hline & \multicolumn{2}{|c|}{ Happy } & \multicolumn{2}{|c|}{ Angry } & \multicolumn{2}{|c|}{ Oval } & \multicolumn{2}{|c|}{ Happy } & \multicolumn{2}{|c|}{ Angry } & \multicolumn{2}{|c|}{ Oval } \\
\hline & $\begin{array}{c}\text { LSAs } \\
(\mathrm{N}=27)\end{array}$ & $\begin{array}{l}\text { HSAs } \\
(\mathrm{N}=24)\end{array}$ & $\begin{array}{c}\text { LSAs } \\
(\mathrm{N}=27)\end{array}$ & $\begin{array}{l}\text { HSAs } \\
(\mathrm{N}=26)\end{array}$ & $\begin{array}{c}\text { LSAs } \\
(\mathrm{N}=15)\end{array}$ & $\begin{array}{c}\text { HSAs } \\
(\mathrm{N}=14)\end{array}$ & $\begin{array}{l}\text { LSAs } \\
(\mathrm{N}=24)\end{array}$ & $\begin{array}{l}\text { HSAs } \\
(\mathrm{N}=25)\end{array}$ & $\begin{array}{c}\text { LSAs } \\
(\mathrm{N}=24)\end{array}$ & $\begin{array}{l}\text { HSAs } \\
(\mathrm{N}=25)\end{array}$ & $\begin{array}{c}\text { LSAs } \\
(\mathrm{N}=15)\end{array}$ & $\begin{array}{c}\text { HSAs } \\
(\mathrm{N}=15)\end{array}$ \\
\hline & $\begin{array}{c}M \\
(S D) \\
\end{array}$ & $\begin{array}{c}M \\
(S D) \\
\end{array}$ & $\begin{array}{c}M \\
(S D) \\
\end{array}$ & $\begin{array}{c}M \\
(S D) \\
\end{array}$ & $\begin{array}{c}M \\
(S D) \\
\end{array}$ & $\begin{array}{c}M \\
(S D) \\
\end{array}$ & $\begin{array}{c}M \\
(S D) \\
\end{array}$ & $\begin{array}{c}M \\
(S D) \\
\end{array}$ & $\begin{array}{c}M \\
(S D) \\
\end{array}$ & $\begin{array}{c}M \\
(S D) \\
\end{array}$ & $\begin{array}{c}M \\
(S D) \\
\end{array}$ & $\begin{array}{c}M \\
(S D) \\
\end{array}$ \\
\hline Age & $\begin{array}{l}18.37 \\
(0.74)\end{array}$ & $\begin{array}{l}18.83 \\
(1.46)\end{array}$ & $\begin{array}{l}19.48 \\
(3.48)\end{array}$ & $\begin{array}{c}18.69 \\
(1.19)\end{array}$ & $\begin{array}{c}18.93 \\
(1.10)\end{array}$ & $\begin{array}{c}18.71 \\
(0.73)\end{array}$ & $\begin{array}{l}19.13 \\
(2.07)\end{array}$ & $\begin{array}{l}18.80 \\
(1.61)\end{array}$ & $\begin{array}{c}18.42 \\
(0.65)\end{array}$ & $\begin{array}{l}18.44 \\
(0.71)\end{array}$ & $\begin{array}{l}19.40 \\
(1.55)\end{array}$ & $\begin{array}{l}18.80 \\
(1.52)\end{array}$ \\
\hline $\begin{array}{l}\text { Gender } \\
(\% \text { Male })\end{array}$ & $44 \%$ & $25 \%$ & $44 \%$ & $35 \%$ & $40 \%$ & $29 \%$ & $46 \%$ & $28 \%$ & $46 \%$ & $32 \%$ & $40 \%$ & $33 \%$ \\
\hline FNES & $\begin{array}{c}5.48 \\
(2.12)\end{array}$ & $\begin{array}{l}25.71 \\
(1.63)\end{array}$ & $\begin{array}{c}5.26 \\
(2.94)\end{array}$ & $\begin{array}{l}26.65 \\
(2.65)\end{array}$ & $\begin{array}{c}5.33 \\
(3.42)\end{array}$ & $\begin{array}{l}24.57 \\
(2.59)\end{array}$ & $\begin{array}{c}4.88 \\
(2.53)\end{array}$ & $\begin{array}{l}25.96 \\
(2.91)\end{array}$ & $\begin{array}{c}4.42 \\
(2.87)\end{array}$ & $\begin{array}{l}25.88 \\
(1.97)\end{array}$ & $\begin{array}{c}5.80 \\
(3.53)\end{array}$ & $\begin{array}{l}26.00 \\
(2.80)\end{array}$ \\
\hline SPS & $\begin{array}{c}8.59 \\
(5.44)\end{array}$ & $\begin{array}{c}25.54 \\
(11.84)\end{array}$ & $\begin{array}{c}9.48 \\
(7.73)\end{array}$ & $\begin{array}{c}27.96 \\
(10.52)\end{array}$ & $\begin{array}{c}7.40 \\
(6.80)\end{array}$ & $\begin{array}{l}24.50 \\
(9.59)\end{array}$ & $\begin{array}{c}8.04 \\
(5.57)\end{array}$ & $\begin{array}{c}27.68 \\
(11.06)\end{array}$ & $\begin{array}{c}6.29 \\
(4.46)\end{array}$ & $\begin{array}{c}26.64 \\
(10.03)\end{array}$ & $\begin{array}{c}10.00 \\
(10.80)\end{array}$ & $\begin{array}{c}30.80 \\
(16.67)\end{array}$ \\
\hline SIAS & $\begin{array}{l}14.30 \\
(5.72)\end{array}$ & $\begin{array}{c}34.13 \\
(10.35)\end{array}$ & $\begin{array}{r}14.44 \\
(8.97)\end{array}$ & $\begin{array}{c}36.62 \\
(13.26)\end{array}$ & $\begin{array}{l}13.67 \\
(7.79)\end{array}$ & $\begin{array}{l}29.29 \\
(9.50)\end{array}$ & $\begin{array}{l}13.71 \\
(5.84)\end{array}$ & $\begin{array}{c}39.44 \\
(11.01)\end{array}$ & $\begin{array}{l}10.92 \\
(4.84)\end{array}$ & $\begin{array}{c}34.36 \\
(11.13)\end{array}$ & $\begin{array}{c}17.13 \\
(12.03)\end{array}$ & $\begin{array}{c}37.13 \\
(13.35)\end{array}$ \\
\hline BDI & $\begin{array}{c}2.78 \\
(3.03)\end{array}$ & $\begin{array}{c}9.42 \\
(4.83)\end{array}$ & $\begin{array}{c}3.74 \\
(4.18)\end{array}$ & $\begin{array}{l}13.27 \\
(7.38)\end{array}$ & $\begin{array}{c}4.13 \\
(6.82)\end{array}$ & $\begin{array}{c}7.14 \\
(5.08)\end{array}$ & $\begin{array}{c}3.17 \\
(2.51)\end{array}$ & $\begin{array}{l}12.04 \\
(9.15)\end{array}$ & $\begin{array}{c}2.25 \\
(2.25)\end{array}$ & $\begin{array}{c}9.32 \\
(5.83)\end{array}$ & $\begin{array}{c}5.20 \\
(4.96)\end{array}$ & $\begin{array}{l}13.40 \\
(8.54)\end{array}$ \\
\hline STAI & $\begin{array}{l}32.85 \\
(3.07)\end{array}$ & $\begin{array}{l}48.83 \\
(5.85) \\
\end{array}$ & $\begin{array}{l}34.81 \\
(5.03)\end{array}$ & $\begin{array}{l}51.46 \\
(8.17) \\
\end{array}$ & $\begin{array}{l}31.47 \\
(4.37)\end{array}$ & $\begin{array}{c}44.14 \\
(6.60)\end{array}$ & $\begin{array}{l}34.75 \\
(5.59)\end{array}$ & $\begin{array}{l}48.04 \\
(8.92) \\
\end{array}$ & $\begin{array}{l}33.67 \\
(4.68) \\
\end{array}$ & $\begin{array}{l}48.32 \\
(7.68) \\
\end{array}$ & $\begin{array}{l}36.47 \\
(7.20)\end{array}$ & $\begin{array}{c}48.53 \\
(11.73)\end{array}$ \\
\hline
\end{tabular}


Table 8. Pre-and Post manipulation anxiety scores across the 12 experiment groups in Experiment 2

\begin{tabular}{|c|c|c|c|c|c|c|c|c|c|c|c|c|}
\hline & \multicolumn{6}{|c|}{ No Bogus Speech Manipulation } & \multicolumn{6}{|c|}{ Bogus Speech Manipulation } \\
\hline & \multicolumn{2}{|c|}{ Happy } & \multicolumn{2}{|c|}{ Angry } & \multicolumn{2}{|c|}{ Oval } & \multicolumn{2}{|c|}{ Happy } & \multicolumn{2}{|c|}{ Angry } & \multicolumn{2}{|c|}{ Oval } \\
\hline & $\begin{array}{c}\text { LSAs } \\
(\mathrm{N}=27)\end{array}$ & $\begin{array}{c}\text { HSAs } \\
(\mathrm{N}=24)\end{array}$ & $\begin{array}{c}\text { LSAs } \\
(\mathrm{N}=27)\end{array}$ & $\begin{array}{l}\text { HSAs } \\
(\mathrm{N}=26)\end{array}$ & $\begin{array}{c}\text { LSAs } \\
(\mathrm{N}=15)\end{array}$ & $\begin{array}{c}\text { HSAs } \\
(\mathrm{N}=14)\end{array}$ & $\begin{array}{c}\text { LSAs } \\
(\mathrm{N}=24)\end{array}$ & $\begin{array}{l}\text { HSAs } \\
(\mathrm{N}=25)\end{array}$ & $\begin{array}{c}\text { LSAs } \\
(\mathrm{N}=24)\end{array}$ & $\begin{array}{l}\text { HSAs } \\
(\mathrm{N}=25)\end{array}$ & $\begin{array}{c}\text { LSAs } \\
(\mathrm{N}=15)\end{array}$ & $\begin{array}{c}\text { HSAs } \\
(\mathrm{N}=15)\end{array}$ \\
\hline & $\begin{array}{c}M \\
(S D) \\
\end{array}$ & $\begin{array}{c}M \\
(S D) \\
\end{array}$ & $\begin{array}{c}M \\
(S D) \\
\end{array}$ & $\begin{array}{c}M \\
(S D) \\
\end{array}$ & $\begin{array}{c}M \\
(S D) \\
\end{array}$ & $\begin{array}{c}M \\
(S D) \\
\end{array}$ & $\begin{array}{c}M \\
(S D) \\
\end{array}$ & $\begin{array}{c}M \\
(S D) \\
\end{array}$ & $\begin{array}{c}M \\
(S D) \\
\end{array}$ & $\begin{array}{c}M \\
(S D) \\
\end{array}$ & $\begin{array}{c}M \\
(S D) \\
\end{array}$ & $\begin{array}{c}M \\
(S D) \\
\end{array}$ \\
\hline Pre & $\begin{array}{c}19.93 \\
(11.50)\end{array}$ & $\begin{array}{c}30.67 \\
(18.19)\end{array}$ & $\begin{array}{c}18.00 \\
(10.97)\end{array}$ & $\begin{array}{c}37.74 \\
(20.23)\end{array}$ & $\begin{array}{c}18.13 \\
(14.19)\end{array}$ & $\begin{array}{c}34.14 \\
(17.91)\end{array}$ & $\begin{array}{c}24.08 \\
(15.81)\end{array}$ & $\begin{array}{c}43.36 \\
(18.81)\end{array}$ & $\begin{array}{l}17.75 \\
(9.86)\end{array}$ & $\begin{array}{c}33.84 \\
(16.49)\end{array}$ & $\begin{array}{c}22.00 \\
(17.20)\end{array}$ & $\begin{array}{c}41.67 \\
(18.90)\end{array}$ \\
\hline Post & $\begin{array}{l}14.81 \\
(7.83)\end{array}$ & $\begin{array}{c}26.75 \\
(14.52)\end{array}$ & $\begin{array}{c}15.41 \\
(15.03)\end{array}$ & $\begin{array}{c}36.08 \\
(19.74)\end{array}$ & $\begin{array}{l}12.81 \\
(8.57)\end{array}$ & $\begin{array}{c}31.00 \\
(13.35)\end{array}$ & $\begin{array}{c}29.62 \\
(19.23)\end{array}$ & $\begin{array}{c}52.32 \\
(21.51)\end{array}$ & $\begin{array}{c}23.67 \\
(14.04)\end{array}$ & $\begin{array}{c}47.92 \\
(21.39)\end{array}$ & $\begin{array}{c}28.13 \\
(22.46)\end{array}$ & $\begin{array}{c}63.47 \\
(23.85)\end{array}$ \\
\hline
\end{tabular}


Table 9. Detection and Identification Rates of the Three Critical Trials across the 12 Experiment Groups in Experiment 2

\begin{tabular}{|c|c|c|c|c|c|c|c|c|c|c|c|c|}
\hline & \multicolumn{6}{|c|}{ No Bogus Speech Manipulation } & \multicolumn{6}{|c|}{ Bogus Speech Manipulation } \\
\hline & \multicolumn{2}{|c|}{ Happy } & \multicolumn{2}{|c|}{ Angry } & \multicolumn{2}{|c|}{ Oval } & \multicolumn{2}{|c|}{ Happy } & \multicolumn{2}{|c|}{ Angry } & \multicolumn{2}{|c|}{ Oval } \\
\hline & $\begin{array}{c}\text { LSAs } \\
(\mathrm{N}=27)\end{array}$ & $\begin{array}{l}\text { HSAs } \\
(\mathrm{N}=24)\end{array}$ & $\begin{array}{l}\text { LSAs } \\
(\mathrm{N}=27)\end{array}$ & $\begin{array}{l}\text { HSAs } \\
(\mathrm{N}=26)\end{array}$ & $\begin{array}{l}\text { LSAs } \\
(\mathrm{N}=15)\end{array}$ & $\begin{array}{l}\mathrm{HSAs} \\
(\mathrm{N}=14)\end{array}$ & $\begin{array}{l}\text { LSAs } \\
(\mathrm{N}=24)\end{array}$ & $\begin{array}{l}\text { HSAs } \\
(\mathrm{N}=25)\end{array}$ & $\begin{array}{l}\text { LSAs } \\
(\mathrm{N}=24)\end{array}$ & $\begin{array}{l}\text { HSAs } \\
(\mathrm{N}=25)\end{array}$ & $\begin{array}{l}\text { LSAs } \\
(\mathrm{N}=15)\end{array}$ & $\begin{array}{l}\text { HSAs } \\
(\mathrm{N}=15)\end{array}$ \\
\hline \multicolumn{13}{|l|}{ Inattentional } \\
\hline Detection Rate (\%) & 59.3 & 62.5 & 63.0 & 46.2 & 0.0 & 7.1 & 66.7 & 44.0 & 54.2 & 72.0 & 6.7 & 0.0 \\
\hline Identification Rate (\%) & 48.1 & 54.2 & 40.7 & 46.2 & 0.0 & 7.1 & 58.3 & 44.0 & 29.2 & 64.0 & 6.7 & 0.0 \\
\hline $\begin{array}{l}\text { Divided Attention } \\
\text { Detection Rate (\%) }\end{array}$ & 88.9 & 83.3 & 92.6 & 92.3 & 26.7 & 35.7 & 95.8 & 88.0 & 83.3 & 100.0 & 26.7 & 26.7 \\
\hline Identification Rate (\%) & 81.5 & 75.0 & 85.2 & 73.1 & 26.7 & 35.7 & 91.7 & 88.0 & 54.2 & 72.0 & 26.7 & 26.7 \\
\hline \multicolumn{13}{|l|}{ Full Attention } \\
\hline Detection Rate (\%) & 100.0 & 100.0 & 100.0 & 100.0 & 93.3 & 100.0 & 100.0 & 100.0 & 95.8 & 100.0 & 100.0 & 100.0 \\
\hline Identification Rate (\%) & 100.0 & 100.0 & 96.3 & 100.0 & 93.3 & 100.0 & 95.8 & 96.0 & 95.8 & 100.0 & 100.0 & 100.0 \\
\hline \multicolumn{13}{|l|}{ Overall Counting Errors } \\
\hline $\begin{array}{c}M \\
(S D)\end{array}$ & $\begin{array}{c}1.88 \\
(1.13)\end{array}$ & $\begin{array}{c}2.22 \\
(1.48)\end{array}$ & $\begin{array}{l}1.97 \\
(.93)\end{array}$ & $\begin{array}{c}2.03 \\
(1.45)\end{array}$ & $\begin{array}{l}1.93 \\
(1.26)\end{array}$ & $\begin{array}{l}1.32 \\
(.67)\end{array}$ & $\begin{array}{c}2.15 \\
(1.35)\end{array}$ & $\begin{array}{c}2.23 \\
(1.45)\end{array}$ & $\begin{array}{l}1.92 \\
(.85)\end{array}$ & $\begin{array}{c}2.05 \\
(1.14)\end{array}$ & $\begin{array}{l}2.08 \\
(.67)\end{array}$ & $\begin{array}{l}2.10 \\
(.69)\end{array}$ \\
\hline
\end{tabular}


Table 10. Counting errors ${ }^{a}$ across trials in Experiment 2

\begin{tabular}{lcccc}
\hline & $\begin{array}{c}\text { Detectors } \\
(\mathrm{N}=120)\end{array}$ & $\begin{array}{c}\text { Non-detectors } \\
(\mathrm{N}=141)\end{array}$ & $\begin{array}{c}\text { Identifiers } \\
(\mathrm{N}=99)\end{array}$ & $\begin{array}{c}\text { Non-identifiers } \\
(\mathrm{N}=162)\end{array}$ \\
\cline { 2 - 5 } & $M(S D)$ & $M(S D)$ & $M(S D)$ & $M(S D)$ \\
\hline Trial 1 & $3.08(2.39)$ & $2.84(2.36)$ & $3.18(2.44)$ & $2.81(2.32)$ \\
\hline Trial 2 & $1.40(1.29)$ & $1.31(1.22)$ & $1.38(1.35)$ & $1.33(1.19)$ \\
\hline $\begin{array}{l}\text { Trial 3 } \\
\text { Inattentional) }\end{array}$ & $2.38(1.91)$ & $1.77(1.56)$ & $2.36(1.90)$ & $1.86(1.63)$ \\
\hline $\begin{array}{l}\text { Trial 4 } \\
\text { (Divided } \\
\text { Attention) }\end{array}$ & $1.74(1.50)$ & $1.65(1.44)$ & $1.74(1.48)$ & $1.67(1.46)$ \\
\hline
\end{tabular}

${ }^{a}$ Counting errors were defined as the difference between the reported number of bounces and the correct number of bounces made by the four black squares in each trial

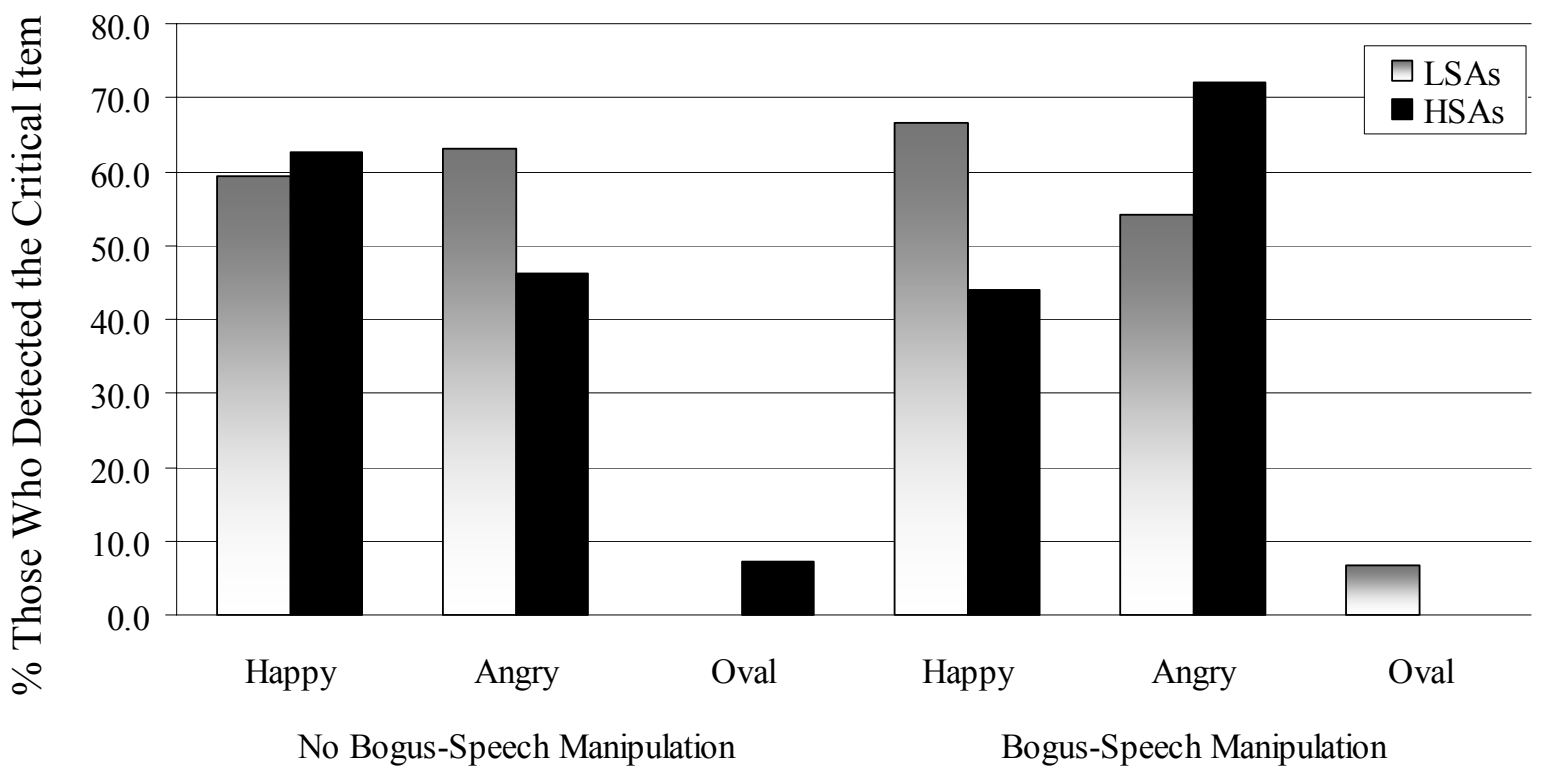

Figure 8. Detection Rates in the Inattentional Trial (Experiment 2) 


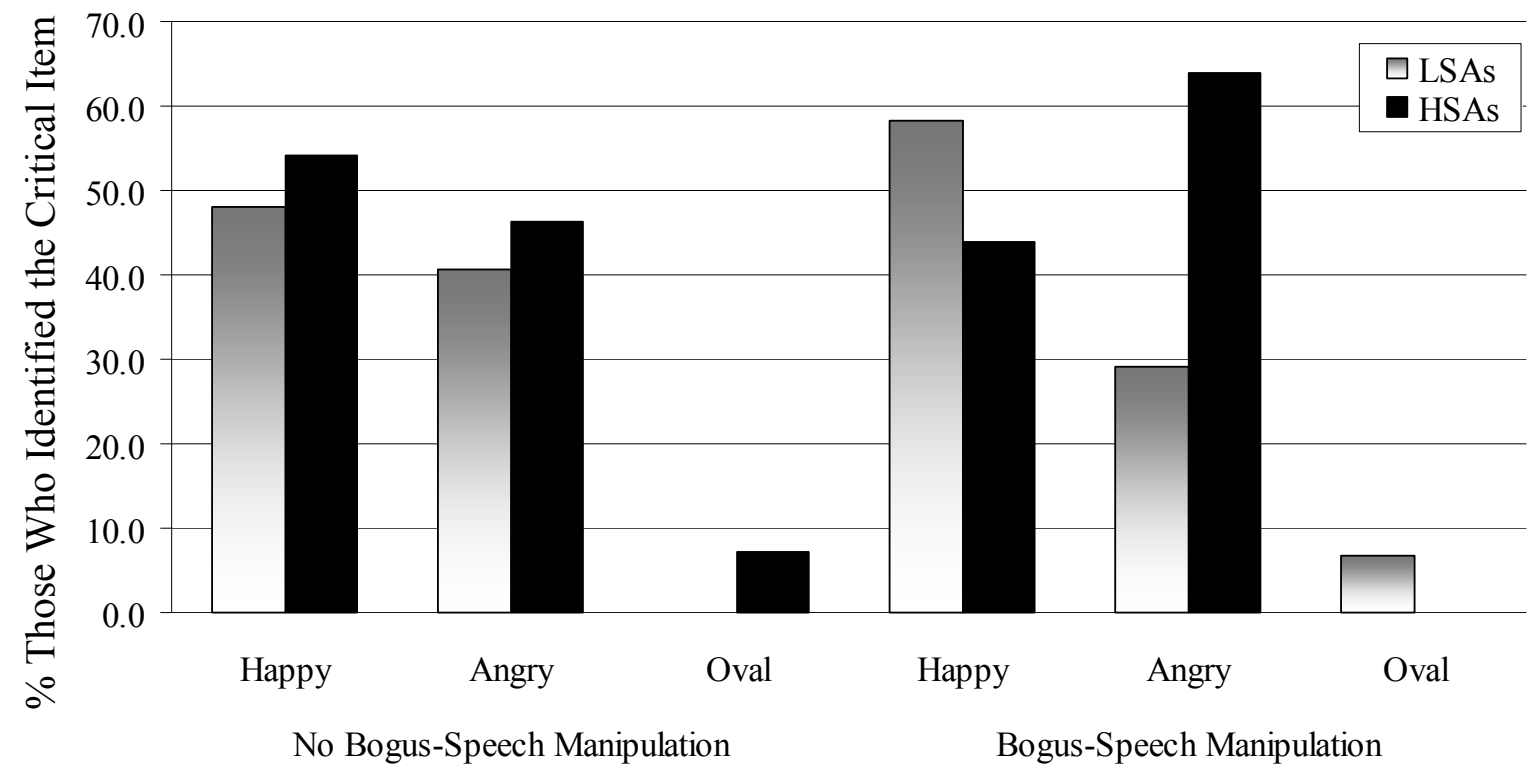

Figure 9. Identification Rates in the Inattentional Trial (Experiment 2)

\subsection{Discussion}

This is the first study to apply the sustained IB paradigm to the field of anxiety disorders specifically or psychopathology more generally. Several experiments conducted by Most and colleagues $(2005,2001)$ have consistently demonstrated the dominant role of the viewer's attentional set in leading the unexpected critical item to capture attention in the sustained IB paradigm. They reached the conclusion that although some bottom-up stimulus properties such as salience could affect the detection of critical items, the most powerful mediator is the attentional set adopted by the individual (Most et al., 2005).

In line with the attentional set hypothesis, this study predicted that relative to LSAs, HSAs would be more likely to detect/identify the angry face, whereas LSAs would 
show a preferential processing of the happy face, in the presence of the bogus-speech manipulation. This prediction hinged on the assumption that HSAs would be more apt to activate an attentional set attuned to negative social cues particularly when expecting a social-evaluative event. Consistent with prediction, relative to LSAs, HSAs were more likely to detect and identify the angry face; whereas relative to HSAs, LSAs were more likely to detect and identify the happy face, in the presence of the bogus speech anxiety induction manipulation. These findings were not accounted for by general emotional distress or demographic variables such as age or gender. The possibility that the observed group differences may be due to differential perceptual accuracy was also examined. However, the overall degree of counting errors made on the primary task did not differ across the experiment groups. Moreover, when detectors and non-detectors from the inattentional trial were compared with respect to their pre-critical trial performance (\# 1 and \#2), no significant difference emerged in counting errors. It indicates that varying detection and identification rates are not attributable to differential perceptual accuracy or attentional investment to the primary counting task.

Several aspects of Experiment 2 data are consistent with the attentional set hypothesis as opposed to the stimuli-salience account. Compared to the distracter stimuli (i.e., 4 black squares and 4 gray ovals), the emotional faces used in Experiment 2 contained several salient physical features such as unique surfaces, gradations, protrusions, internal facial components, as well as a unique motion path. However, the happy face and the angry face shared most of these physical features except the emotional expression they delivered. Had the stimulus salience been the factor governing the 
detection of critical items, HSAs and LSAs should not have differed in detecting/identifying the emotional faces. Thus, these findings are suggestive of the operation of some top-down process that tuned the viewer's attentional set to a certain kind of stimuli above and beyond the attentional benefit of physical salience. Moreover, similar to findings based on the static IB paradigm in Experiment 1, Experiment 2 also showed a stark contrast in detection and identification rates for social critical items vs. non-social critical items. In the inattentional trial, the (critical-item) oval went almost completely undetected, whereas the overall detection and identification rates for the happy and angry faces were $58.0 \%$ and $58.8 \%$, respectively. From the standpoint of the attentional set hypothesis, one would easily explicate these data. First, the critical-item oval was very similar to the distracter ovals randomly moving on the display, although it was still visually distinguished from the four distracter ovals due to its coarser contour and the uniquely straight motion path. Considering the explicit instructions that led subjects to disregard ovals while keeping track of squares, the zero-level detection rates for the oval stand to reason. The previous study (Most et al., 2005) also reported that the detection rate was virtually zero when the critical item was identical to the ignored distracter items of the induced attentional set. Second, in Experiment 2, the bogus-speech anxiety induction procedure was another key ingredient intended to affect the viewer's attentional set. In contrast with emotional faces, the gray oval was very unlikely to gain any attentional benefit from the induced attentional set or heighten social anxiety.

The bogus-speech manipulation seemed to play an important role in amplifying the potential differences between HSAs and LSAs in response to the inattentional trial. It 
may be that the bogus-speech manipulation activated the subjects' cognitive schema related to social-evaluative situations, and thus making the socially threatening or positive cues a particularly relevant dimension in their attentional set as a function of levels of their dispositional social anxiety. In the absence of the bogus-speech manipulation, there was a tendency for HSAs to detect the happy face better than the angry face (62.5\% vs. $46.2 \%)$, which seems to suggest the possibility for HSAs to display attentional avoidance from the negative social cue. However, once the bogus-speech manipulation was administered, the angry face was detected significantly better than the happy face by HSAs ( $72 \%$ vs. $44 \%)$. In the case of LSAs, they showed equivalent detection rates between the happy and angry faces in the absence of the bogus-speech manipulation. However, in the presence of the bogus-speech manipulation, there was a non-significant trend for LSAs to detect the happy face better than the angry face $(66.7 \%$ VS. $44.0 \%)$.

Interestingly, similar to findings from Experiment 1, there was a noticeable drop in the identification rate of LSAs presented with the angry face. In the presence of the bogus-speech manipulation, only $54 \%$ of the LSA detectors from the inattentional trial correctly identified the angry face, whereas $89 \%$ of the HAS detectors identified the angry face. Unlike Experiment 1, this tendency was observed in LSAs without regards to the presence of the bogus-speech manipulation procedure. One speculation is that LSAs' dispositionally low social anxiety rendered their attentional set attuned to more positive or benign social cues and thus preventing them from allocating sufficient attention to the socially negative critical item that did not match their attentional set. Some additional 
analyses revealed that among the entire non-detectors in the inattentional trial, HSAs and LSAs did not differ in guessing the critical item from the object array (of 66 LSA nondetectors, 5 chose the happy face and 1 selected the angry face; of 68 HAS non-detectors, 4 chose the happy face and 2 selected the angry face). These data suggest that the LSAs' pattern of misidentifying the angry face was not likely to be confounded by a response bias that would have led individuals to preferentially process the positive vs. negative social cue according to the level of their social anxiety.

Taken together, the present data may contribute to the literature indicating the operation of attentional hypervigilance in social anxiety. The present study also demonstrated the promising utility of the sustained IB task in investigating attentional biases in social anxiety, particularly due to several methodological strengths: (a) preclusion of potential response factors, (b) use of emotional faces as the main search target, and (c) delivery of the emotional cue tapping the core of social anxiety. Moreover, unlike other cognitive experiments addressing millisecond matters such as the emotional Stroop or dot-probe task, this version of the sustained IB task found the evidence of attentional hypervigilance in a more realistic testing situation that examined how the individual indeed processed an unexpected social cue lasting over a 5-second period while engaging in a judgment task. The naturalistic viewing conditions may contribute to enhancing the ecological validity of the findings. Similar to the static IB task, the sustained IB task also presents a secondary measure of attentional allocation via the accuracy (or errors) on the primary discrimination task. Experiment 2 showed that 
attentional hypervigilance to the unexpected object was accompanied by a significant loss of accuracy on the primary task.

Some limitations of the study and considerations for future research are worthy of note. First, although subjects were instructed to focus on the central cue of the display throughout all trials, their adherence was not directly measured. I doubt this would affect the observed findings because each subject was exposed to the same five dynamic displays except the differing critical item. However, it is still worthwhile to examine whether a certain pattern of eye movement could affect the performance on this paradigm. Secondly, the nonclinical nature of the current data limits the generalizability of findings. Replication with a clinical sample of social phobics is needed. Thirdly, one might argue that the object array containing emotionally-valenced items could introduce a response bias in the recognition test of critical trials. However, this is unlikely given that nondetector HSAs and LSAs did not show any preferential selection towards a particular emotional face in the recognition test. Had a response bias operated in the object-array recognition test, choices of the emotional faces would have differed as a function of the level of social anxiety. Nonetheless, future research may include additional items to the object array such as a neutral face to lower any chance of response biases. Moreover, the neutral face may be used for constituting another critical item condition to enhance the interpretability of data. A neutral face would provide baseline levels of detection and identification rates to be compared with those from emotional faces. For instance, with regard to preferential processing of either a happy or an angry face, the neutral face 
condition would help quantify the magnitude of advantage/disadvantage in attention processing occurring in response to each emotional expression. 


\section{CHAPTER 6: GENERAL DISCUSSION}

\subsection{Inattentional Blindness in Clinical Reality}

Jack is a 25 -yr old graduate student who had suffered severe social anxiety problems for more than 10 years. He just started giving a research presentation on cognitive experimental paradigms in front of his peers and departmental faculty when his heart started pounding painfully. He could hardly step aside the podium for fear of revealing his trembling hands and legs. He could also sense a film of perspiration on his forehead. His research addressed several complicated issues, which made the presentation a very cognitively-demanding task. The audience started displaying a wide range of unexpected reactions. Some were smiling, nodding, leaning forward, or taking notes. Others suddenly stood up and left the room. Some others were yawning or making a grimace. In the middle of this demanding task, Jack's attention automatically shifted to the audience, but he was unaware of the varied reactions of his audience. Rather, he suddenly noticed his research advisor giving a heavy yawn and making a face sitting in the corner of the room. When it occurred, he thought to himself, 'That just means my performance is so poor and a way below his expectations. That exactly matches what I was afraid to see.' To make matters worse, several of his friends in the audience taunted him by asking irrelevant questions, pretending to request a behavioral demonstration of his findings: "The two young men sitting in the front row just left the room. The one who kept yawning left a sheet of paper on the chair. Did you notice where it was? Tell me the location quickly. Is it on the right or left chair?" Another one also added, "In the second 
row, there are people smiling, dozing off, or just listening. Name the color of their hair very quickly." ......

The cost of failing to see an unexpected object could be enormous in reality. As noted by Most et al. (2005), many traffic accidents seem to be accounted for by drivers' obvious failure to detect obstacles placed in front of their eyes despite no factors hindering their vision. Conversely, some clinical conditions such as anxiety disorders are characterized by superior detection of potentially threatening cues. This seems particularly true in the case of social anxiety disorder, in which attentional hypervigilance is considered to play a central role in its maintenance (Rapee \& Heimberg, 1997).

The present dissertation study presents data from two independent experiments conducted with nonclinical college student samples using the static and sustained IB tasks in order to investigate attentional biases in social anxiety. Overall findings from both Experiment 1 and 2 indicate that in response to a social evaluative event, HSAs are more likely to display hypervigilant attentional processing towards negative social cues, whereas LSAs are more likely to display preferential attentional processing towards positive social cues. Considering the clinical relevance of the IB paradigm (as illustrated in the case vignette presented earlier), as well as its several methodological strengths including the preclusion of response biases, the current data (a) present a robust demonstration of attentional hypervigilance implicated in social anxiety, and (b) provide evidence supporting the utility of this paradigm as an attentional bias measure for social anxiety and perhaps other more psychopathological conditions. The current data also 
support the cognitive model of social anxiety (Rapee \& Heimberg, 1997) suggesting that social phobics display vigilant response to potential social threats.

\subsection{A Model of Attentional Processing for the IB paradigm}

There is one intriguing question arising specifically from the IB testing situations. How come the individual fails to see the emotional face if he/she has already checked its meaning (in the case of the static IB paradigm) or compared its properties against his/her own attentional set (in the case of the sustained IB paradigm)? This question would remain as an inextricable tangle if the operation of implicit attentional processing is not taken into consideration. One of the previous sustained IB experiments that included a control condition in which subjects were presented with no critical item in the inattentional trial (Most et al., 2005) revealed that the emergence of the critical item led to a significant reduction in counting accuracy even for non-detectors, although the greatest decrease was observed among detectors. These findings led Most et al. (2005) to suggest that an implicit shift of attention may precede the awareness of an unexpected object appearing during an attentionally-demanding task, although it does not guarantee the conscious experience of the critical item unless one's attentional set matches the critical item.

Based on the current data and the original work done by Mack and Rock (1998) and Most et al., (2005; 2001), a 2-stage attentional processing model is postulated for the IB paradigm (particularly with respect to the inattention trial), including (a) implicit, transient, and automatic attentional processing, and (b) extended attentional processing. In between the two stages, some top-down filtering or matching process seems to play a 
mediating role in determining whether the unexpected item receives further attentional resources in the extended attentional processing stage on the basis of the implicitly processed stimulus features. In the case of the static IB task, based on the implicitly gleaned stimulus features, the top-down process would determine whether or not the threshold for meaningfulness has been reached. Likewise, in the case of the sustained IB paradigm, this top-down process would examine the implicitly gleaned stimulus features to determine whether the unexpected object presents a good match in comparison with one's own attentional set. Once implicitly processed stimulus input passes through this top-down mechanism, it would receive extended attentional processing.

The entirety of perceptual representation of the stimulus input would depend on the extent to which attentional resources are allocated to the extended attentional processing stage. Thus, an unexpected object receiving a sufficient amount of extended attentional processing is likely to be both detected and identified. In contrast, an object receiving a limited amount of further attentional resources may end up with a partial perceptual representation that could be misidentified despite the threshold for detection being already met. This seems to provide a reasonable account for the tendency observed in both Experiment 1 and 2 that relative to HSAs, LSAs was more likely to misidentify the negative face following the detection of its unexpected emergence. Finally, some bottom-up stimulus features (e.g., salience) may also contribute to the detection of the unexpected object by bypassing the top-down filtering/matching mechanism (See Figure 10 and 11). 
One line of research has investigated two types of attentional processing using the spatial cueing paradigm developed by Posner and colleagues (Posner, 1980; Posner et al., 1980): endogenous attention vs. exogenous attention (e.g., Prinzmetal, McCool, \& Park, 2005; Prinzmetal, Park, \& Garrett, 2005). Several classification schemes corresponding to this attention taxonomy have been put forth: voluntary vs. involuntary attention, goaldirected attention vs. stimulus-driven capture, controlled vs. automatic attention, push vs. pull attention, channel enhancement vs. channel selection (e.g., Wundt, 1902; Jonides, 1976, 1980; Posner, 1980; Klein \& Shore, 2000; Prinzmetal et al., 2005). According to Prinzmetal et al., (2005), endogenous attention is voluntary and strategic, is deployed to the location that may contain goal-directed information (i.e., working with informative cues indicating the target location), and purposes to enhance perceptual representation (i.e., channel enhancement for a veridical perceptual representation). In contrast, exogenous attention is involuntary and stimulus-driven, works when cues are not informative (i.e., invalid cues), affects a non-perceptual serial selection mechanism/decision process (i.e., channel selection for the rapid decision of a relevant response channel). However, the endogenous-exogenous taxonomy does not map on to the two attentional processing stages proposed in this chapter primarily because (a) the critical factor to operationally classify the endogenous-exogenous attention is based on the validity of preceding cues that do not exist in the IB paradigm, and (b) the intention to search the display for the target operates in both endogenous and exogenous attention. Particularly, the IB paradigm was designed to eliminate the strategic, voluntary, and endogenous form of attention. Nevertheless, the implicit attentional shift discussed in the 
proposed IB attentional processing model seems similar to exogenous attention, given its transient and stimulus-driven characteristics. Moreover, in line with the nature of implicit attentional processing in the proposed model, it was suggested that exogenous shifts of attention can automatically occur without resulting in awareness of the cue (McCormick, 1997).

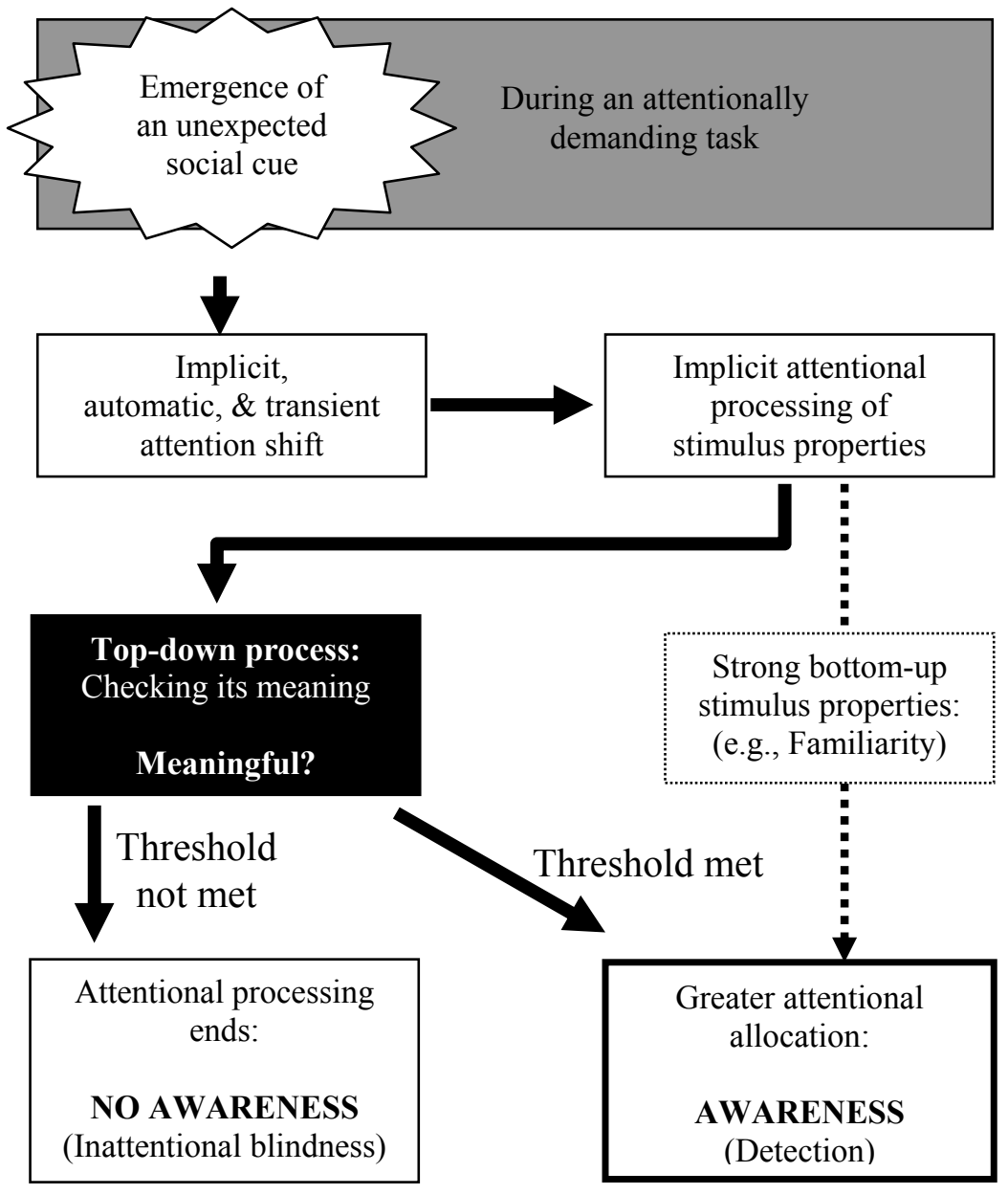

Figure 10. Attentional Processing Model of the Static IB Paradigm 
The proposed IB attentional processing model seems also in accordance with Posner's (1980) distinction between orienting and detecting. He suggested that allocating attentional resources to the target signal (i.e., orienting) is a pre-requisite for becoming aware of the signal (i.e., detection). In the proposed IB model, the "orienting process" would be assessed by examining whether the unexpected item successfully elicited sustained attentional processing (i.e., success or failure of detection), and the "detecting process" would be evaluated by examining the quality of perceptual representation manifested in two different levels: detection with identification, or misidentification/detection failure (i.e., identification rates).

Based on the proposed 2-stage attentional processing model, the current findings may be rephrased more specifically as follows:

(1) Relative to LSAs, HSAs are more likely to sustain the implicitly shifted attention towards potentially negative (as opposed to positive) social cues (i.e., Hypervigilant Attentional Orienting). This implicates that social phobics may be quicker in attending to potentially threatening cues emerging in social situations even with limited attentional resources, compared to individuals low in social anxiety.

(2) Relative to LSAs, HSAs are more likely to allocate greater attentional resources towards potentially negative (as opposed to positive) social cues following an automatic attentional shift to them, which would lead to a more veridical perceptual representation of the social cues and a greater hindrance to the ongoing task performance (i.e., Deeper Attentional Processing Leading to Better Detection). This implicates that social phobics may more extensively process potentially threatening cues and perceive the threat value 
more clearly at early stages of information processing, compared to individuals low in social anxiety.

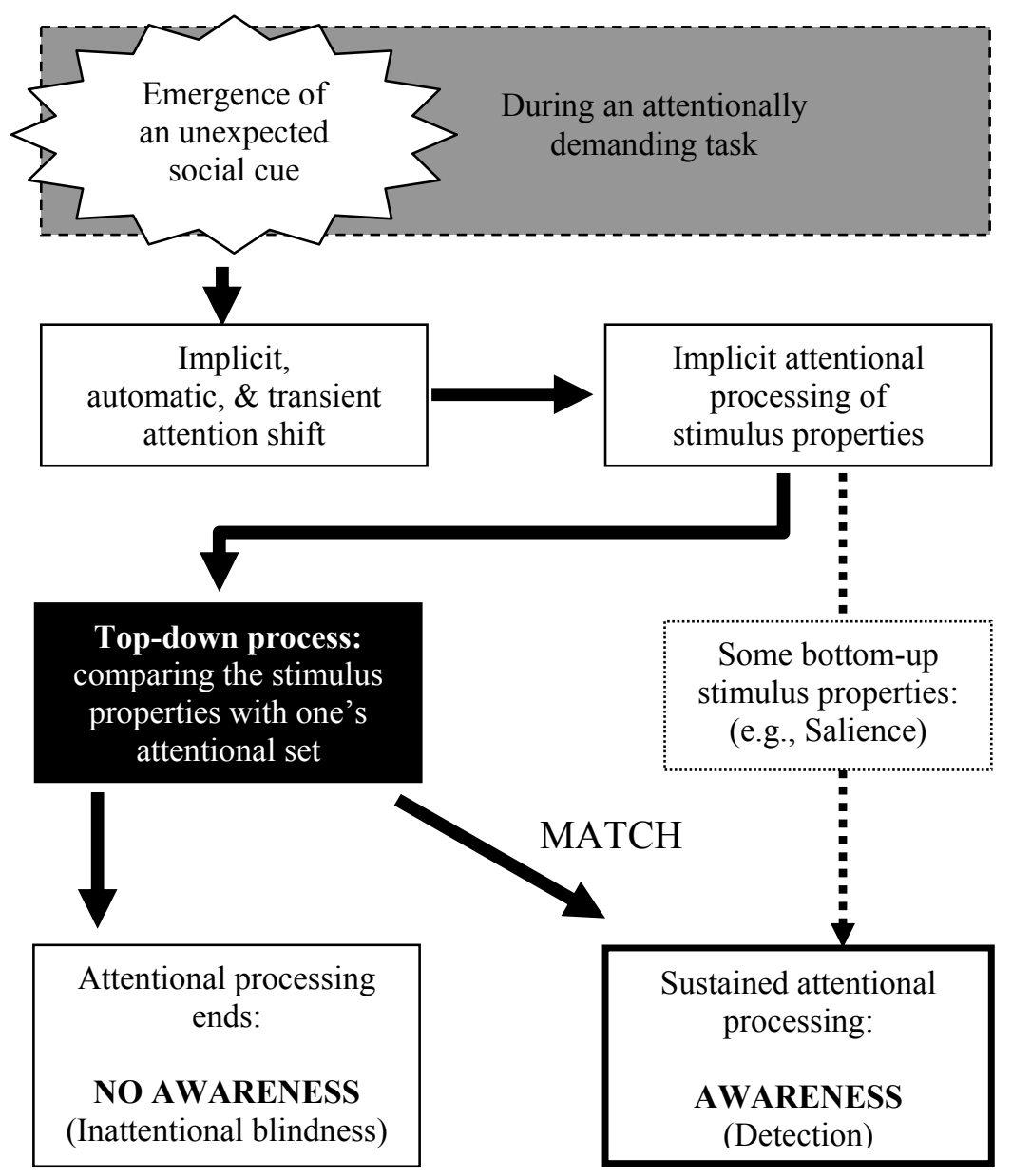

Figure 11. Attentional Processing Model of the Sustained IB Paradigm

Unlike the IB paradigm, investigations of biased attentional processing using the modified dot-probe paradigm seems to tap into only a limited facet of attentional processing. Namely, it only measures the orientation of relatively early (typically $500 \mathrm{~ms}$, but Cooper and Langton (2006) argued this is not early enough) attentional deployment 
forced between two paired stimuli, without accounting for how the social cue itself was attentionally processed. Paired stimuli also make it difficult to infer underlying response mechanisms in the dot-probe paradigm leading to varying detection speed (i.e., one attracting attention, another inhibiting attention, or both?). The emotional Stroop task is activating exogenous attention that affects the selection between two competing channels (i.e., words vs. color) according to Printzmetal et al. (2005). However, as reviewed earlier, this task appears plagued with numerous potential response bias factors that could affect the channel selection process, thus rendering it a questionable measure of attentional bias. In contrast, the IB task as an attention-bias measure is capable of assessing multifaceted or sequential aspects of attentional processing, yielding more informative indices of attentional bias, compensating for limitations of existing cognitive experiments. Consequently, the IB paradigm may provide a more purely attentional processing index by assessing how extensively the social cue itself was processed while precluding the influence of potential strategies or intention to search. From a clinical vantage point, hypervigilant attention may be important in social anxiety to the extent that the social cue is followed by negatively-biased extended cognitive processing (e.g., negatively biased perceptions, interpretations, retrieval of memories, etc.).

\subsection{Static vs. Dynamic Critical Items}

In the present study, both experiments yielded consistent results despite the considerable methodological variations within the IB paradigm. Although the hypothesized three-way interaction of social anxiety status by critical item by bogusspeech manipulation was not observed for detection rates from the inattention trial of 
Experiment 1, the observed trend under the bogus-speech manipulation was similar to that of Experiment 2.

There are several differences between the two IB tasks worth noting. The most distinctive parameter is the duration of the critical items. Compared to the static IB task, which presents a static critical item for $200 \mathrm{~ms}$, the sustained dynamic IB task presents a moving critical item over a 5 -sec period during the course of a 15 -sec judgment trial. As mentioned earlier, this prolonged duration effectively excludes the possibility of inattentional amnesia causing the IB phenomenon. For the memory-failure account to hold, there should exist a reasonable explanation about some top-down process that could prevent even the presence of the detected item from being consolidated into an explicit memory for $5 \mathrm{sec}$ (Most et al., 2005).

Second, Experiment 1 used schematic facial icons either smiling vs. frowning, whereas Experiment 2 used Ekman's facial pictures expressing happiness vs. anger. The use of less potent schematic icons conveying less social anxiety-relevant emotion might have attenuated attentional bias in Experiment 1. A static IB task presenting relevant emotional faces may attain greater sensitive to detect attentional bias in social anxiety.

Third, unlike the static IB task, the sustained IB task leaves room for eyemovement. Future study may include an eye-tracking device to examine (a) subjects' adherence to instructions, (b) potential additive evidence of attention bias derived from eye-movements in conjunction with the processing of critical items, and (c) the relationship between eye-movements and performance on the IB task. Prinzmetal et al., (2005) suggested that exogenous attention may be related to eye-movement system. 
Taken together, eye-tracking may constitute a particularly useful addition to the sustained IB paradigm.

\subsection{The Role of Bogus-Speech Manipulation in Attentional Bias Investigation}

Both Experiment 1 and 2 revealed a different pattern of interaction between social anxiety status and critical-item condition according to the presence of absence of the bogus-speech manipulation procedure. What is the exact role of the bogus-speech anxiety induction manipulation in attentional bias investigation? Generally, it has been regarded as an experimental procedure to temporarily heighten (state) social anxiety. Accordingly, most studies (e.g., Sposari \& Rapee, 2007; Mansell et al., 1999), including the present study, checked the success of bogus-speech manipulation by assessing the levels of state anxiety before and after the manipulation procedure.

Findings using existing experiment paradigms such as the Stroop and the dotprobe are equivocal concerning the effects of speech threat: the suppression of Stroop interference observed with a speech threat (Amir et al., 1996), attentional avoidance from faces observed with a speech threat (Mansell et al., 1999), attentional avoidance from faces observed without any social threat (Chen et al., 2002), and attentional hypervigilance observed with a speech threat (Sposari \& Rapee, 2007). Particularly, Chen et al., (2002) found attentional avoidance from faces using a clinical sample in a modified dot-probe task without a bogus-speech manipulation. Thus, they argued that bogusspeech manipulation is not necessary with clinical samples of SAD patients due to their already heightened sensitivity to social evaluation. However, Sposari and Rapee (2007) replicated this study using the same dot-probe task with the addition of a bogus speech 
task, and found a greater vigilance for faces in patients with $\mathrm{SAD}$, relative to normal controls. Thus, it appears that the presence of speech threat does affect attentional processing without regard to the clinical status of subjects. This also suggests the possibility that the primary role of bogus-speech manipulation may not be a (state) social anxiety enhancer.

Another, perhaps more important, role of the bogus-speech manipulation may be to activate a cognitive schema related to social-evaluative situations. Cognitive models of social anxiety posit the strong effects of negative social beliefs originating from early experience (i.e., schema) on biased information processing of social cues (Rapee \& Heimberg, 1997; Clark \& Wells, 1995). Schemas are deep mental structures serving as a cognitive framework to organize and process information (Bartlett, 1932; 1958; Mandler, 1984; Rumelhart, 1980). This construct was developed in cognitive psychology and later applied to emotional disorders and personality disorders as vulnerability factors governing maladaptive and negatively biased processing of information about self, others, and the environment (e.g., Beck et al., 1979, Young, 1990). Particularly, a maladaptive social schema may lead the individual to selectively attend to negative social cues or misinterpret the meaning of ambiguous or neutral social cues in a way confirming the negative schema. In both Experiment 1 and 2, identification rates from the inattentional trial showed the tendency that the preferential processing for the happy face in the case of LSAs, and the angry face in the case of HSAs was more prominent when the speech threat was introduced. It may be that the bogus-speech task helped amplify underlying cognitive style via the activation of cognitive schema related to social-evaluative 
situation. HSAs' schema may be replete with themes centering around embarrassment, shame, awkwardness, and so forth; whereas that of LSAs may suggest that pleasant social interactions and favorable social feedback are likely to occur. (Clark \& Wells, 1995; Rapee \& Heimberg, 1997). Thus, a bogus-speech task is expected to exert differential influence on attentional processing as a function of the level of dispositional social anxiety. Particularly, in the context of investigating attentional bias in social anxiety, the attentional set in the sustained IB task may be strongly affected by underlying cognitive schemas guiding selective encoding of information related to social-evaluative situations. Future studies need to attempt to assess the activation of schema related to socialevaluative situations as a manipulation check for the bogus-speech task to examine this hypothesis.

\subsection{Conclusions}

Understanding the characteristics and underlying mechanisms of biased attentional processing in psychopathological conditions may contribute to elaborating cognitive accounts of their maintenance, which often serve to guide the development of specific treatment strategies. The present study demonstrated the IB paradigm's promising utility as a vehicle for investigating attentional bias in social anxiety and perhaps other psychopathological conditions. Particularly, the IB paradigm enables multiple aspects of attentional processing (e.g., orienting and detecting) to be examined while controlling for potential response bias factors. However, it is noteworthy that the IB experiment may need to be implemented inevitably relying on a completely-crossed between-subjects design, which requires a relatively large number of participants and 
limits the examination of attentional bias within the intra-individual level. Nevertheless, the IB paradigm offers several methodological advantages that would compensate for limitations of existing cognitive experimental paradigms. It would be worthwhile to pursue clinical replication, including different diagnostic groups of anxiety disorders. This would help establish the specificity of current findings as well as examine its utility for other psychopathological conditions in which biased attentional processing is implicated. 


\section{REFERENCES}

Alden, L. E., \& Bieling, P. (1998). Interpersonal consequences of the pursuit of safety. Behaviour Research and Therapy, 36(1), 53-64.

Amir, N., Elias, J., Klumpp, H., \& Przeworski, A. (2003). Attentional bias to threat in social phobia: facilitated processing of threat or difficulty disengaging attention from threat? Behaviour Research and Therapy, 41(11), 1325-1335.

Amir, N., McNally, R. J., Riemann, B. C., Burns, J., Lorenz, M., \& Mullen, J. T. (1996). Suppression of the emotional Stroop effect by increased anxiety in patients with social phobia. Behaviour Research and Therapy, 34(11-12), 945-948.

Asmundson, G. J. G., \& Stein, M. B. (1994). Selective Processing of Social Threat in Patients with Generalized Social Phobia - Evaluation Using a Dot-Probe Paradigm. Journal of Anxiety Disorders, 8(2), 107-117.

Barrett, P. M., Rapee, R. M., Dadds, M. M., \& Ryan, S. M. (1996). Family enhancement of cognitive style in anxious and aggressive children. Journal of Abnormal Child Psychology, 24(2), 187-203.

Bartlett, F.C. (1932). Remembering: An Experimental and Social Study. Cambridge: Cambridge University Press.

Bartlett, F.C. (1958). Thinking. New York: Basic Books.

Beatty, M. J., Heisel, A. D., Hall, A. E., Levine, T. R., \& La France, B. H. (2002). What can we learn from the study of twins about genetic and environmental influences on interpersonal affiliation, aggressiveness, and social anxiety?: A meta-analytic study. Communication Monographs, 69(1), 1-18. 
Beck, A. T., Rush, A. J., Shaw, B. F., \& Emery, G. (1979). Cognitive therapy of depression. New York: Guilford.

Beck, A. T., Emery, G., \& Greenberg, R. L. (1985). Anxiety disorders and phobias : a cognitive perspective. New York: Basic Books.

Becker, E. S., Rinck, M., Margraf, J., \& Roth, W. T. (2001). The emotional Stroop effect in anxiety disorders - General emotionality or disorder specificity? Journal of Anxiety Disorders, 15(3), 147-159.

Bogels, S. M., \& Mansell, W. (2004). Attention processes in the maintenance and treatment of social phobia: hypervigilance, avoidance and self-focused attention. Clinical Psychology Review, 24(7), 827-856.

Bruch, M. A., \& Heimberg, R. G. (1994). Differences in Perceptions of Parental and Personal Characteristics between Generalized and Nongeneralized Social Phobics. Journal of Anxiety Disorders, 8(2), 155-168.

Chen, Y. P., Ehlers, A., Clark, D. M., \& Mansell, W. (2002). Patients with generalized social phobia direct their attention away from faces. Behaviour Research and Therapy, 40(6), 677-687.

Clark, D. M. (2001). A cognitive perspective on social phobia. In W. R. Crozier \& L. E. Alden (Eds.), International handbook of social anxiety : concepts, research, and interventions relating to the self and shyness (pp. 405-430). Chichester; New York: Wiley. 
Clark, D. M., \& Wells, A. (1995). A cognitive model of social phobia. In R. G. Heimberg (Ed.), Social phobia : diagnosis, assessment, and treatment (pp. 69-93). New York: Guilford Press.

Cooper, R. M., \& Langton, S. R. H. (2006). Attentional bias to angry faces using the dotprobe task? It depends when you look for it. Behaviour Research and Therapy, 44, 1321-1329.

Dadds, M. R., Barrett, P. M., Rapee, R. M., \& Ryan, S. (1996). Family process and child anxiety and aggression: An observational analysis. Journal of Abnormal Child Psychology, 24(6), 715-734.

Davidson, J. R. T., Hughes, D. C., George, L. K., \& Blazer, D. G. (1994). Boundary of Social Phobia - Exploring the Threshold. Archives of General Psychiatry, 51(12), 975-983.

Davidson, J. R. T., Hughes, D. L., George, L. K., \& Blazer, D. G. (1993). The Epidemiology of Social Phobia - Findings from the Duke Epidemiologic Catchment-Area Study. Psychological Medicine, 23(3), 709-718.

Davidson, J. R. T., Potts, N., Richichi, E., Krishnan, R., Ford, S. M., Smith, R., et al. (1993). Treatment of Social Phobia with Clonazepam and Placebo. Journal of Clinical Psychopharmacology, 13(6), 423-428.

den Boer, J. A. (2000). Social anxiety disorder/social phobia: Epidemiology, diagnosis, neurobiology, and treatment. Comprehensive Psychiatry, 4l(6), 405-415.

Ekman, P. (1976). Pictures of facial affect. Palo Alto, CA: Consulting Psychologists Press. 
Ekman, P., \& Friesen, W. V. (1984). Unmasking the face. Palo Alto, CA: Consulting Psychologists Press.

Erwin, B. A., Heimberg, R. G., Juster, H., \& Mindlin, M. (2002). Comorbid anxiety and mood disorders among persons with social anxiety disorder. Behaviour Research and Therapy, 40(1), 19-35.

Esteves, F. (1999). Attentional bias to emotional facial expressions. European Review of Applied Psychology-Revue Europeenne De Psychologie Appliquee, 49(2), 91-96.

Foa, E. B., Feske, U., Murdock, T. B., Kozak, M. J., \& Mccarthy, P. R. (1991).

Processing of Threat-Related Information in Rape Victims. Journal of Abnormal Psychology, 100(2), 156-162.

Foa, E. B., Ilai, D., Mccarthy, P. R., Shoyer, B., \& Murdock, T. (1993). InformationProcessing in Obsessive-Compulsive Disorder. Cognitive Therapy and Research, 17(2), 173-189.

Fyer, A. J. (1993). Heritability of Social Anxiety - a Brief Review. Journal of Clinical Psychiatry, 54, 10-12.

Fyer, A. J., Mannuzza, S., Chapman, T. F., Martin, L. Y., \& Klein, D. F. (1995). Specificity in Familial Aggregation of Phobic Disorders. Archives of General Psychiatry, 52(7), 564-573.

Garner, M., Mogg, K., \& Bradley, B. P. (2006). Orienting and Maintenance of Gaze to Facial Expressions in Social Anxiety. Journal of Abnormal Psychology, 4, 760770. 
Garner, M., Rutherford, D., Baldwin, D. S., Bradley, B. P., \& Mogg, K. (2005). Attentional bias for facial expressions in generalized social phobia: An eyemovement study. Journal of Psychopharmacology, 19(5), A16-A16.

Gilboa-Schechtman, E., Foa, E. B., \& Amir, N. (1999). Attentional biases for facial expressions in social phobia: The face-in-the-crowd paradigm. Cognition \& Emotion, 13(3), 305-318.

Greenberg, P. E., Sisitsky, T., Kessler, R. C., Finkelstein, S. N., Berndt, E. R., Davidson, J. R. T., et al. (1999). The economic burden of anxiety disorders in the 1990s. Journal of Clinical Psychiatry, 60(7), 427-435.

Heimberg, R. G., Stein, M. B., Hiripi, E., \& Kessler, R. C. (2000). Trends in the prevalence of social phobia in the United States: a synthetic cohort analysis of changes over four decades. European Psychiatry, 15(1), 29-37.

Heinrichs, N., \& Hofmann, S. G. (2001). Information processing in social phobia: A critical review. Clinical Psychology Review, 21(5), 751-770.

Himmelhoch, J., Levine, J., \& Gershon, S. (2001). Historical overview of the relationship between anxiety disorders and affective disorders. Depression and Anxiety, 14(2), 53-66.

Holt, C. S., Heimberg, R. G., Hope, D. A., \& Liebowitz, M. R. (1992). Situational Domains of Social Phobia. Journal of Anxiety Disorders, 6(1), 63-77.

Hope, D. A., Rapee, R. M., Heimberg, R. G., \& Dombeck, M. J. (1990). Representations of the Self in Social Phobia - Vulnerability to Social Threat. Cognitive Therapy and Research, 14(2), 177-189. 
Horenstein, M., \& Segui, J. (1997). Chronometrics of attentional processes in anxiety disorders. Psychopathology, 30(1), 25-35.

Horley, K., Williams, L. M., Gonsalvez, C., \& Gordon, E. (2003). Social phobics do not see eye to eye: A visual scanpath study of emotional expression processing. Journal of Anxiety Disorders, 17(1), 33-44.

Horley, K., Williams, L. M., Gonsalvez, C., \& Gordon, E. (2004). Face to face: visual scanpath evidence for abnormal processing of facial expressions in social phobia. Psychiatry Research, 127(1-2), 43-53.

Hudson, J. L., \& Rapee, R. M. (2000). The origins of social phobia. Behavior Modification, 24(1), 102-129.

Hunt, C., \& Andrews, G. (1995). Comorbidity in the anxiety disorders: The use of a lifechart approach. Journal of Psychiatric Research, 29(6), 467-480.

Jonides, J. (1976). Voluntary vs. reflexive control of the mind's eye's movement. Paper presented at the annual meeting of the Psychonomic Society, St. Louis.

Jonides, J. (1980). Towards a model of the mind's eye's movement. Canadian Journal of Psychology, 34, 103-112.

Kaspi, S. P., Mcnally, R. J., \& Amir, N. (1995). Cognitive Processing of Emotional Information in Posttraumatic-Stress-Disorder. Cognitive Therapy and Research, $19(4), 433-444$.

Katzelnick, D. J., Kobak, K. A., DeLeire, T., Henk, H. J., Greist, J. H., Davidson, J. R. T., et al. (2001). Impact of generalized social anxiety disorder in managed care. American Journal of Psychiatry, 158(12), 1999-2007. 
Katzelnick, D. J., Kobak, K. A., Greist, J. H., Jefferson, J. W., Mantle, J. M., \& Serlin, R. C. (1995). Sertraline for Social Phobia - a Double-Blind, Placebo-Controlled Crossover Study. American Journal of Psychiatry, 152(9), 1368-1371.

Kendler, K. S., Karkowski, L. M., \& Prescott, C. A. (1999). Fears and phobias: reliability and heritability. Psychological Medicine, 29(3), 539-553.

Kendler, K. S., Neale, M. C., Kessler, R. C., Heath, A. C., \& Eaves, L. J. (1992). The Genetic Epidemiology of Phobias in Women - the Interrelationship of Agoraphobia, Social Phobia, Situational Phobia, and Simple Phobia. Archives of General Psychiatry, 49(4), 273-281.

Kessler, R. C., McGonagle, K. A., Zhao, S. Y., Nelson, C. B., Hughes, M., Eshleman, S., et al. (1994). Lifetime and 12-Month Prevalence of Dsm-Iii-R PsychiatricDisorders in the United-States - Results from the National-Comorbidity-Survey. Archives of General Psychiatry, 51(1), 8-19.

Klein, R. M., \& Shore, D. I. (2000). Relations among modes of visual orienting. In S. Monsell \& J. Driver (Eds.), Control of cognitive processes: Attention and performance XVIII (pp. 195-208). Cambridge, MA: MIT Press.

Klieger, D. M., \& Cordner, M. D. (1990). The Stroop Task as Measure of Construct Accessibility in Depression. Personality and Individual Differences, 11(1), 19-27.

Lavy, E., Vandenhout, M., \& Arntz, A. (1993). Attentional Bias and Spider Phobia Conceptual and Clinical Issues. Behaviour Research and Therapy, 31(1), 17-24. 
Lavy, E., Vanoppen, P., \& Vandenhout, M. (1994). Selective Processing of Emotional Information in Obsessive-Compulsive Disorder. Behaviour Research and Therapy, $32(2), 243-246$.

Liebowitz, M. R., Gorman, J. M., Fyer, A. J., \& Klein, D. F. (1985). Social Phobia Review of a Neglected Anxiety Disorder. Archives of General Psychiatry, 42(7), 729-736.

Liebowitz, M. R., Heimberg, R. G., Fresco, D. M., Travers, J., \& Stein, M. B. (2000). Social phobia or social anxiety disorder: What's in a name? Archives of General Psychiatry, 57(2), 191-192.

Lima, L., Salazar, M., \& Trejo, E. (1993). Modulation of 5ht(1a) Receptors in the Hippocampus and the Raphe Area of Rats Treated with Clonazepam. Progress in Neuro-Psychopharmacology \& Biological Psychiatry, 17(4), 663-677.

Lundh, L. G., \& Ost, L. G. (1996). Stroop interference, self-focus and perfectionism in social phobics. Personality and Individual Differences, 20(6), 725-731.

Mack, A., \& Rock, I. (1998). Inattentional blindness. Cambridge, Mass.: MIT Press.

Mack, A. (2003). Inattentional blindness: Looking without seeing. Psychological Science, $12,180-184$.

Magee, W. J., Eaton, W. W., Wittchen, H. U., McGonagle, K. A., \& Kessler, R. C. (1996). Agoraphobia, simple phobia, and social phobia in the national comorbidity survey. Archives of General Psychiatry, 53(2), 159-168.

Mandler, J. (1984). Stories, Scripts, and Scenes: Aspects of Schema Theory. Hillsdale, NJ: Erlbaum. 
Maidenberg, E., Chen, E., Craske, M., Bohn, P., \& Bystritsky, A. (1996). Specificity of attentional bias in panic disorder and social phobia. Journal of Anxiety Disorders, 10(6), 529-541.

Mancini, C., VanAmeringen, M., Szatmari, P., Fugere, C., \& Boyle, M. (1996). A highrisk pilot study of the children of adults with social phobia. Journal of the American Academy of Child and Adolescent Psychiatry, 35(11), 1511-1517.

Mansell, W., Clark, D. M., Ehlers, A., \& Chen, Y. P. (1999). Social anxiety and attention away from emotional faces. Cognition \& Emotion, 13(6), 673-690.

Mansell, W., Ehlers, A., Clark, D. M., \& Chen, Y. P. (2002). Attention to positive and negative social-evaluative words: Investigating the effects of social anxiety, trait anxiety and social threat. Anxiety Stress and Coping, 15(1), 19-29.

Marks, I. M., \& Gelder, M. G. (1966). Different ages of onset in varieties of phobia. American Journal of Psychiatry, 123, 218-221.

Mathews, A., \& Macleod, C. (1985). Selective Processing of Threat Cues in AnxietyStates. Behaviour Research and Therapy, 23(5), 563-569.

Mathews, A., \& Sebastian, S. (1993). Suppression of Emotional Stroop Effects by FearArousal. Cognition \& Emotion, 7(6), 517-530.

Mattia, J. I., Heimberg, R. G., \& Hope, D. A. (1993). The Revised Stroop Color-Naming Task in Social Phobics. Behaviour Research and Therapy, 31(3), 305-313.

McCormick, P. A. (1997). Orienting attention without awareness. Journal of Experimental Psychology: Human Perception and Performance, 23, 168-180. 
Mcnally, R. J., Amir, N., Louro, C. E., Lukach, B. M., Riemann, B. C., \& Calamari, J. E. (1994). Cognitive Processing of Idiographic Emotional Information in Panic Disorder. Behaviour Research and Therapy, 32(1), 119-122.

Mcnally, R. J., English, G. E., \& Lipke, H. J. (1993). Assessment of Intrusive Cognition in Ptsd - Use of the Modified Stroop Paradigm. Journal of Traumatic Stress, 6(1), $33-41$.

Mcnally, R. J., Riemann, B. C., \& Kim, E. (1990). Selective Processing of Threat Cues in Panic Disorder. Behaviour Research and Therapy, 28(5), 407-412.

Mcnally, R. J., Riemann, B. C., Louro, C. E., Lukach, B. M., \& Kim, E. (1992). Cognitive Processing of Emotional Information in Panic Disorder. Behaviour Research and Therapy, 30(2), 143-149.

Mcneil, D. W., Ries, B. J., Taylor, L. J., Boone, M. L., Carter, L. E., Turk, C. L., et al. (1995). Comparison of Social Phobia Subtypes Using Stroop Tests. Journal of Anxiety Disorders, 9(1), 47-57.

Mellings, T. M. B., \& Alden, L. E. (2000). Cognitive processes in social anxiety: the effects of self-focus, rumination and anticipatory processing. Behaviour Research and Therapy, 38(3), 243-257.

Mertens, I., Siegmund, H., \& Grusser, O. J. (1993). Gaze Motor Asymmetries in the Perception of Faces During a Memory Task. Neuropsychologia, 31(9), 989-998.

Mogg, K., Philippot, P., \& Bradley, B. P. (2004). Selective attention to angry faces in clinical social phobia. Journal of Abnormal Psychology, 113(1), 160-165. 
Morgan, H., \& Raffle, C. (1999). Does reducing safety behaviours improve treatment response in patients with social phobia? Australian and New Zealand Journal of Psychiatry, 33(4), 503-510.

Most, S. B., Scholl, B. J., Clifford, E. R., \& Simons, D. J. (2005). What you see is what you set: Sustained inattentional blindness and the capture of awareness. Psychological Review, 112(1), 217-242.

Most, S. B., Simons, D. J., Scholl, B. J., Jimenez, R., Clifford, E., \& Chabris, C. F. (2001). How not to be seen: The contribution of similarity and selective ignoring to sustained inattentional blindness. Psychological Science, 12(1), 9-17.

Musa, C., Lepine, J. P., Clark, D. M., Mansell, W., \& Ehlers, A. (2003). Selective attention in social phobia and the moderating effect of a concurrent depressive disorder. Behaviour Research and Therapy, 41(9), 1043-1054.

Patel, A., Knapp, M., Henderson, J., \& Baldwin, D. (2002). The economic consequences of social phobia. Journal of Affective Disorders, 68(2-3), 221-233.

Posner, M. I. (1980). Orienting of attention. Quarterly Journal of Experimental Psychology, 32, 3-25.

Posner, M. I., Snyder, C. R. R., \& Davidson, B. J. (1980). Attention and the detection of signals. Journal of Experimental Psychology: General, 109, 160-174.

Prinzmetal, W., Park, S., \& Garrett, R. (2005). Involuntary attention and identification accuracy. Perception and Psychophysics, 67, 1344-1353. 
Prinzmetal, W., McCool, C., \& Park, S. (2005). Attention: Reaction time and accuracy reveal different mechanisms. Journal of Experimental Psychology: General, 134, 73-92.

Rapee, R. M. (1997). Potential role of childrearing practices in the development of anxiety and depression. Clinical Psychology Review, 17(1), 47-67.

Rapee, R. M., \& Heimberg, R. G. (1997). A cognitive-behavioral model of anxiety in social phobia. Behaviour Research and Therapy, 35(8), 741-756.

Rapee, R. M., \& Spence, S. H. (2004). The etiology of social phobia: Empirical evidence and an initial model. Clinical Psychology Review, 24(7), 737-767.

Reich, J., Goldenberg, I., Goisman, R., Vasile, R., \& Keller, M. (1994). A Prospective, Follow-Along Study of the Course of Social Phobia .2. Testing for Basic Predictors of Course. Journal of Nervous and Mental Disease, 182(5), 297-301.

Reich, J., Goldenberg, I., Vasile, R., Goisman, R., \& Keller, M. (1994). A Prospective Follow-Along Study of the Course of Social Phobia. Psychiatry Research, 54(3), 249-258.

Reinherz, H. Z., Giaconia, R. M., Lefkowitz, E. S., Pakiz, B., \& Frost, A. K. (1993). Prevalence of Psychiatric-Disorders in a Community Population of Older Adolescents. Journal of the American Academy of Child and Adolescent Psychiatry, 32(2), 369-377.

Rinck, M., \& Becker, E. S. (2005). A comparison of attentional biases and memory biases in women with social phobia and major depression. Journal of Abnormal Psychology, 114(1), 62-74. 
Rumelhart, D.E. (1980). Schemata: The building blocks of cognition. In R.J. Spiro, B.Bruce, \& W.F. Brewer (eds.), Theoretical Issues in Reading and Comprehension. Hillsdale, NJ: Erlbaum.

Sanderson, W. C., Dinardo, P. A., Rapee, R. M., \& Barlow, D. H. (1990). Syndrome Comorbidity in Patients Diagnosed with a Dsm-Iii-R Anxiety Disorder. Journal of Abnormal Psychology, 99(3), 308-312.

Schneier, F. R., Chin, S. J., Hollander, E., \& Liebowitz, M. R. (1992). Fluoxetine in Social Phobia. Journal of Clinical Psychopharmacology, 12(1), 62-64.

Schneier, F. R., Heckelman, L. R., Garfinkel, R., Campeas, R., Fallon, B. A., Gitow, A., et al. (1994). Functional Impairment in Social Phobia. Journal of Clinical Psychiatry, 55(8), 322-329.

Schneier, F. R., Johnson, J., Hornig, C. D., Liebowitz, M. R., \& Weissman, M. M. (1992). Social Phobia - Comorbidity and Morbidity in an Epidemiologic Sample. Archives of General Psychiatry, 49(4), 282-288.

Segal, Z. V., Truchon, C., Gemar, M., \& Guirguis, M. (1995). A Priming Methodology for Studying Self-Representation in Major Depressive Disorder. Journal of Abnormal Psychology, 104(1), 205-213.

Segal, Z. V., \& Vella, D. D. (1990). Self-Schema in Major Depression - Replication and Extension of a Priming Methodology. Cognitive Therapy and Research, 14(2), $161-176$.

Simons, D. J., \& Chabris, C. F. (1999). Gorillas in our midst: sustained inattentional blindness for dynamic events. Perception, 28(9), 1059-1074. 
Spector, I. P., Pecknold, J. C., \& Libman, E. (2003). Selective attentional bias related to the noticeability aspect of anxiety symptoms in generalized social phobia. Journal of Anxiety Disorders, 17(5), 517-531.

Sposari J. A., \& Rapee, R. M. (2007). Attentional bias toward facial stimuli under conditions of social threat in socially phobic and nonclinical participants. Cognitive Therapy and Research, 31, 23-37.

Stein, M. B., \& Kean, Y. M. (2000). Disability and quality of life in social phobia: Epidemiologic findings. American Journal of Psychiatry, 157(10), 1606-1613.

Stein, M. B., Liebowitz, M. R., Lydiard, R. B., Pitts, C. D., Bushnell, W., \& Gergel, I. (1998). Paroxetine treatment of generalized social phobia (social anxiety disorder) - A randomized controlled trial. Jama-Journal of the American Medical Association, 280(8), 708-713.

Stroop, J. R. (1935). Studies of interference in serial verbal reactions. Journal of Experimental Psychology, 18, 643-662.

Tancer, M. E., Mailman, R. B., Stein, M. B., Mason, G. A., Carson, S. W., \& Golden, R. N. (1994). Neuroendocrine Responsivity to Monoaminergic System Probes in Generalized Social Phobia. Anxiety, 1(5), 216-223.

Tiihonen, J., Kuikka, J., Bergstrom, K., Lepola, U., Koponen, H., \& Leinonen, E. (1997). Dopamine reuptake site densities in patients with social phobia. American Journal of Psychiatry, 154(2), 239-242. 
Tillfors, M., Furmark, T., Marteinsdottir, I., Fischer, H., Pissiota, A., Langstrom, B., et al. (2001). Cerebral blood flow in subjects with social phobia during stressful speaking tasks: A PET study. American Journal of Psychiatry, 158(8), 1220-1226.

Tillfors, M., Furmark, T., Marteinsdottir, I., \& Fredrikson, M. (2002). Cerebral blood flow during anticipation of public speaking in social phobia: A PET study. Biological Psychiatry, 52(11), 1113-1119.

Turk, C. L., Heimberg, R. G., \& Hope, D. A. (2001). Social anxiety disorder. In D. H. Barlow (Ed.), Clinical handbook of psychological disorders : a step-by-step treatment manual (3rd ed., pp. 114-153). New York: Guilford Press.

Turner, S. M., Beidel, D. C., Dancu, C. V., \& Keys, D. J. (1986). Psychopathology of Social Phobia and Comparison to Avoidant Personality-Disorder. Journal of Abnormal Psychology, 95(4), 389-394.

Walkersmith, G. J., Gale, A. G., \& Findlay, J. M. (1977). Eye-Movement Strategies Involved in Face Perception. Perception, 6(3), 313-326.

Weiller, E., Bisserbe, C., Boyer, P., Lepine, J. P., \& Lecrubier, Y. (1996). Social phobia in general health care - An unrecognised undertreated disabling disorder. British Journal of Psychiatry, 168(2), 169-174.

Wells, A., Clark, D. M., Salkovskis, P., Ludgate, J., Hackmann, A., \& Gelder, M. (1995). Social Phobia - the Role of in-Situation Safety Behaviors in Maintaining Anxiety and Negative Beliefs. Behavior Therapy, 26(1), 153-161.

Williams, J. M. G., Mathews, A., \& MacLeod, C. (1996). The emotional stroop task and psychopathology. Psychological Bulletin, 120(1), 3-24. 
Wolfe, J. (1999). Inattentional amnesia, In V. Coltheart (Ed.), Fleeting memories (pp. 7194). Cambridge, MA: MIT Press.

Wundt, W. (1902). Outlines of psychology (C. H. Judd, Trans.). Leipzig: Engelmann.

Young, J. E. (1990). Cognitive therapy for personality disorders: A schema-focused approach. Sarasota, FL: Professional Resource Press. 


\section{VITA}

Han-Joo Lee was born in Seoul, Republic of Korea on January 7, 1975, the son of Hae Woong Lee and Hye Soon Kim. After finishing his work at Yong Moon High School, Seoul, Korea, he entered Seoul National University in 1993. He received a Bachelor of Arts (B.A.) in psychology from Seoul National University in Spring 1997 and a Master of Arts (M.A.) in Clinical and Counseling Psychology from Seoul National University in Spring 1999. Afterwards, he completed a three-year clinical psychology residency training program at the Department of Psychiatry, the College of Medicine, Seoul National University and obtained licenses of Korean Professional Clinical Psychologist and Korean Mental Health Clinical Psychologist in Spring 2002. In August 2002, he entered the Graduate School of the University of Texas at Austin. During the academic year of 2008-2009, he completed a pre-doctoral clinical internship at the University of Mississippi Medical Center/G.V. (Sonny) Montgomery VA Medical Center Consortium.

Permanent Address: 7201 Wood Hollow Dr. \#211, Austin, Texas 78731.

This dissertation was typed by the author. 